\title{
Prussian blue nanozymes with enhanced catalytic activity: size tuning and application in ELISA-like immunoassay
}

Pavel Khramtsov*, Maria Kropaneva, Artem Minin, Maria Bochkova, Valeria Timganova, Andrey Maximov, Alexey Puzik, Svetlana Zamorina, Mikhail Rayev

\begin{abstract}
Prussian blue nanozymes possessing peroxidase-like activity gather significant attention as alternatives to natural enzymes in therapy, biosensing, and environmental remediation. Recently, prussian blue nanoparticles with enhanced catalytic activity prepared by reduction of $\mathrm{FeCl}_{3} / \mathrm{K}_{3}\left[\mathrm{Fe}(\mathrm{CN})_{6}\right]$ mixture have been reported. These nanoparticles were denoted as 'artificial peroxidase' nanozymes. Our study provides insights into the process of synthesis of 'artificial peroxidase' nanozymes. We studied how the size of nanozymes and synthesis yield can be controlled via adjustment of the synthesis conditions. Based on these results, we developed a reproducible and scalable method for the preparation of 'artificial peroxidase' with tunable sizes allowing the obtaining of nanozymes with enhanced catalytic activity. 'Artificial peroxidase' nanozymes modified with gelatin shell and functionalized with affine molecules were applied as labels in colorimetric immunoassays of prostate-specific antigen and tetanus antibodies, enabling detection of these analytes in the range of clinically relevant concentrations. Protein coating provides excellent colloidal stability of nanozymes in physiological conditions and stability upon long-term storage.
\end{abstract}

Keywords: nanozyme, prussian blue, immunoassay, sensor, conjugate, peroxidase

\section{Introduction}

Nanozymes are artificial nanomaterial-based catalysts, capable of mimicking the functions of enzymes $[\mathbf{1 , 2}]$. Physical-chemical stability, low cost, and tunable properties make them a promising alternative to enzymes like horseradish peroxidase (HRP), alkaline phosphatase, $\beta$-galactosidase that are used as labels in colorimetric immunoassays [3]. Colorimetric immunoassays include enzyme-linked immunosorbent assay (ELISA), lateral flow immunoassay (LFIA), dotimmunobinding assay, flow-through assay, and other less common modifications. In this type of assay, enzymes and their artificial analogs are responsible for the conversion of colorless substrate to colored product [4]. Nowadays colorimetric immunoassays are one of the key analytical instruments in medicine, food quality control, and biotechnology $[\mathbf{5}, \mathbf{6}]$. Despite nanozymes not being mature enough and numerous challenges present [6], they emerge as prospective alternatives to natural enzymes in the field of biosensing $[7,8]$.

In 2018, the research group of Prof. Arkadiy Karyakin reported a method for the preparation of prussian blue nanoparticles with increased peroxidase-like activity denoted as 'artificial peroxidase' nanoparticles [9]. The key feature of 'artificial peroxidase' is the synthesis procedure based on reduction of $\mathrm{FeCl}_{3} / \mathrm{K}_{3}\left[\mathrm{Fe}(\mathrm{CN})_{6}\right]$ 
mixture with hydrogen peroxide (while other reductants were also effective), whereas typically prussian blue nanozymes are prepared by reaction between $\mathrm{FeCl}_{3}$ and $\mathrm{K}_{4}\left[\mathrm{Fe}(\mathrm{CN})_{6}\right][\mathbf{1 0}, \mathbf{1 1}]$ or by solvothermal method from the single precursor (e.g. $\left.\mathrm{K}_{3}\left[\mathrm{Fe}(\mathrm{CN})_{6}\right]\right)$ [12]. 'Artificial peroxidase' possesses almost tenfold higher catalytic activity in terms of $\mathrm{K}_{\text {cat }}$ in comparison with prussian blue nanozymes prepared by the traditional approach. Moreover, the authors demonstrated that the increase of catalytic activity accompanied the growth of nanoparticle diameter, which was explained by the diffusion of a substrate to the inner parts of the nanoparticle body. Therefore the idea to synthesize large $(200-300 \mathrm{~nm})$ nanoparticles, functionalize them with recognition molecules, and use them as peroxidase-like labels in colorimetric immunoassay was very attractive. However, in the course of the preliminary experiments, we failed to reproduce the size control method described in the original paper [9], which relies on a change of ratio between iron salts and hydrogen peroxide (related experiment and a possible explanation is given in the Section "Change of ratio between iron salts and hydrogen peroxide does not allow to properly control of the size of 'artificial peroxidase' nanozymes"). Prompted by the excellent catalytic properties of 'artificial peroxidase' which were harnessed for the creation of several sensitive assays $[13, \mathbf{1 4}, \mathbf{1 5}]$, we decided to develop a more robust method for the preparation of 'artificial peroxidase' nanozymes with the desired size.

Prussian blue nanoparticles can be synthesized via different routes (extensively reviewed in $[\mathbf{1 6}, \mathbf{1 7}]$ ). The most popular one is the mixing of $\mathrm{FeCl}_{3}$ and $\mathrm{K}_{4}\left[\mathrm{Fe}(\mathrm{CN})_{6}\right]$, usually in the presence of citric acid which forms complexes with ferric ions and provides more homogeneous nanoparticles by decreasing the rate of nucleation [18]. Other methods include hydrothermal decomposition of single precursor (e.g. $\left.\mathrm{K}_{3}\left[\mathrm{Fe}(\mathrm{CN})_{6}\right]\right)$ [19] or reduction of $\mathrm{FeCl}_{3} / \mathrm{K}_{3}\left[\mathrm{Fe}(\mathrm{CN})_{6}\right]$ with $\mathrm{H}_{2} \mathrm{O}_{2}[\mathbf{2 0}]$. The latter approach enables the preparation of 'artificial peroxidase' nanozymes. The reductive approach is used infrequently, therefore there is a limited number of studies dedicated to regulating the sizes of nanoparticles prepared by this method. In particular, Liu et al. prepared small (circa $50 \mathrm{~nm}$ ) nanoparticles by the gradual addition of $\mathrm{FeCl}_{3}$ to $\mathrm{K}_{3}\left[\mathrm{Fe}(\mathrm{CN})_{6}\right.$ ] (both solutions contained $\mathrm{H}_{2} \mathrm{O}_{2}$ ) [20]. Sonication allows further decreasing nanoparticle size to $5 \mathrm{~nm}$ [21]. Shiba et al. manipulated the diameter of nanoparticles by varying the concentration of reductant (ascorbic acid) and addition of pre-formed nanoparticles in the reaction mixture (seed-growth method), however, the size of nanoparticles did not exceed $150 \mathrm{~nm}$ [22]. The utilization of polymers as capping agents is another excellent option to regulate the size of prussian blue nanoparticles $[\mathbf{2 3}, \mathbf{2 4}, \mathbf{2 5}]$.

Thus, this study aims to develop a reproducible and scalable synthesis method for obtaining 'artificial peroxidase' nanoparticles with sizes between 100 and 300 $\mathrm{nm}$ and utilize them as labels in colorimetric immunoassay.

The goals of this research were as follows:

1) Evaluation of different methods to control the size of prussian blue nanoparticles;

2) Synthesis of 'artificial peroxidase' nanoparticles with the desired size at a larger scale; 
3) Comparison of catalytic activity of 'artificial peroxidase' nanoparticles with prussian blue nanozymes prepared by conventional technique;

4) Modification of 'artificial peroxidase' nanoparticles with gelatin A and further functionalization with affine molecules (monoclonal antibodies and Streptococcal protein G)

5) Application of the nanozymes in colorimetric immunoassays of prostatespecific antigen and antibodies against tetanus toxoid.

\section{Experimental section}

Regulation of size of 'artificial peroxidase' nanoparticles by changing the concentration of iron salts and $\mathrm{H}_{2} \mathrm{O}_{2}$

The method of nanoparticle size regulation was based on the original paper [9]. Synthesis was performed in $10 \mathrm{~mL}$ glass vials at room temperature. The length of the magnet matched the diameter of the vial bottom. $8.8 \mathrm{M}$ hydrogen peroxide was quickly added (to 2.27-176 mM) into an equimolar aqueous solution of $\mathrm{FeCl}_{3}$ and $\mathrm{K}_{3}\left[\mathrm{Fe}(\mathrm{CN})_{6}\right](1.56-25 \mathrm{mM})$ under vigorous stirring $(1000 \mathrm{rpm})$. The total volume of the mixture was $8.9 \mathrm{~mL}$. After $60 \mathrm{~min}$ the suspension was divided into 8 parts of $1 \mathrm{~mL}$, transferred into centrifuge tubes, and centrifuged at $20000 \mathrm{~g}$ for 60 min. The dark blue precipitate was washed three times with $1 \mathrm{ml}$ of deionized water by centrifugation at $20000 \mathrm{~g}$ for $15 \mathrm{~min}$. After the final centrifugation, $100 \mu \mathrm{L}$ of water was added to each tube. Nanoparticles were redispersed by the brief sonication and combined. $800 \mu \mathrm{L}$ of the resulting suspension were ultrasonicated using a probe sonicator on the ice bath (probe diameter - $3 \mathrm{~mm}$; amplification - 60\%; duration - 1 $\mathrm{min}$ ). The remaining aggregates were removed by centrifugation at $1600 \mathrm{~g}$ for $5 \mathrm{~min}$. Supernatants containing nanoparticles were collected.

The size of nanoparticles was measured by dynamic light scattering (DLS). For this, nanoparticles were diluted at 1:375 in water.

Influence of various factors on the size of 'artificial peroxidase' nanoparticles

Synthesis of prussian blue nanoparticles was carried out in a glass beaker under vigorous stirring $(1000 \mathrm{rpm})$ with temperature control. The length of the magnet matched the diameter of the beaker (experimental setup is shown in Figure 1). In deionized water $0.1 \mathrm{M}$ solutions of $\mathrm{FeCl}_{3}$ and $\mathrm{K}_{3}\left[\mathrm{Fe}(\mathrm{CN})_{6}\right]$ were added to 3.125 $\mathrm{mM}$, then different chemical compounds were added depending on experiment: citric acid (to 2.0-5.5 mM), oxalic acid (to $1.0-4.0 \mathrm{mM}$ ), $\mathrm{HCl}$ (to $\mathrm{pH} 1$ or 2), $\mathrm{KOH}$ (to $\mathrm{pH}$ 4), or $\mathrm{KCl}$ (to 0.1-3.0 M). In some experiments ratio of $\mathrm{FeCl}_{3}$ to $\mathrm{K}_{3}\left[\mathrm{Fe}(\mathrm{CN})_{6}\right]$ was $5: 1\left(15.65 \mathrm{mM}\right.$ of $\mathrm{FeCl}_{3}+3.125 \mathrm{mM}$ of $\left.\mathrm{K}_{3}\left[\mathrm{Fe}(\mathrm{CN})_{6}\right]\right), 2: 1\left(6.250 \mathrm{mM}\right.$ of $\mathrm{FeCl}_{3}$ $+3.125 \mathrm{mM}$ of $\left.\mathrm{K}_{3}\left[\mathrm{Fe}(\mathrm{CN})_{6}\right]\right), 1: 1\left(3.125 \mathrm{mM}\right.$ of $\mathrm{FeCl}_{3}+3.125 \mathrm{mM}$ of $\left.\mathrm{K}_{3}\left[\mathrm{Fe}(\mathrm{CN})_{6}\right]\right)$, $1: 2\left(3.125 \mathrm{mM}\right.$ of $\mathrm{FeCl}_{3}+6.250 \mathrm{mM}$ of $\left.\mathrm{K}_{3}\left[\mathrm{Fe}(\mathrm{CN})_{6}\right]\right), 1: 5\left(3.125 \mathrm{mM}\right.$ of $\mathrm{FeCl}_{3}+$ $15.65 \mathrm{mM}$ of $\left.\mathrm{K}_{3}\left[\mathrm{Fe}(\mathrm{CN})_{6}\right]\right)$. In temperature experiments, a solution containing 3.125 $\mathrm{mM}$ of $\mathrm{FeCl}_{3}$ and $\mathrm{K}_{3}\left[\mathrm{Fe}(\mathrm{CN})_{6}\right]$ was heated to $+60{ }^{\circ} \mathrm{C}$. In all other syntheses, the temperature of the reaction medium was $+30{ }^{\circ} \mathrm{C}$. Prussian Blue nanoparticles deposition was initiated by $8.8 \mathrm{M} \mathrm{H}_{2} \mathrm{O}_{2}$ addition (to $22 \mathrm{mM}$ ). The final volume of the reaction mixture was $25 \mathrm{ml}$. 
$500 \mu \mathrm{L}$ aliquots were taken from the reaction mixture at different time points: after $\mathrm{FeCl}_{3}$ and $\mathrm{K}_{3}\left[\mathrm{Fe}(\mathrm{CN})_{6}\right]$ mixing, after the addition of chemicals (if required), immediately after the $\mathrm{H}_{2} \mathrm{O}_{2}$ addition ( $0 \mathrm{~min}$ ), and then after $10,30,60,90,120,150$ minutes to monitor the process of nanoparticles formation during the synthesis. The formed nanoparticles were washed with water by centrifugation at $20000 \mathrm{~g}$ and sonicated on ice for 60 seconds (probe diameter - $3 \mathrm{~mm}$; amplification - 60\%; duration - $1 \mathrm{~min}$ ). Size, zeta potential, and $\mathrm{A}_{700}$ of nanoparticles were measured before (in situ samples) and after the washing (washed samples).

After 150 minutes of the synthesis, the $8 \mathrm{ml}$ nanoparticles were washed by centrifugation at $20000 \mathrm{~g}$, redispersed in $0.8 \mathrm{ml}$ of water, sonicated on ice for 60 seconds (probe diameter - $3 \mathrm{~mm}$; amplification - 60\%; duration - $1 \mathrm{~min}$ ), and centrifuged for 5 minutes at 1600 or $100 \mathrm{~g}$ to remove large aggregates. The centrifugation speed depended on the synthesis method. For example, after centrifugation at $1600 \mathrm{~g}$, sedimentation of nanoparticles larger than $200 \mathrm{~nm}$ was observed. Thus, suspensions of nanoparticles synthesized by the addition of citric and oxalic acids were centrifuged at $100 \mathrm{~g}$. After that, the sizes, zeta potential, and $\mathrm{A}_{700}$ were measured as described below. 


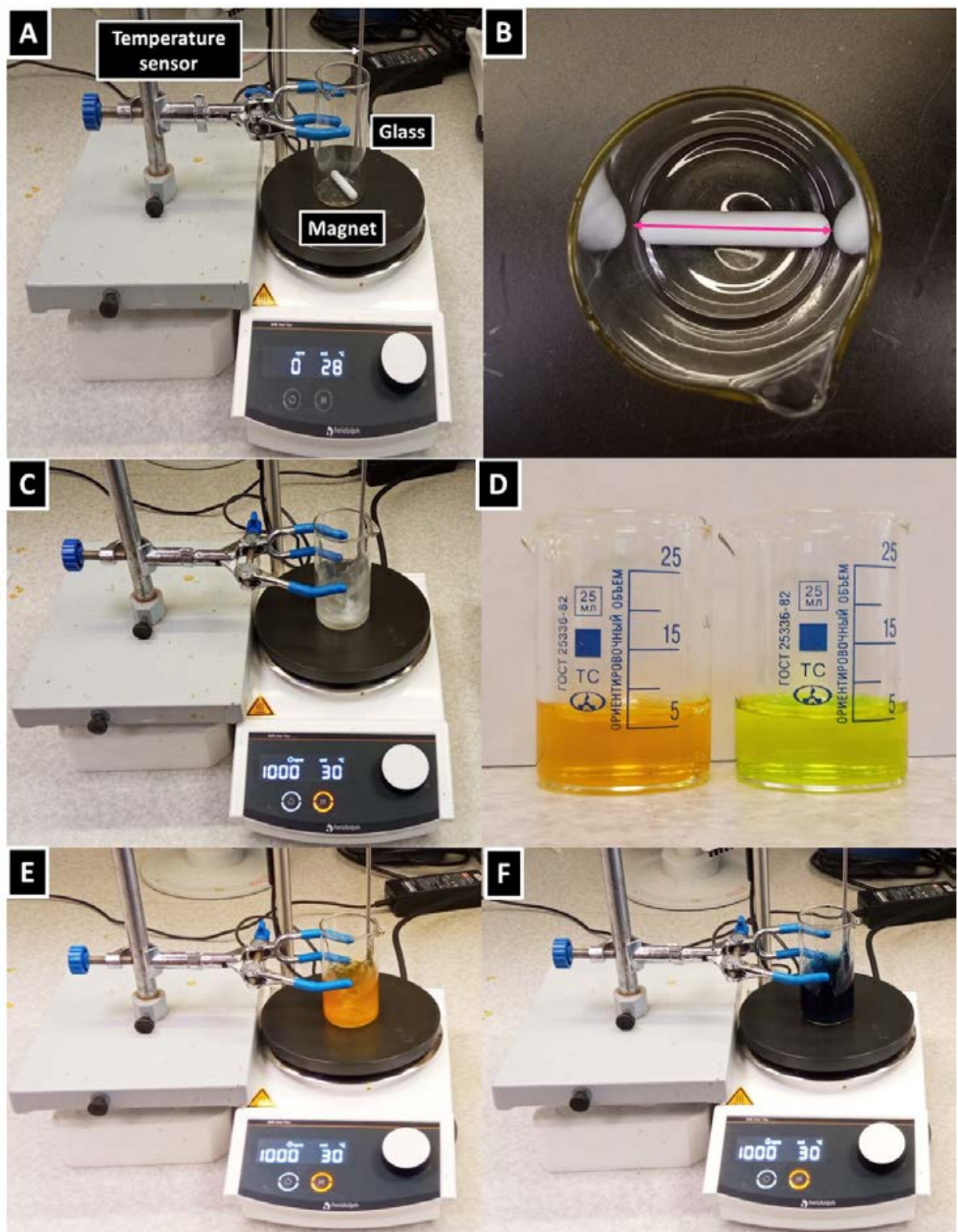

Figure 1. Synthesis of 'artificial peroxidase' prussian blue nanoparticles. (A) Experimental setup. (B) The stir bar matches the diameter of the beaker. (C) Prewarming of the water before the addition of iron salts. (D) Concentrated solutions of $\mathrm{FeCl}_{3}$ (left) and $\mathrm{K}_{3}\left[\mathrm{Fe}(\mathrm{CN})_{6}\right]$ (right). Mixture $(25 \mathrm{ml})$ of $\mathrm{FeCl}_{3}$ of $\mathrm{K}_{3}\left[\mathrm{Fe}(\mathrm{CN})_{6}\right]$ before (E) and after the addition of $\mathrm{H}_{2} \mathrm{O}_{2}(\mathrm{~F})$.

Preparation of prussian blue nanoparticles with various sizes at $10 x$ scale

Prussian blue nanoparticles were prepared by reductive (5 types) and traditional (3 types) approach. Three batches were obtained for each type of nanoparticles, except $\mathbf{T} / \mathbf{d w} / \mathbf{r t}$ nanoparticles, for which only two batches were prepared. The overall description of nanoparticle synthesis is given below. Details of the synthesis procedure, specific for each type are given in the Table 1. 
Table 1. Details of prussian blue nanoparticle synthesis (scale-up experiment)

\begin{tabular}{|c|c|c|}
\hline $\begin{array}{l}\text { Number of } \\
\text { method }\end{array}$ &  & Synthesis conditions \\
\hline 1 & $\mathbf{R}$ & $\begin{array}{l}\mathbf{F e C l}_{3} \text { и } \mathbf{K}_{3}\left[\mathbf{F e}(\mathbf{C N})_{6}\right]-3,125 \mathrm{MM} ; \mathbf{H}_{2} \mathbf{O}_{2}-22 \mathrm{MM} ;+30{ }^{\circ} \mathrm{C} \text {, stirring - } \\
1000 \mathrm{rpm} \text {, sonication - } 40 \mathrm{~min} \text {, final centrifugation at } 1600 \mathrm{~g} \text { for } 15 \mathrm{~min}\end{array}$ \\
\hline 2 & R4.5C & $\begin{array}{l}\mathrm{FeCl}_{3} \text { и } \mathbf{K}_{3}\left[\mathbf{F e}(\mathbf{C N})_{6}\right]-3,125 \mathrm{MM} ; \text { Citric acid- } 4,5 \mathrm{mM} ; \mathbf{H}_{2} \mathbf{O}_{2}-22 \mathrm{MM} ; \\
+30{ }^{\circ} \mathrm{C} \text {, stirring - } 1000 \mathrm{rpm} \text {, sonication - } 60 \mathrm{~min} \text {, final centrifugation at } \\
100 \mathrm{~g} \text { for } 5 \mathrm{~min}\end{array}$ \\
\hline 3 & R2C & $\begin{array}{l}\mathbf{F e C l}_{3} \text { и } \mathbf{K}_{3}\left[\mathbf{F e}(\mathbf{C N})_{6}\right]-3,125 \mathrm{MM} \text {; Citric acid- } 2 \mathrm{mM} ; \mathbf{H}_{2} \mathbf{O}_{2}-22 \mathrm{MM} ; \\
+30{ }^{\circ} \mathrm{C} \text {, stirring }-1000 \mathrm{rpm} \text {, sonication }-60 \mathrm{~min} \text {, final centrifugation at } \\
100 \mathrm{~g} \text { for } 15 \mathrm{~min}\end{array}$ \\
\hline 4 & $\mathbf{R 2 O}$ & $\begin{array}{l}\mathrm{FeCl}_{3} \mathbf{~ и ~}_{\mathbf{3}}\left[\mathbf{F e}(\mathbf{C N})_{6}\right]-3.125 \mathrm{MM} ; \text { Oxalic acid }-2 \mathrm{mM} ; \mathbf{H}_{2} \mathbf{O}_{2}-22 \mathrm{MM} ; \\
+30{ }^{\circ} \mathrm{C} \text {, stirring - } 1000 \mathrm{rpm} \text {, sonication - } 40 \mathrm{~min} \text {, final centrifugation at } \\
100 \mathrm{~g} \text { for } 15 \mathrm{~min}\end{array}$ \\
\hline 5 & RKH & $\begin{array}{l}\mathbf{F e C l}_{3} \text { и } \mathbf{K}_{3}\left[\mathbf{F e}(\mathbf{C N})_{6}\right]-3.125 \mathrm{MM} ; \mathrm{HCl}-0.1 \mathrm{M} ; \mathrm{KCl}-0.1 \mathrm{M} ; \mathbf{H}_{2} \mathbf{O}_{2}- \\
22 \mathrm{MM} ;+30{ }^{\circ} \mathrm{C} \text {, stirring }-1000 \mathrm{rpm} \text {, sonication }-60 \mathrm{~min} \text {, final } \\
\text { centrifugation at } 1600 \mathrm{~g} \text { for } 10 \mathrm{~min}\end{array}$ \\
\hline 6 & T25C & $\begin{array}{l}\mathbf{F e C l}_{3} \text { и } \mathbf{K}_{4}\left[\mathbf{F e}(\mathbf{C N})_{6}\right]-1 \mathrm{mM} \text {; Citric acid- } 25 \mathrm{mM} ;+55^{\circ} \mathrm{C} \text {, stirring - } \\
1000 \mathrm{rpm} \text {, sonication - } 30 \mathrm{~min} \text {, final centrifugation at } 1600 \mathrm{~g} \text { for } 10 \mathrm{~min}\end{array}$ \\
\hline 7 & $\mathbf{T}$ & $\begin{array}{l}\mathbf{F e C l}_{3} \mathbf{~ и ~}_{4}\left[\mathbf{F e}(\mathbf{C N})_{6}\right]-1 \mathrm{MM} ;+55^{\circ} \mathrm{C} \text {, stirring }-1000 \mathrm{rpm} \text {, sonication } \\
-30 \mathrm{~min} \text {, final centrifugation at } 1600 \mathrm{~g} \text { for } 10 \mathrm{~min}\end{array}$ \\
\hline 8 & T/dw/rt & $\begin{array}{l}\text { FeCl }_{3} \text { и } \mathbf{K}_{4}\left[\mathbf{F e}(\mathbf{C N})_{6}\right]-1 \mathrm{MM} \text {; the solution of } \mathrm{K}_{4}\left[\mathrm{Fe}(\mathrm{CN})_{6}\right] \text { was added } \\
\text { to the } \mathrm{FeCl} 3 \text { solution dropwise with a rate of } 10 \mathrm{ml} / \mathrm{h} \text { using a peristaltic } \\
\text { pump; room temperature, stirring - } 7000 \mathrm{rpm} \text {, sonication - } 30 \mathrm{~min} \text {, final } \\
\text { centrifugation at } 1600 \mathrm{~g} \text { for } 10 \mathrm{~min}\end{array}$ \\
\hline
\end{tabular}

${ }^{a} \boldsymbol{R}$ - synthesis of Prussian blue nanoparticles based on reduction of a mixture of ferricyanide and ferric ions by hydrogen peroxide, $\boldsymbol{C}$ - citric acid, $\boldsymbol{O}$ - oxalic acid, $\boldsymbol{T}$ - traditional synthesis of Prussian blue nanoparticles, $\boldsymbol{d} \boldsymbol{w}$ dropwise, $\boldsymbol{r t}$ - room temperature

\section{Synthesis of prussian blue nanoparticles by the traditional approach}

Aqueous solutions of $1 \mathrm{mM} \mathrm{K}_{4}\left[\mathrm{Fe}(\mathrm{CN})_{6}\right]$ and $1 \mathrm{mM} \mathrm{FeCl}_{3}$ were pre-heated to $+55{ }^{\circ} \mathrm{C}$ and then mixed by pouring $125 \mathrm{~mL} 1 \mathrm{mM} \mathrm{K}_{4}\left[\mathrm{Fe}(\mathrm{CN})_{6}\right]$ into $125 \mathrm{~mL} 1 \mathrm{mM}$ $\mathrm{FeCl}_{3}$ under stirring on a magnetic stirrer. Citric acid was added to the iron salts solutions prior to their mixing if necessary. The final volume of the reaction mixture was $250 \mathrm{ml}$. The mixture was kept at $+55^{\circ} \mathrm{C}$ for $10 \mathrm{~min}$. The solution was allowed to cool down to room temperature with stirring. $\mathrm{NaCl}$ was added to $1 \mathrm{M}$ to nanoparticle solution, which induced their aggregation. Nanoparticles were centrifuged at $16000 \mathrm{~g}$ until complete sedimentation; the supernatants were carefully removed, and the nanoparticle pellet was redispersed in $1 \mathrm{M} \mathrm{NaCl}$. The washing procedure was repeated 3 times. After that dark blue precipitate was redispersed in $25 \mathrm{~mL}$ of $\mathrm{H}_{2} \mathrm{O}$, ultrasonicated with $60 \%$ amplification for $30 \mathrm{~min}$, and centrifuged at $1600 \mathrm{~g}$ for 5-15 min. Purification of the prussian blue nanoparticles was carried out by dialysis in $10 \mathrm{kDa} \mathrm{MWCO}$ dialysis tubing against $2 \mathrm{~L}$ of deionized water. The water was changed three times. Obtained suspensions were stored at $+4{ }^{\circ} \mathrm{C}$.

Preparation of prussian blue nanoparticles by reductive approach ('artificial peroxidase' nanoparticles)

In deionized water, $0.1 \mathrm{M}$ solutions of $\mathrm{FeCl}_{3}$ and $\mathrm{K}_{3}\left[\mathrm{Fe}(\mathrm{CN})_{6}\right]$ were added to $3.125 \mathrm{mM}$. Then, citric, oxalic acids, $\mathrm{HCl}$, and $\mathrm{KCl}$ (depending on the synthesis 
method) were added to the required concentration. Prussian blue nanoparticles deposition was initiated by $\mathrm{H}_{2} \mathrm{O}_{2}$ addition (to $22 \mathrm{mM}$ ). The final volume of the reaction mixture was $250 \mathrm{ml}$. After $60 \mathrm{~min}$ the suspension was transferred into centrifuge tubes, and centrifuged at $16000 \mathrm{~g}$ until complete sedimentation; the supernatants were carefully removed, and the nanoparticle pellet was redispersed in $\mathrm{H}_{2} \mathrm{O}$ by vortexing. The washing procedure was repeated 3 times. After that nanoparticles were redispersed in $25 \mathrm{~mL}$ of $\mathrm{H}_{2} \mathrm{O}$, ultrasonicated $(6 \mathrm{~mm}$ probe, $60 \%$ amplification), and centrifuged (Table 1). Obtained suspensions were stored at +4 ${ }^{\circ} \mathrm{C}$

Size, zeta-potential, and absorbance measurement

The zeta-potential and diameter of the nanoparticles were measured by M3PALS (mixed mode measurement-phase analysis light scattering) technique and DLS respectively. For size measurements, 'artificial peroxidase' nanoparticles were diluted 1:375 $\left(2 \mu \mathrm{l}\right.$ of nanoparticle suspension $+750 \mu \mathrm{l}$ of $\left.\mathrm{H}_{2} \mathrm{O}\right)$ in deionized water; prussian blue nanoparticles prepared by traditional method and 'artificial peroxidase' nanoparticles synthesized in the presence of $1 \mathrm{M} \mathrm{HCl}, \mathrm{KCl}$ were diluted 1:125 (6 $\mu \mathrm{l}$ of nanoparticle suspension $+750 \mu \mathrm{l}$ of $\left.\mathrm{H}_{2} \mathrm{O}\right)$ in deionized water. Plastic cuvettes $(10 \times 4 \times 45 \mathrm{~mm})$ were used for measurements. Measurements were performed at the scattering angle of $173^{\circ}$ in auto mode. A general-purpose model was used to fit the data. Z-average diameters are reported throughout the article unless otherwise stated. The concentration of nanoparticles was preliminary optimized (Figure S1).

For zeta-potential measurement, samples were diluted 1:100 in deionized water with the addition of $1 \mathrm{mM}$ of $\mathrm{NaCl}$ and $0.05 \%$ Tween-20 $(7 \mu \mathrm{l}$ of nanoparticle suspension $+700 \mu \mathrm{l}$ of water). The $\mathrm{pH}$ of the solution was adjusted to 6 using $1 \mathrm{M}$ $\mathrm{NaOH}$. Plastic cuvettes $(10 \times 10 \times 45 \mathrm{~mm})$ were used for measurements. Measurements were performed in auto mode using a Dip Cell electrode (Malvern, UK). All measurements were done in triplicate.

To assess the $A_{700}$ of the resulting suspensions, prussian blue nanoparticles were diluted 1:21 in deionized water $\left(5 \mu \mathrm{l}\right.$ of particles $\left.+100 \mu \mathrm{H}_{2} \mathrm{O}\right)$ in 96-well plates; then, spectra at $400-1000 \mathrm{~nm}$ were measured.

\section{Elemental analysis}

The concentration of iron and potassium in the obtained samples was estimated by inductively coupled plasma atomic emission spectroscopy (ICP-MS).

\section{Gravimetric analysis}

Porcelain crucibles were heated at $+140{ }^{\circ} \mathrm{C}$ to constant weight. Then samples were poured into them in a volume of $1 \mathrm{~mL}$ or $3 \mathrm{~mL}(\mathbf{T}, \mathbf{T 2 5 C}$, and $\mathbf{T} / \mathbf{d w} / \mathbf{r t})$. The water was evaporated at $+95{ }^{\circ} \mathrm{C}$, after which the samples were dried to constant weight at $+140{ }^{\circ} \mathrm{C}$. 
The specific activity of prussian blue nanoparticles and horseradish peroxidase was measured according to the protocol proposed by Jiang et al. [26], with modifications. Measurements were performed in $4 \mathrm{ml}$ plastic cuvettes $(10 \mathrm{~mm}$ path length). All solutions were kept at $+37{ }^{\circ} \mathrm{C}$ in the water bath before mixing. Nanoparticles (or enzyme) were added to $1 \mathrm{mM} \mathrm{Na}_{2} \mathrm{HPO}_{4} / 0.5 \mathrm{M}$ citric acid buffer, $\mathrm{pH} 5$ and incubated for 1 minute at $+37^{\circ} \mathrm{C}$. The concentration of iron was from 25 to $400 \mathrm{ng} / \mathrm{ml}$. TMB $(1 \mathrm{mg} / \mathrm{ml}$ in DMSO) was then added to $0.048 \mathrm{mg} / \mathrm{ml}$. The solution was incubated at $+37{ }^{\circ} \mathrm{C}$ for 1 more minute. Then $\mathrm{H}_{2} \mathrm{O}_{2}$ was added in the final concentration of $0.1 \mathrm{M}$. In the control samples deionized water was added. Cuvettes were immediately placed in a cell holder of a spectrophotometer, whose temperature was kept at $+37^{\circ} \mathrm{C}$. Absorbance at $652 \mathrm{~nm}\left(\mathrm{~A}_{652}\right)$ was recorded every 5 sec after $\mathrm{H}_{2} \mathrm{O}_{2}$ addition over 60 seconds. The resulting absorbance was received by subtraction of the background absorbance at $652 \mathrm{~nm}$ caused by nanozymes themselves (samples without $\mathrm{H}_{2} \mathrm{O}_{2}$ addition)

The duration of the initial rate period was chosen with the criterion $\mathrm{R} 2$ close to 1 after a linear regression analysis. Specific activity was calculated using protocols developed by [26]

\section{Storage stability of prussian blue nanoparticles}

Storage stability of prussian blue nanoparticles with various sizes, synthesized at 10x scale was evaluated by DLS right after preparation, and then after 1, 3, and 5 months of storage at $4{ }^{\circ} \mathrm{C}$. After three months of storage, aggregation was observed in some samples: $\mathbf{R}, \mathbf{R 2 C}$, and $\mathbf{R 2 O}$. We solved this problem by additional ultrasonication and centrifugation at a low speed (Table S1).

Preparation of conjugates of prussian blue nanoparticles with a monoclonal antibody against $P S A$, protein $G$, and bovine serum albumin

Evaluation of gelatin $A$ adsorption on the prussian blue nanoparticles

Prussian blue nanoparticles in the final concentration of $1 \mathrm{mg} / \mathrm{ml}$ were mixed with gelatin $\mathrm{A}$ in the mass ratio of 1:1, 1:2, 1:4, and 1:8 in deionized water. Samples were vortexed, briefly sonicated (probe diameter - $3 \mathrm{~mm}$; amplification - 60\%; duration - $10 \mathrm{~s}$ ), incubated at $+37^{\circ} \mathrm{C}$ for $60 \mathrm{~min}$ on a rotational mixer (10 RPM), and centrifuged at $20000 \mathrm{~g}$ until complete sedimentation. The concentration of gelatin in supernatants was measured by BCA assay. The size of nanoparticles after incubation with gelatin A was measured by DLS.

\section{Conjugation of prussian blue nanoparticles with antibodies and protein $G$}

Prussian blue nanoparticles (R2C) were added to the gelatin A (180 bloom) aqueous solution to the final concentration of $2.41 \mathrm{mg} / \mathrm{mL}$. The nanoparticles to gelatin mass ratio were 1:8. The resulting volume of the suspension was approximately $12 \mathrm{ml}$. Sample was vortexed, briefly sonicated (probe diameter - 3 $\mathrm{mm}$; amplification - $60 \%$; duration - $10 \mathrm{~s}$ ), and incubated at $+37^{\circ} \mathrm{C}$ for $60 \mathrm{~min}$ on a rotator $(10 \mathrm{rpm})$. Prussian blue nanoparticles coated with gelatin $\mathrm{A}(\mathrm{PB} / \mathrm{Gel} \mathrm{A})$ were mixed with an equal volume of $25 \%$ glutaraldehyde $(\mathrm{pH} 7)$, incubated at $+37^{\circ} \mathrm{C}$ for $30 \mathrm{~min}$. Absorbance at $700 \mathrm{~nm}$ of glutaraldehyde-activated nanoparticles (further 
referred to as $\mathrm{PB} / \mathrm{Gel} \mathrm{A}-\mathrm{COH}$ ) was measured and used to assess nanoparticle concentration at the following synthesis stages. $\mathrm{PB} / \mathrm{Gel} \mathrm{A}-\mathrm{COH}$ was centrifuged at $20000 \mathrm{~g}$ until complete sedimentation. Then the precipitate was redispersed into deionized water by brief sonication (probe diameter - $3 \mathrm{~mm}$; amplification - $60 \%$; duration - $10 \mathrm{~s}$ ) and centrifuged at $20000 \mathrm{~g}$ for $15 \mathrm{~min}$. In total, nanoparticles were washed three times. After the final wash, nanoparticles were redispersed in a $10 \mathrm{mM}$ phosphate buffer ( $\mathrm{pH}$ 7). Then suspension of $\mathrm{PB} / \mathrm{Gel} \mathrm{A}-\mathrm{COH}$ was divided into 3 parts. Each part was added under stirring to the solution of one of the three proteins: anti-PSA monoclonal antibodies (MAb; clone 1A6), protein G, or BSA. Mentioned proteins were preliminarily diluted in a $10 \mathrm{mM}$ phosphate buffer $(\mathrm{pH} 7)$. $\mathrm{PB} / \mathrm{Gel} \mathrm{A}$ $\mathrm{COH}$ to protein mass ratio was $1 \mathrm{mg}$ to $100 \mu \mathrm{g}$. After that, obtained mixtures were vortexed and kept on a rotator (10 RPM) overnight at $+4^{\circ} \mathrm{C}$. Glycine was added to $0.1 \mathrm{M}$ to quench unreacted aldehyde groups, and the mixture was incubated at +37 ${ }^{\circ} \mathrm{C}$ for two more hours. Nanoparticles were washed with water as described above. After the final wash, nanoparticles were redispersed in $\mathrm{H}_{2} \mathrm{O}$ by sonication (probe diameter - $3 \mathrm{~mm}$; amplification - $60 \%$, duration - $30 \mathrm{~s}$ ). The conjugates were stored at $+4{ }^{\circ} \mathrm{C}$.

Conjugates of $\mathrm{PB} / \mathrm{Gel} \mathrm{A}$ with $\mathrm{MAb}$, protein $\mathrm{G}$, and $\mathrm{BSA}$ were labeled as $\mathrm{PB} / \mathrm{Gel} \mathrm{A} / \mathrm{MAb}, \mathrm{PB} / \mathrm{Gel} \mathrm{A}$ /protein $\mathrm{G}$, and $\mathrm{PB} / \mathrm{Gel} \mathrm{A} / \mathrm{BSA}$, respectively.

\section{Properties and stability of gelatin-coated prussian blue nanoparticles}

Long-term storage stability of nanoparticle conjugates

Conjugates $\mathrm{PB} / \mathrm{Gel} \mathrm{A} / \mathrm{BSA}, \mathrm{PB} / \mathrm{Gel} \mathrm{A} /$ Protein $\mathrm{G}$, and $\mathrm{PB} / \mathrm{Gel} \mathrm{A} / \mathrm{MAb}$ were stored at $+4{ }^{\circ} \mathrm{C}$ in deionized water without stabilizers or preservatives. The concentration of prussian blue nanoparticles was between 1.03 and $1.16 \mathrm{mg} / \mathrm{mL}$ (concentration of coating protein is not taken into account). The size of nanoparticles was measured by DLS after the synthesis, then in 5 and 7 months.

Short-term colloidal stability of gelatin-coated prussian blue nanoparticles in comparison with non-coated ones

R2C and $\mathrm{PB} / \mathrm{Gel} \mathrm{A} /$ Protein $\mathrm{G}$ nanoparticles were diluted to $50 \mu \mathrm{g} / \mathrm{mL}$ in water and $0.2 \mathrm{M} \mathrm{Na}_{2} \mathrm{HPO}_{4} / 0.1 \mathrm{M}$ citric acid (McIlvaine) buffer, $\mathrm{pH} 3-7$. After $60 \mathrm{~min}$ of incubation, the size of nanoparticles was measured by DLS. Three technical replicates were measured for each sample.

\section{Zeta-potential of gelatin-coated prussian blue nanoparticles}

$\mathrm{PB} / \mathrm{Gel} \mathrm{A} /$ Protein $\mathrm{G}$ was diluted to $10 \mu \mathrm{g} / \mathrm{mL}$ in $5 \mathrm{mM} \mathrm{Na}_{2} \mathrm{HPO}_{4} /$ citric acid buffer, $\mathrm{pH}$ 3.1-7. Zeta potential was measured by M3-PALS technique. Three technical replicates were measured for each sample.

Assessment of hydrolysis intensity of gelatin-coated prussian blue nanoparticles

$\mathrm{PB} / \mathrm{Gel} \mathrm{A} / \mathrm{BSA}$ nanoparticles were diluted to $25 \mu \mathrm{g} / \mathrm{mL}$ in water, in $0.2 \mathrm{M}$ $\mathrm{Na}_{2} \mathrm{HPO}_{2} / 0.1 \mathrm{M}$ citric acid buffer ( $\left.\mathrm{pH} 2.5-8\right)$, in $0.1 \mathrm{M}$ Glycine- $\mathrm{HCl}$ ( $\mathrm{pH} 2$ and 3), $0.1 \mathrm{M}$ acetic acid-NaOH (pH 4 and 5), 0.1 M MES-NaOH (pH 6), and 0.1 M TRIS$\mathrm{HCl}$ (pH 7 and 8). Nanoparticles were kept in plastic cuvettes in the dark humid chamber for $24 \mathrm{~h}$ at room temperature. One cuvette was prepared for each condition. Absorbance at $700 \mathrm{~nm}$ was measured after the dilution in the following time points: 
$15 \mathrm{~min}, 60 \mathrm{~min}, 120 \mathrm{~min}$, and $24 \mathrm{~h}$. Photos of cuvettes were taken before measurements. After $24 \mathrm{~h}$, the size of nanoparticles was measured by DLS. Nanoparticles were resuspended by pipetting before measurement of absorbance and size if the sediment was observed

\section{Assays for PSA and Anti-Tetanus Toxoid IgG detection}

Assay procedure: sandwich immunoassay of PSA

One hundred microliters of $0.05 \mathrm{mg} / \mathrm{mL}$ mouse anti-PSA IgG (clone $3 \mathrm{~A} 6$ ) in a $0.2 \mathrm{M}$ carbonate buffer ( $\mathrm{pH} 9.6$ ) were added into the wells of a 96-well polystyrene plate. Plates were kept at $+4{ }^{\circ} \mathrm{C}$ overnight. Plates were washed three times with 300 $\mu \mathrm{L}$ of sodium phosphate buffer with $0.1 \%$ Tween-20, $\mathrm{pH} 7$ (PBT) using a microplate washer, and then $250 \mu \mathrm{L}$ of a blocking buffer (PBT $+2 \%$ casein $+1 \%$ BSA, pH 7) was added. After 60 min of blocking, plates were washed three times. Four-fold dilutions of PSA in the blocking buffer $(100 \mu \mathrm{L}$ per well) from 1000 to $0.24 \mathrm{ng} / \mathrm{ml}$ were added, then plates were incubated for $60 \mathrm{~min}$ and washed three times. The $\mathrm{PB} / \mathrm{Gel} \mathrm{A} / \mathrm{MAb}$ suspension $(100 \mu \mathrm{L}, 0.025 \mathrm{mg} / \mathrm{mL})$ in the blocking buffer was added and reacted for $60 \mathrm{~min}$. After washing, $100 \mu \mathrm{L}$ of the substrate buffer $(1 \mathrm{ml}$ of 1 $\mathrm{mg} / \mathrm{ml}$ of TMB in DMSO $+9 \mathrm{~mL}$ of citrate-phosphate buffer $+100 \mu \mathrm{L}$ of $30 \% \mathrm{H}_{2} \mathrm{O}_{2}$ ) was added. After $30 \mathrm{~min}$, the reaction was stopped by the addition of $100 \mu \mathrm{L}$ of $2 \mathrm{M}$ sulphuric acid. The absorbance at $450 \mathrm{~nm}$ was measured by a microplate reader. All the assay steps except for the washing and measurement steps were performed in the thermoshaker at $+37^{\circ} \mathrm{C}$ (mixing speed - $300 \mathrm{RPM}$ ).

\section{Assay procedure: indirect detection of anti-tetanus toxoid IgG}

One hundred microliters of $0.05 \mathrm{mg} / \mathrm{mL}$ tetanus toxoid in a $0.2 \mathrm{M}$ carbonate buffer ( $\mathrm{pH}$ 9.6) was added into the wells of a 96-well polystyrene plate. Plates were kept at $+4{ }^{\circ} \mathrm{C}$ overnight. Plates were washed three times with $300 \mu \mathrm{L}$ of sodium phosphate buffer with $0.1 \%$ Tween-20, $\mathrm{pH} 7$ (PBT) using a microplate washer, and then $250 \mu \mathrm{L}$ of a blocking buffer (PBT $+2 \%$ casein $+1 \%$ BSA, $\mathrm{pH} 7$ ) was added. After $60 \mathrm{~min}$ of blocking, plates were washed three times. Four-fold dilutions of anti-tetanus antibodies in the blocking buffer $(100 \mu \mathrm{L}$ per well) from $100 \mathrm{mIU} / \mathrm{mL}$ to $0.024 \mathrm{mIU} / \mathrm{mL}$ were added, then plates were incubated for $60 \mathrm{~min}$ and washed three times. The PB/Gel A/Protein G suspension $(100 \mu \mathrm{L}, 0.025 \mathrm{mg} / \mathrm{mL})$ in the blocking buffer was added and reacted for $60 \mathrm{~min}$. After washing, $100 \mu \mathrm{L}$ of the substrate buffer $(1 \mathrm{ml}$ of $1 \mathrm{mg} / \mathrm{ml}$ of TMB in DMSO $+9 \mathrm{~mL}$ of citrate-phosphate buffer $+100 \mu \mathrm{L}$ of $30 \% \mathrm{H}_{2} \mathrm{O}_{2}$ ) was added. After 30 min the reaction was stopped by the addition of $100 \mu \mathrm{L}$ of $2 \mathrm{M}$ sulphuric acid. The absorbance at $450 \mathrm{~nm}$ was measured by a microplate reader. All the assay steps except for the washing and measurement steps were performed in the thermoshaker at $+37^{\circ} \mathrm{C}$ (mixing speed 300 RPM).

\section{Results and discussion}

Change of ratio between iron salts and hydrogen peroxide does not allow to properly control of the size of 'artificial peroxidase' nanozymes 
The method of obtaining 'artificial peroxidase' nanoparticles with improved peroxidase-like activity proposed in the original paper [9] relies on the addition of a reducing agent $\left(\mathrm{H}_{2} \mathrm{O}_{2}\right)$ to the mixture of $\mathrm{FeCl}_{3}$ and $\mathrm{K}_{3}\left[\mathrm{Fe}(\mathrm{CN})_{6}\right]$. According to the mentioned paper, the size of nanoparticles can be controlled in a relatively wide range, from tens of nanometers to $300-400 \mathrm{~nm}$ by changing the ratio between salts and hydrogen peroxide. Unfortunately, it is not easy to predict the size of nanoparticles from a 3D graph made by the authors. Reproduction of the original method is also rather challenging, because the description of the synthesis conditions (stirring and ultrasonication regime) is not detailed enough, being however crucial for obtaining nanoparticles of the desired size. Since the mixing conditions and synthesis duration were not indicated, we synthesized nanoparticles under vigorous stirring conditions at a fixed stirring speed $(1000 \mathrm{~g})$. The concentration of iron salts was between 1.56 and $25 \mathrm{mM}$, whereas $\mathrm{H}_{2} \mathrm{O}_{2}$ concentration varied between 2.75 and $176 \mathrm{mM}$. Unlike the original article, synthesis was performed without the addition of $\mathrm{HCl}$ and $\mathrm{KCl}$.



Figure 2. Size and polydispersity of prussian blue nanoparticles prepared at different concentrations of $\mathrm{FeCl}_{3} / \mathrm{K}_{3}\left[\mathrm{Fe}(\mathrm{CN})_{6}\right]$ (shown above the histograms) and $\mathrm{H}_{2} \mathrm{O}_{2}$. Dh - hydrodynamic diameter (blue bars), PdI - polydispersity index (claret red bars). The dotted line at $150 \mathrm{~nm}$ is for easier visual comparison of samples. The absence of a bar means an aggregation of nanoparticles. $n=3$, mean \pm SD

In general, larger nanoparticles were formed when the concentration of $\mathrm{FeCl}_{3} / \mathrm{K}_{3}\left[\mathrm{Fe}(\mathrm{CN})_{6}\right]$ increased (Fig. 2). This growth however was limited - up to 150$170 \mathrm{~nm}$ (expected diameter was 200-300 nm and more). Importantly, polydispersity was also relatively high (larger than the commonly accepted threshold of 0.2 [27]) at $\mathrm{FeCl}_{3} / \mathrm{K}_{3}[\mathrm{Fe}(\mathrm{CN}) 6]$ concentrations exceeding $6.25 \mathrm{mM}$, despite all nanoparticles being intensively sonicated and centrifuged at low speed. High polydispersity is undesirable because it negatively affects the reproducibility of nanoparticle applications and hinders control over nanoparticle processing. Notably, after prolonged post-synthesis sonication nanoparticle diameter gradually decreased until 
constant value (Fig. S2), which indicates the importance of optimization of the postsynthesis treatment.

In total, we were not able to manipulate the size of the prussian blue nanoparticles in the desired range by changing the ratio between iron salts and $\mathrm{H}_{2} \mathrm{O}_{2}$. A two-fold increase in nanoparticle size was hardly reached, moreover, the polydispersity of larger nanoparticles was too high. We admit that we did not completely follow the original protocol because $\mathrm{HCl}$ and $\mathrm{KCl}$ were not added in the course of synthesis. Nevertheless, obtained results demonstrate the non-universal nature of the size control method proposed in the original paper. Moreover, further (see Section "Preparation of prussian blue nanoparticles with various sizes at $10 x$ scale") we show that despite both $\mathrm{HCl}$ and $\mathrm{KCl}$ can affect the size and yield of nanoparticles, they are not essential for the preparation of 'artificial peroxidase' with high catalytic activity.

We suggest the size of nanoparticles depends more on the stirring conditions and post-synthesis treatment (centrifugation speed, sonication duration and intensity, and so forth), rather than the concentration of iron salts. These results motivated us to study the influence of different factors including $\mathrm{pH}$, temperature, ionic strength, and addition of low-molecular-weight ligands on the size and polydispersity of 'artificial peroxidase' nanozymes.

The size of "artificial peroxidase" nanozymes can be controlled by tuning synthesis conditions: $p H$, temperature, ionic strength, and so on

Alteration of various synthesis parameters (temperature [28, 29], $\mathrm{pH}[\mathbf{3 0}, \mathbf{3 1}]$, presence of chelating agent $[32,33,34]$, ratio of reactants [35], addition of organic solvent $[36,37])$ enables manipulating the size of prussian blue nanoparticles prepared by traditional double precursor method or hydrothermal single precursor method. We determined the influence of most of these factors on the diameter and yield of 'artificial peroxidase' nanozymes. We did not utilize polymers to control the nanoparticle size, because the presence of a polymer shell may limit further surface modification.

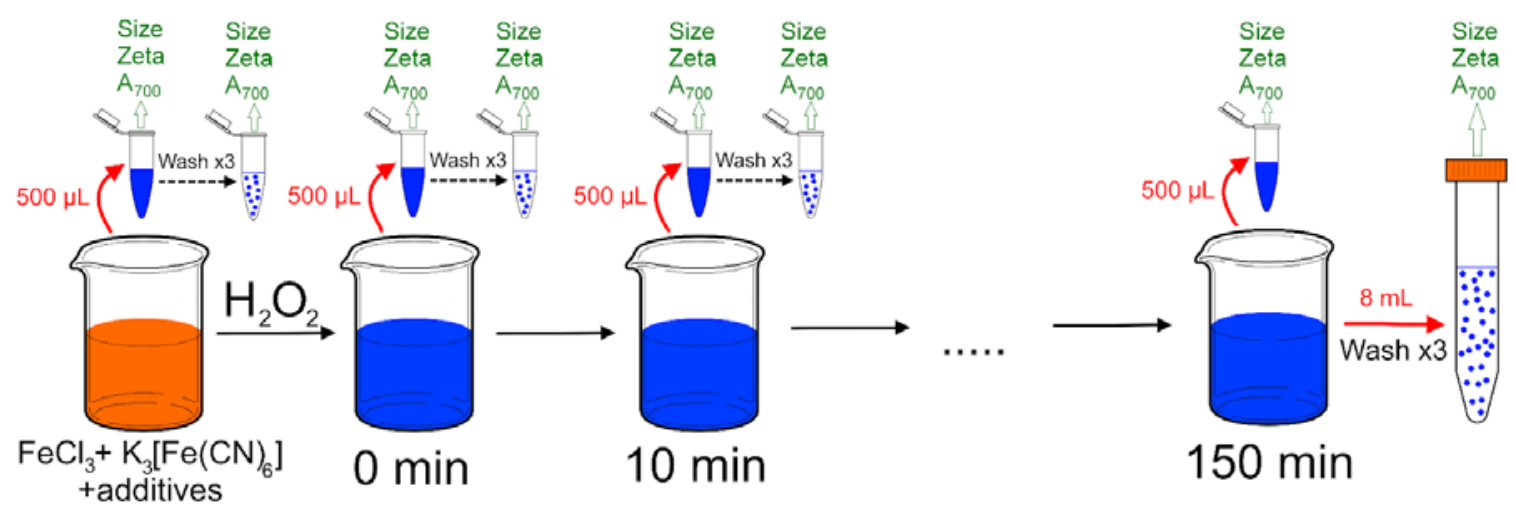

Figure 3. Influence of different factors on the synthesis of 'artificial peroxidase' nanozymes: design of the experiment. 
Syntheses were performed in $25 \mathrm{ml}$ volume. The order of reagent addition was the same in all experiments: first, we added iron salts, then additives (citric or oxalic acids, potassium chloride, hydrochloric acid, potassium hydroxide), finally, the formation of prussian blue was initiated by the addition of hydrogen peroxide. Samples from the reaction medium were taken before and after the addition of $\mathrm{H}_{2} \mathrm{O}_{2}$, and then at 10,30,60, 90, 120, and $150 \mathrm{~min}$. The following parameters were measured: size and polydispersity, zeta potential, and absorbance at $700 \mathrm{~nm}\left(\mathrm{~A}_{700}\right)$ (in situ samples). Then samples were centrifuged, washed, and the above-mentioned parameters were measured again (centrifuged samples) to evaluate what nanoparticles would be obtained if the synthesis had been completed at the moment of sampling. The scheme of the experiment is given in Figure 3. Size, zeta potential, and $\mathrm{A}_{700}$ (which reflects the concentration of prussian blue) of nanoparticles synthesized in various conditions are summarized in the Figure 4. Below some technological features of the 'artificial peroxidase' preparation process are listed.

Analysis of centrifuged samples obtained at 0 and $150 \mathrm{~min}$ time points revealed that the size of prussian blue nanoparticles is determined in the first minutes after the addition of hydrogen peroxide (Figures S3-S8). However, in the case of 3$4.5 \mathrm{mM}$ of citric acid addition (Figure S7) enlargement of nanoparticles was observed for 30-60 min, probably due to assembling of smaller nanoparticles into large ones (see Section "Preparation of prussian blue nanoparticles with various sizes at $10 x$ scale").

In the course of synthesis, prussian blue nanoparticles usually form large loose aggregates. It allows centrifugation of formed prussian blue at relatively low speed, facilitating the purification process. Final ultrasound treatment leads to the destruction of these loose aggregates and obtaining nanoparticle dispersion. These nanoparticles can require a much higher centrifugation speed (30000-40000 g or more) for complete sedimentation. This feature may hinder the following functionalization process and should be taken into account. Conversely, in the course of synthesis at elevated temperature, the size of nanoparticles and their polydispersity gradually decreased.

An increase of nanoparticle concentration $\left(\mathrm{A}_{700}\right)$ occurred even after $150 \mathrm{~min}$ from the start of synthesis (Figure S9), therefore agitation can be potentially prolonged for several hours to increase the yield of nanoparticles.

In the following paragraphs, we highlight the key relationships between synthesis conditions and nanoparticle size and yield, then the choice of conditions for preparation of 'artificial peroxidase' nanozyme at a larger scale is justified.

Temperature. Three independent syntheses were performed at $+30{ }^{\circ} \mathrm{C}$ and +60 ${ }^{\circ} \mathrm{C}$. With temperature increase, the mean diameter of nanoparticles grew from 103 to $152 \mathrm{~nm}$. Absorption at $700 \mathrm{~nm}$ was $15 \%$ higher for prussian blue nanoparticles synthesized at $+30{ }^{\circ} \mathrm{C}$. An increase in absorbance can be explained by both the higher yield and the smaller mean diameter [38] of obtained nanoparticles. Enlargement of nanoparticles at higher temperatures is a typical situation when reagent concentration is sufficient for both formation of new nuclei and the growth of formed particles [39]. 
A

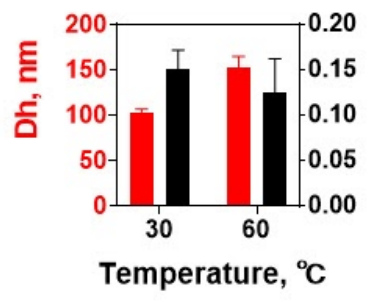

D

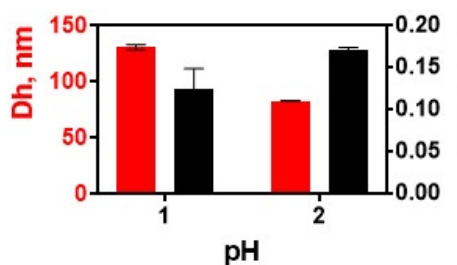

pH

\section{II}

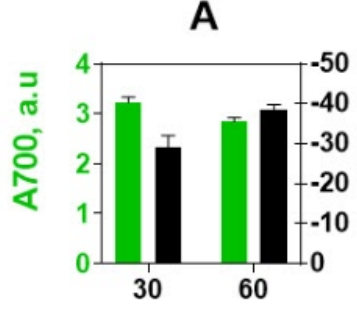

Temperature, ${ }^{\circ} \mathrm{C}$

D

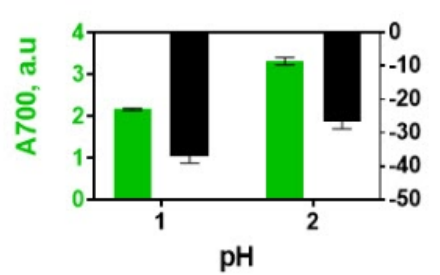

B

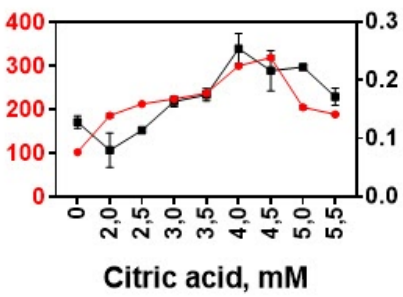

E

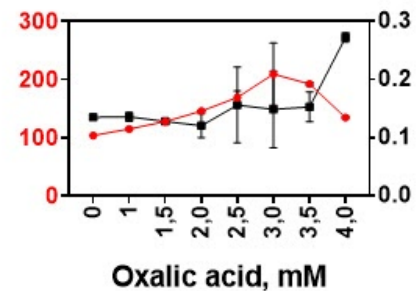

Oxalic acid, mM
C

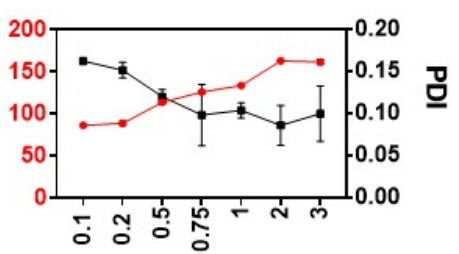

lonic strength, $\mathrm{mM}$

F

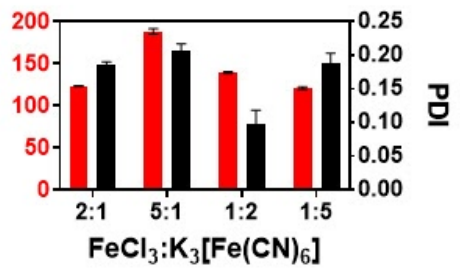

B



Citric acid, mM

E

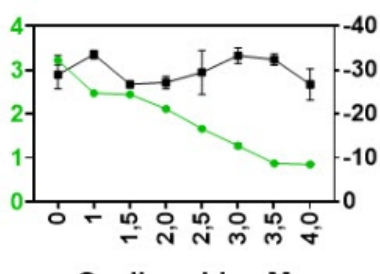

Oxalic acid, mM



Ionic strength, $\mathrm{mM}$

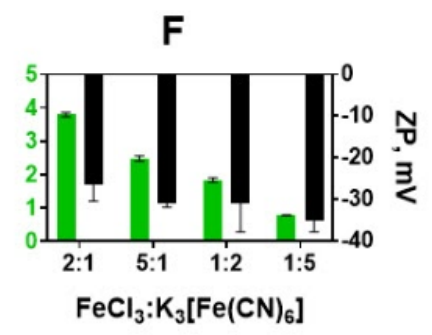

Figure 4. Influence of different factors: (A) temperature, (B) citric acid concentration, (C) ionic strength, (D) $\mathrm{pH}$, (E) oxalic acid concentration, (F) molar ratios of $\mathrm{FeCl}_{3}$ and $\mathrm{K}_{3}\left[\mathrm{Fe}(\mathrm{CN})_{6}\right]$ on the 'artificial peroxidase' nanozymes formation. $\mathrm{I}$ - size (Dh) and polydispersity (PDI) of nanoparticles; II - yield $\left(\mathrm{A}_{700}\right)$ and zetapotential $(\mathrm{ZP})$ of nanoparticles. $\mathrm{n}=3$, mean $\pm \mathrm{SD}$

Chelating agents. The rate of prussian blue formation was assessed by measuring $\mathrm{A}_{700}$ in 10 and 150 min after the addition of hydrogen peroxide. The addition of citric and oxalic acids decreased both starting concentration and the rate of prussian blue formation [40] (Figure S10). This is explained by the interaction of acid molecules with ferric ions which hinders their reaction with hexacyanoferrate ions [33]. Decrease of nuclei number and slower growth results in larger 
nanoparticles, however at the expense of lower yield. An increase in citric or oxalic acid concentration resulted in a gradual increase in nanoparticle diameter. Only negligible $\mathrm{pH}$ change was caused by the addition of carboxylic acids, therefore we suggest that size increase was not due to the $\mathrm{pH}$ decline (see results on the influence of the $\mathrm{pH}$ below). Notably, a too-large concentration of carboxylic acids has the opposite effect: nanoparticles become smaller, while their yield decreases. The turning point is close to equimolar concentration. The obtained results are in line with previous reports. Specifically, Shokouhimehr demonstrated that five-fold molar excess of citric acid led to a decrease of nanoparticle size whereas an increase in size was observed from 5\% to 50\% of citric acid [41]. Similarly, Kim et al. [42] obtained prussian blue nanoparticles of 50-60 $\mathrm{nm}$ or 20-25 $\mathrm{nm}$ by using, respectively, 13- and a 26-fold excess of citric acid. Oppositely, Jia et al. observed that slight growth of prussian blue nanoparticles accompanied the addition of excessive amounts of oxalic acid [43]. Probably, the larger aging time is the reason for this result [34]. Citric acid allows for the regulation of nanoparticle size in a wider range in comparison with oxalic acid. It can be explained by the stronger complexation of iron ions by citric acid $[\mathbf{4 4}, \mathbf{4 5}]$.

Effect of $\mathrm{pH}$, ionic strength, and iron salts ratio. The $\mathrm{pH}$ of the reaction mixture was 2.8-2.9 and did not change during 150 minutes of synthesis under reference conditions $\left(3.125 \mathrm{mM} \mathrm{FeCl}_{3}\right.$ and $\left.\mathrm{K}_{3}\left[\mathrm{Fe}(\mathrm{CN})_{6}\right], 22 \mathrm{mM} \mathrm{H}_{2} \mathrm{O}_{2},+30^{\circ} \mathrm{C}\right)$. The addition of citric or oxalic acids up to $4-5.5 \mathrm{mM}$ had almost no effect on the $\mathrm{pH}$ of the reaction medium. Particle formation wasn't observed while the $\mathrm{pH}$ of the reaction mixture was adjusted to 4 by the addition of $1 \mathrm{M} \mathrm{KOH}$. The decrease of $\mathrm{pH}$ to 2 had almost no influence on the size and yield of nanoparticles (compare Fig. 4IA and Fig. 4ID), whereas at $\mathrm{pH} 1$ larger nanoparticles were formed (130 vs $82 \mathrm{~nm}$ ).

The ionic strength of the reaction mixture during synthesis under reference conditions was $37.5 \mathrm{mM}$. The ionic strength of the reaction mixture was adjusted by the addition of $1 \mathrm{M} \mathrm{KCl}$. An increase of ionic strength led to a growth of nanoparticles from $86 \mathrm{~nm}$ at $0.1 \mathrm{M}$ to $161 \mathrm{~nm}$ at $3 \mathrm{M}$. The effect of ionic strength on zeta potential and polydispersity index was insignificant. A pronounced decline of nanoparticle yield $\left(\mathrm{A}_{700}\right)$ was observed at $\mathrm{KCl}$ concentrations higher than $1 \mathrm{M}$.

The effect of four different molar ratios of $\mathrm{FeCl}_{3}$ and $\mathrm{K}_{3}\left[\mathrm{Fe}(\mathrm{CN})_{6}\right](5: 1,2: 1$, 1:5, 1:2) on characteristics of prussian blue nanoparticles was evaluated. Excessive amounts of $\mathrm{FeCl}_{3}$ increased the size of nanoparticles and their polydispersity, while an excess of $\mathrm{K}_{3}\left[\mathrm{Fe}(\mathrm{CN})_{6}\right]$ has no significant effect.

Relationships between the process of crystal formation and crystallization conditions such as $\mathrm{pH}$ or ionic strength of ions are rather complex and depend on multiple parameters, for example, type of cations and anions [46, 47]. For this reason, we are unable to present a complete explanation of observed patterns.

Based on obtained results we decided to add citric and oxalic acids into the reaction medium to obtain 'artificial peroxidase' nanozymes with diameters from 100 to $300 \mathrm{~nm}$. The advantage of carboxylic acid addition is the possibility to obtain nanoparticles with a broad range of sizes and reasonably low polydispersity. 
Preparation of prussian blue nanoparticles with various sizes at $10 x$ scale

Five types of nanoparticles were obtained using the reductive approach ('artificial peroxidase') and three types of nanoparticles were synthesized by the traditional approach. Scalability and good reproducibility of nanoparticle synthesis are mandatory for their real-world application $[48,49]$. Therefore, for each type of nanoparticles, 3 individual batches were synthesized (only 2 were prepared for $\mathbf{T} / \mathbf{d w} / \mathbf{r t}$ ). Starting reaction volume was increased tenfold in comparison with previous experiments: from 25 to $250 \mathrm{~mL}$.

The purposes of this part of the study included 1) to confirm the applicability of the developed method of 'artificial peroxidase' nanoparticle size tuning; 2) to assess scalability and reproducibility of nanoparticle synthesis; 3) to obtain an amount of nanoparticles sufficient for examination of their properties and synthesis of reagents for immunoassay.

Based on previous results, four types of conditions were chosen to synthesize nanoparticles with diameters from 100 to $300 \mathrm{~nm}$ by the reductive approach. Citric and oxalic acid were utilized to control the diameter of nanoparticles. One more type of nanoparticles was prepared by the reductive approach using conditions $(0.1 \mathrm{M}$ $\mathrm{KCl}$ and $0.1 \mathrm{M} \mathrm{HCl}$ ) proposed in the original paper by Komkova et al. [9]. Additionally, three types of prussian blue nanoparticles were synthesized using the traditional approach, their sizes varied from 60 to $130 \mathrm{~nm}$. Characteristics and naming of all types of nanoparticles can be found in the Tables 1 and 2 .

Size and morphology. Preparation of large nanoparticles by the traditional method is a rather challenging task. The largest size of nanoparticles we were able to reach $(120-130 \mathrm{~nm})$ was achieved by the very slow addition of $\mathrm{K}_{4}\left[\mathrm{Fe}(\mathrm{CN})_{6}\right]$ to the $\mathrm{FeCl}_{3}$ solution (Figure 5A). It was important to prepare such large nanoparticles because we were interested in comparing nanoparticles of similar size prepared by two different approaches. Unfortunately, we failed to synthesize 'artificial peroxidase' nanoparticles smaller than $90 \mathrm{~nm}$, therefore batches $\mathbf{R}, \mathbf{T}, \mathbf{R 2 C}$, and $\mathbf{T} / \mathbf{d w} / \mathbf{r t}$ were the only ones with similar sizes. Syntheses were performed on different days using freshly prepared salt solutions to closely imitate real-world situation. The size of nanoparticles was assessed by DLS, which is known to overestimate the mean diameter of nanoparticles (in comparison with TEM) [34]. TEM analysis showed that "artificial peroxidase" nanoparticles have an irregular shape and are rather disordered assemblies of smaller nanoparticles (Figure S11). The irregular shape of nanoparticles made impossible an accurate measurement of their diameter by TEM. In all samples, small nanoparticles were presented in dispersions together with larger ones. In sample RKH along with large nanoparticles, small cubic nanoparticles having similar sizes were also observed (Figure S11M-O). These factors together explain the relatively high polydispersity (no samples with PdI lower than 0.1) of 'artificial peroxidase' nanoparticles. Besides, we observed between-replicate inconsistencies when the size of nanoparticles was measured by DLS. Usually, one of three technical replicates had a size significantly different from two others (larger size and polydispersity), which is explained by the high sensitivity of the DLS method to the presence of aggregates 
[50]. These replicates were not taken into account when the analysis was performed (Table S4).
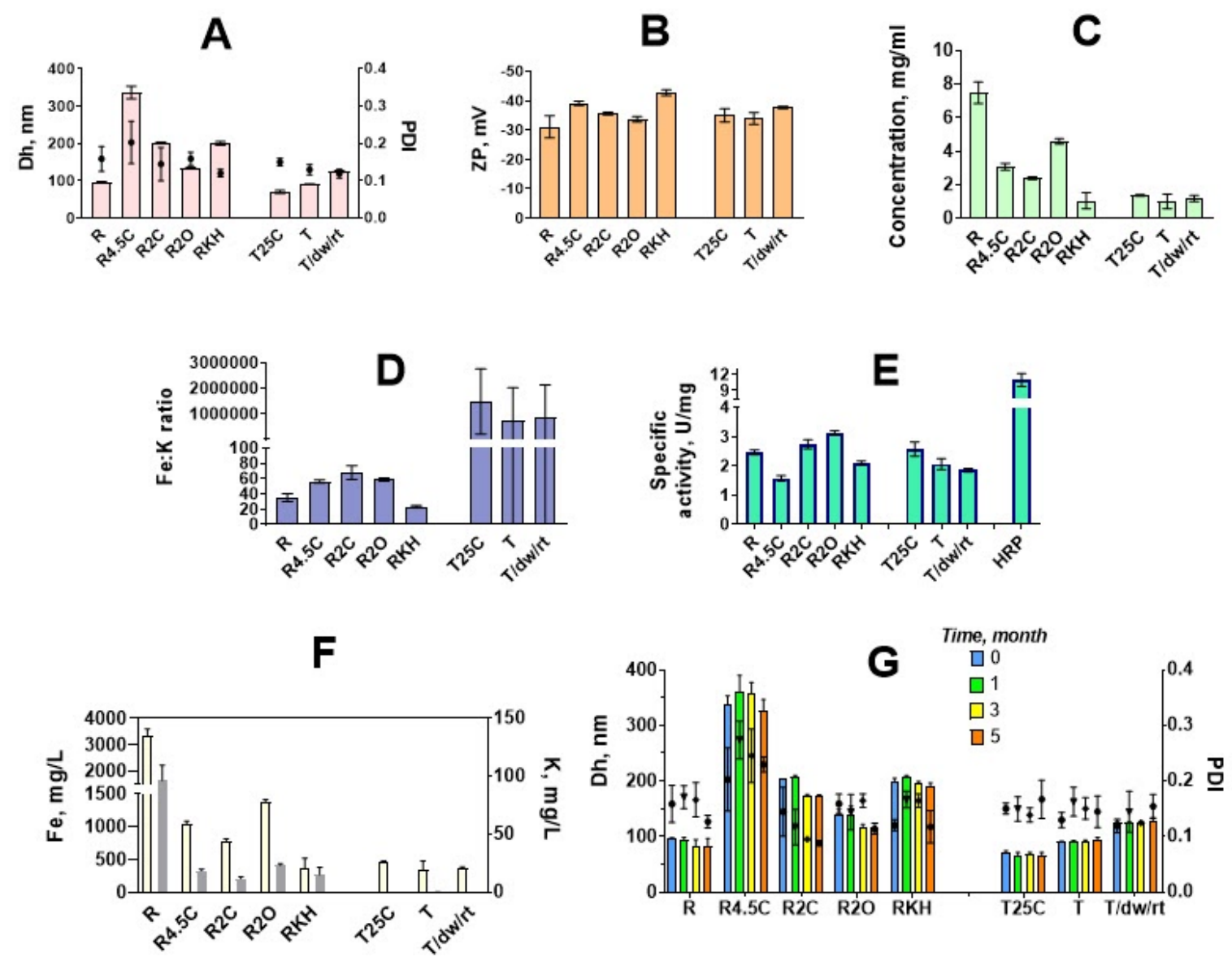

Figure 5. Characterization of prussian blue nanoparticles synthesized at 10x scale. (A) mean hydrodynamic diameter (Dh) and polydispersity index (PDI); (B) zeta-potential (ZP) of obtained nanoparticles; (C) concentrations (dry mass per unit volume); (D) Fe:K mass ratio; (E) specific peroxidase-like activity (HRP horseradish peroxidase); (F) concentration of $\mathrm{Fe}$ and $\mathrm{K}$; (G) size and polydispersity of nanoparticles after 1,3 , and 5 months of storage at $+4{ }^{\circ} \mathrm{C} . \mathrm{n}=3$, mean of three individual batches $\pm \mathrm{SD}$

Size reproducibility. In general, the size of 'artificial peroxidase' nanoparticles was close to the target size (nanoparticles prepared in identical conditions in $25 \mathrm{ml}$ reaction volume). The difference between target size and observed size was in the range from $-9 \%$ to $+11 \%$. Therefore, the addition of carboxylic acids allows to properly control the size of nanoparticles prepared by the reductive approach. The reproducibility of nanoparticle preparation was examined by estimating the batch-to-batch coefficient of variation for mean hydrodynamic diameter. The coefficient of variation was between 0.3 and $2.6 \%$ for "artificial peroxidase" nanoparticles, indicating good batch-to-batch reproducibility. For comparison, between-batch coefficients of variation reported for other nanoparticles were 2-5\% (gold nanoparticles) [51], 10-42\% (dextran-coated iron oxide nanoparticles) [52], less than 5\% (poly(D,l-lactide-co-glycolide) nanoparticles) [53] . 
Table 2. Hydrodynamic diameters (Dh) and polydispersity (PdI) of prussian blue nanoparticles synthesized in different conditions at 10x scale. Target - target size of nanoparticles predicted from experiments in a lower reaction volume. Diff. size difference between obtained and target size. $\mathrm{CV}$ - coefficient of variation of Dh of three batches.

\begin{tabular}{|c|c|c|c|c|c|c|c|c|c|c|c|}
\hline Type & & №1 & & & №2 & & & №3 & & & \\
\hline & Target & $\mathrm{D}_{\mathrm{h}}, \mathrm{nm}$ & PdI & Diff. & $\mathbf{D}_{\mathrm{h}}, \mathbf{n m}$ & PdI & Diff. & $\mathrm{D}_{\mathrm{h}}, \mathbf{n m}$ & PdI & Diff. & $\mathrm{CV}, \%$ \\
\hline $\mathbf{R}$ & $\begin{array}{l}101.3 ; \\
0.119\end{array}$ & $\begin{array}{c}96,3 \pm \\
8,8\end{array}$ & $\begin{array}{c}0,19 \pm \\
0,05\end{array}$ & $-5 \%$ & $\begin{array}{l}92,9 \pm \\
0,005\end{array}$ & $\begin{array}{c}0,159 \pm \\
0,001\end{array}$ & $-9 \%$ & $\begin{array}{c}97,7 \pm \\
0,6\end{array}$ & $\begin{array}{c}0,125 \pm \\
0,007\end{array}$ & $-4 \%$ & 2,6 \\
\hline R4.5C & $\begin{array}{c}318.6 ; 0 \\
.22\end{array}$ & $\begin{array}{c}355,6 \pm \\
4,9 \\
\end{array}$ & $\begin{array}{c}0,15 \pm \\
0,04\end{array}$ & $+11 \%$ & $\begin{array}{c}330, \pm \\
1,9\end{array}$ & $\begin{array}{c}0,264 \pm \\
0,01\end{array}$ & $+4 \%$ & $\begin{array}{c}323,5 \pm \\
2,2 \\
\end{array}$ & $\begin{array}{c}0,19 \pm \\
0,02\end{array}$ & $+1 \%$ & 1,4 \\
\hline R2C & $\begin{array}{c}185.5 \\
0.08\end{array}$ & $\begin{array}{c}202 \pm \\
0,2\end{array}$ & $\begin{array}{c}0,14 \pm \\
0,07\end{array}$ & $+9 \%$ & $\begin{array}{c}202,9, \pm \\
0.9\end{array}$ & $\begin{array}{c}0,19 \pm \\
0,06\end{array}$ & $+9 \%$ & $\begin{array}{c}203,4 \pm \\
2,6\end{array}$ & $\begin{array}{c}0,102 \pm \\
0,02\end{array}$ & $+10 \%$ & 0,3 \\
\hline R2O & $\begin{array}{c}145.6 \\
0.12\end{array}$ & $\begin{array}{l}135 \pm \\
0,75\end{array}$ & $\begin{array}{c}0,17 \pm \\
0,08\end{array}$ & $-7 \%$ & $\begin{array}{c}133, \pm \\
0,7\end{array}$ & $\begin{array}{c}0,14 \pm \\
0,02\end{array}$ & $-9 \%$ & $\begin{array}{c}134,4 \pm \\
1,35\end{array}$ & $\begin{array}{c}0,169 \pm \\
0,07\end{array}$ & $-8 \%$ & 0,8 \\
\hline RKH & & $\begin{array}{c}194,1 \pm \\
1,98\end{array}$ & $\begin{array}{c}0,13 \pm \\
0,01\end{array}$ & & $\begin{array}{c}203, \pm \\
0,7\end{array}$ & $\begin{array}{c}0,109 \pm \\
0,02\end{array}$ & & $\begin{array}{c}202,6 \pm \\
2,4\end{array}$ & $\begin{array}{c}0,12 \pm \\
0,02\end{array}$ & & 2,5 \\
\hline T25C & $\begin{array}{c}54.04 ; \\
0.15\end{array}$ & $\begin{array}{c}67,18 \pm \\
0,38\end{array}$ & $\begin{array}{c}0,16 \pm \\
0,02\end{array}$ & $+24 \%$ & $\begin{array}{c}75,0 \pm \\
1,73\end{array}$ & $\begin{array}{l}0,15 \pm \\
0,015\end{array}$ & $+38 \%$ & $\begin{array}{c}68,3 \pm \\
1,6\end{array}$ & $\begin{array}{l}0,14 \pm \\
0,024\end{array}$ & $+26 \%$ & 6,1 \\
\hline $\mathbf{T}$ & $\begin{array}{c}84.6 ; \\
0.2\end{array}$ & $\begin{array}{c}89,85 \pm \\
0,7\end{array}$ & $\begin{array}{l}0,13 \pm \\
0,001\end{array}$ & $+6 \%$ & $\begin{array}{c}91,1 \pm \\
1,4\end{array}$ & $\begin{array}{l}0,14 \pm \\
0,031\end{array}$ & $+8 \%$ & $\begin{array}{c}91,21 \pm \\
0,3\end{array}$ & $\begin{array}{c}0,116 \pm \\
0,02\end{array}$ & $+8 \%$ & 0,9 \\
\hline T/dw/rt & $\begin{array}{c}135.8 \\
0.14\end{array}$ & $\begin{array}{c}126,7 \pm \\
0,34\end{array}$ & $\begin{array}{l}0,12 \pm \\
0,004\end{array}$ & $-7 \%$ & $\begin{array}{c}123 \pm \\
0,7\end{array}$ & $\begin{array}{c}0,11 \pm \\
0,01\end{array}$ & $-9 \%$ & - & - & - & 2,1 \\
\hline
\end{tabular}

Yield. For each batch concentration of nanoparticles (dry weight per unit volume) was determined. Nanoparticle concentration allows assessment of the process yield. As can be seen from the Figure 5C the largest yield was observed when no additives were present in the reaction medium - approximately $200 \mathrm{mg}$ of nanoparticles were isolated, which is in agreement with data on absorbance at 700 $\mathrm{nm}$ obtained in small-scale experiments (Figure 4IIA-F). Both citric and oxalic acid decreases the concentration of nanoparticles. In general, the larger the diameter of nanoparticles, the lower the yield. The presence of $\mathrm{KCl}$ and $\mathrm{HCl}$ (as in the original paper) resulted in a two-fold lower yield in comparison with the R2C sample, despite sizes being almost the same.

Elemental analysis. The concentration of iron and potassium was determined for each batch by the ICP-MS. Iron content was used to normalize peroxidatic activity of prussian blue nanoparticles synthesized by various methods (see below in this section). Depending on the potassium concentration two types of prussian blue can be distinguished: soluble (contains potassium ions) and insoluble (does not contain potassium ions) [54]. Insoluble prussian blue contains $\mathrm{Fe}^{\mathrm{II}}(\mathrm{CN})_{6}{ }^{4-}$ vacancies, filled with water molecules that are partially coordinated to $\mathrm{Fe}^{\mathrm{III}}$ ions. Soluble prussian blue contains potassium ions in interstitial sites of prussian blue cubic structure. In this case, the number of vacancies depends on potassium content [54]. All prussian blue nanoparticles prepared by the traditional method consisted of insoluble prussian blue, whereas 'artificial peroxidase' nanozymes contained sufficient amounts of potassium. Fe:K mass ratio was from 17.6 (RKH) to 66.8 (R2C). RKH nanoparticles were more saturated with potassium because they were synthesized in the presence of $0.1 \mathrm{M} \mathrm{KCl}$. Opposite to the previous report [55], we did not observe a clear relationship between potassium content and catalytic activity of nanozymes (Figure 5D-F). Even if some dependence exists, in this study it was 
masked by other factors, first of all, the size difference between nanoparticles prepared in various conditions.

\section{The catalytic activity of prussian blue nanozymes}

The most important feature of 'artificial peroxidase' nanozymes is improved peroxidatic activity in comparison with prussian blue nanoparticles synthesized by the traditional method. Komkova et al. [9] calculated catalytic activity of 'artificial peroxidase' considering a single nanoparticle as a catalytic unit. The issue of measurement of nanozymes' catalytic activity has been recently discussed by Zandieh and Liu [56]. They recommended calculating the number of catalytically active sites, e.g. surface iron atoms in non-porous iron oxide nanoparticles, to avoid over- or underestimation of catalytic activity. However, an accurate determination of the number of prussian blue nanoparticles or surface iron atoms is difficult, because synthesized nanoparticles despite having a relatively narrow size distribution are not monodisperse. Besides, according to TEM analysis, their shape is irregular. Interaction with substrates is one more factor that complicates the quantification of catalytically active metal sites in prussian blue nanozymes. Catalytic mechanism of 'artificial peroxidase' includes reduction of nanozyme to prussian white by TMB or another substrate, which is followed by oxidation of prussian white with $\mathrm{H}_{2} \mathrm{O}_{2}$ [57]. Substrate molecules are able to penetrate the nanoparticle body being able to evolve inner metal atoms into a catalytic process [9], however estimation of catalytically active metal sites is hardly possible as depends on the particle diameter. Therefore, we chose a more straightforward approach and measured catalytic activity normalized to the iron concentration (units per milligram of iron, $\mathrm{U} / \mathrm{mgFe}$ ).

Catalytic activity was expressed in terms of specific activity units, i.e. number of moles of a substrate that are converted to product by one milligram of catalyst in one minute. This measure was used because the determination of specific activity is conducted in the conditions of substrate excess which resembles the detection step in colorimetric analyses. Indeed, nanozymes with increased specific activity provided a lower limit of detection in colorimetric immunoassay [58]. The whole procedure of specific activity determination was adapted from Jiang et al. [26], however, buffer composition was preliminary optimized. The decreased ionic strength of the reaction buffer prevented nanoparticle aggregation. The concentration of hydrogen peroxide was also lowered to $100 \mathrm{mM}$ to achieve better reproducibility. The specific activity of horseradish peroxidase was determined in the same conditions. Undoubtedly, experimental conditions were suboptimal for horseradish peroxidase, because in conventional ELISA horseradish peroxidase reacts in the presence of 1-5 $\mathrm{mM}$ of $\mathrm{H}_{2} \mathrm{O}_{2}$. Higher $\mathrm{H}_{2} \mathrm{O}_{2}$ can decrease the specific activity of enzymes due to heme destruction. Optimal conditions for nanozymes (buffer composition, ionic strength, $\mathrm{pH}$ [59]) were also not optimized, because our primary goal was to compare nanozymes synthesized in different conditions rather than maximize their performance. The issue of comparison between enzymes and nanozymes is complex and outside the scope of this work, however, even in nonoptimal conditions horseradish peroxidase outperformed nanozymes (Figure 5E). 
Prussian blue nanoparticles obtained by the reductive approach ('artificial peroxidase') exhibited an equal or higher peroxidase-like activity in comparison with nanoparticles synthesized by the traditional method having similar size ( $\mathbf{R}$ vs T: $2.46 \pm 0.08 \mathrm{U} / \mathrm{mgFe}$ vs $2.06 \pm 0.019 \mathrm{U} / \mathrm{mgFe}, \mathrm{p}=0.079$, and $\mathbf{R 2 O}$ vs $\mathbf{T} / \mathbf{d w} / \mathbf{r t :}$ $3.13 \pm 0.07 \mathrm{U} / \mathrm{mgFe}$ vs $1.85 \pm 0.06 \mathrm{U} / \mathrm{mgFe}, \mathrm{p}<0.001$; Figure 5E, Tables $\mathrm{S} 2, \mathrm{~S} 3$ ). Moreover, the catalytic activity of $\mathbf{R 2 C}$ and $\mathbf{R 2 O}$ exceeds that of $\mathbf{T}$ and $\mathbf{T} / \mathbf{d w} / \mathbf{r t}$, which have much smaller hydrodynamic diameters (Tables S2,S3). RKH is equally active to $\mathbf{T}$ and $\mathbf{T} / \mathbf{d w} / \mathbf{r t}$, which are almost two-fold lower. As a rule, smaller nanoparticles have higher catalytic activity due to larger specific surface area [60] and this is true for nanoparticles synthesized by the traditional approach (Figure 5E). More complex relationships were observed for 'artificial peroxidase' nanozymes. The largest nanoparticles (R4.5C) have the lowest catalytic activity, however, the smallest ones $(\mathbf{R})$ are not the most active. Nanoparticles, synthesized in the presence of $2 \mathrm{mM}$ oxalic acid (R2O) show the best catalytic performance. In general, nanoparticles prepared with the addition of carboxylic acid have better activity in comparison with nanoparticles synthesized according to the original method (RKH). Probably, carboxylic acids somehow enhance the catalytic activity of prussian blue nanoparticles. Recently, Feng et al. prepared prussian blue nanoparticles in the presence of citric acid with various sizes and crystallinity by regulating the regime of reagents addition [34]. Authors demonstrated that more amorphous nanoparticles possessed better peroxidase- and catalase-like activity, which is also true for other nanomaterials [61]. However, these nanoparticles were the smallest ones and it was not clear whether their activity stems from a small size or structural defects. In our study, highly active nanoparticles prepared by carboxylic acids-assisted processes (R2C and R2O) were larger or similar to nanoparticles synthesized in the absence of acids. Therefore, we suggested that they have a more amorphous structure in comparison with other nanoparticles because in previous studies addition of citrate in the course of synthesis led to the appearance of internal and external defects in gold nanoparticles $[\mathbf{6 2}]$ and prussian blue analogs $[\mathbf{2 9}, \mathbf{6 3}]$. On the other hand, citric acid facilitated the preparation of prussian blue nanoparticles with perfect crystallinity [40]. Evidently, the morphology of prussian blue nanoparticles depends on both concentration of chelating agent and aging time $[\mathbf{3 4}, \mathbf{6 4}]$. Synthesis in the presence of hydrogen peroxide also decreased the crystallinity of prussian blue analogs [65]. Selected area electron diffraction (SAED) patterns obtained for synthesized nanoparticles exhibited amorphous structure of 'artificial peroxidase' nanozymes (Figure S12), however some nanoparticles synthesized by the traditional method were also amorphous (Figure S12). Therefore, SAED analysis did not reveal a significant difference in crystallinity of 'artificial peroxidase' nanozymes. Unfortunately, the amount of synthesized nanoparticles was not sufficient to measure their specific area by nitrogen adsorption analysis. Surface charge also affects the catalytic activity of nanozymes by regulating interactions with the substrate [66]. The zeta potential of all prussian blue nanoparticles was less than -30 $\mathrm{mV}$ (Figure 5B) facilitating adsorption of positively charged TMB. We did not observe any relationship between zeta potential and the specific activity of nanozymes. 
Taken together, our results indicate that 'artificial peroxidase' nanozymes have an amorphous structure, beneficial for their catalytic activity. The reasons underlying the difference in catalytic activity between 'artificial peroxidase' nanozymes synthesized in various conditions and nanoparticles prepared by the traditional approach are not clear and require more detailed study.

Storage stability. In terms of the preparation of diagnostic reagents, it is convenient to store nanoparticle preparations that are readily available for conjugation. From our point of view, concentrated aqueous suspensions of prussian blue nanoparticles are the most suitable form for long-term storage. Komkova et al. [9] suggested storage of 'artificial peroxidase' in a dry state or in $0.1 \mathrm{M} \mathrm{KCl}+0.1 \mathrm{M}$ $\mathrm{HCl}$ solution in order to prevent hydrolysis, however, the latter approach requires preliminary removal of acid and salt. This can be challenging because smaller nanoparticles (less than $100 \mathrm{~nm}$ ) require very high centrifugation speed, whereas other desalting methods like dialysis or gel filtration are time-consuming. Dry nanoparticles can be easily diluted in the medium of interest, however, drying can affect their size, therefore additional ultrasound treatment may be necessary. In this work, prussian blue nanoparticles were stored in deionized water for 5 months. It has been shown that the size of nanoparticles didn't change during three months for all types of synthesis (Figure 5G, Table S4). After three months of storage, aggregation was observed in some batches (see section). Aggregates were removed by nanoparticle ultrasound treatment and low-speed centrifugation. Nevertheless, these additional manipulations are time-consuming, therefore the storage period of nanozyme suspensions should not exceed 3 months. One should note that we did not examine the stability of dried or freeze-dried nanoparticles.

Conjugation of 'artificial peroxidase' nanoparticles with recognition molecules and their application in ELISA-like immunoassay

Intrinsic peroxidatic activity of prussian blue nanoparticles allows them to be utilized as labels in colorimetric immunoassay instead of commonly used enzymes like horseradish peroxidase. Conventional ELISA relies on affine binding of the target molecule by recognition molecules such as monoclonal antibodies, which in turn are conjugated with an enzyme that converts the colorless substrate into colored product. Enzymes are usually covalently attached to antibodies, however, in the case of prussian blue nanoparticles, direct covalent binding of antibodies is hardly possible. The two most popular solutions are simple adsorption of antibodies onto nanoparticle surface or coating the nanoparticles with polymers providing functional groups that are suitable for covalent attachment of antibodies. The first approach is much easier and has been previously used to obtain prussian blue-antibody conjugates [11]. The second approach, despite being more complex, may potentially prevent leakage of non-covalently adsorbed nanoparticles. Recently, Ciaurriz et al. demonstrated that direct adsorption of antibodies on nanoparticles can be more efficient even in comparison with oriented covalent attachment [67]. Therefore, we functionalized 'artificial peroxidase' nanoparticles with Streptococcal protein G, monoclonal antibodies against the prostate-specific antigen, and BSA by both 
covalent attachment and adsorption and compared the performance of obtained conjugates in the immunoassay.

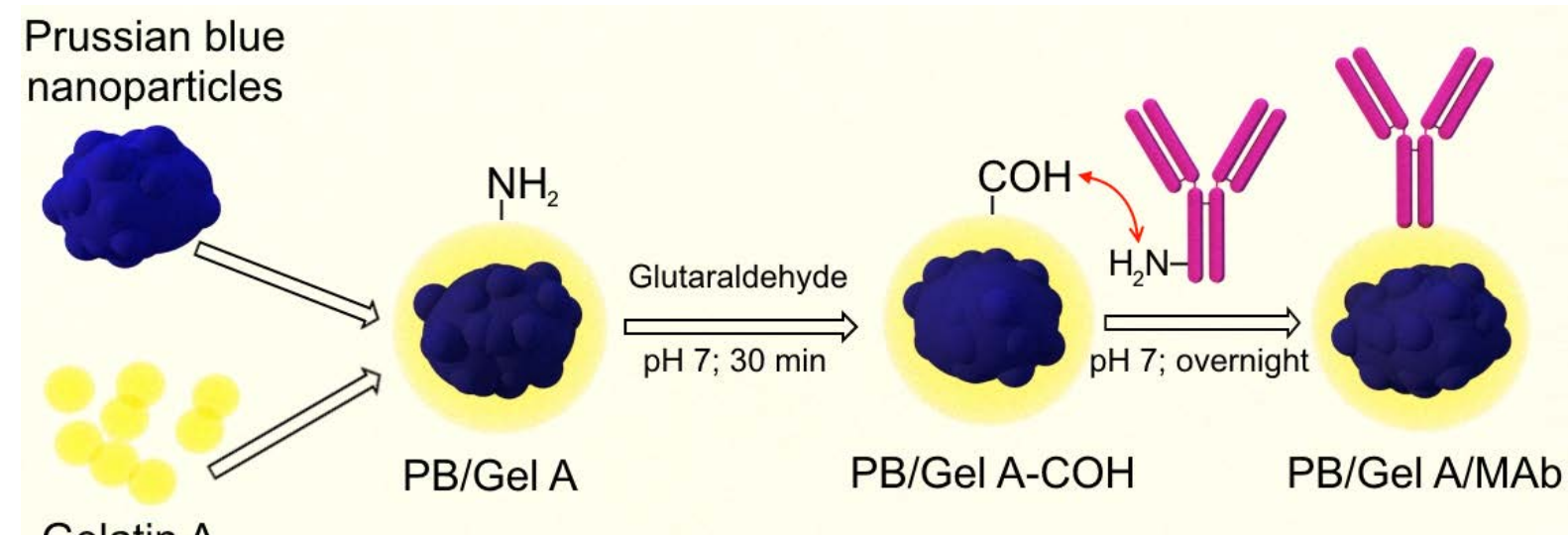

Gelatin A

Figure 6. Conjugation of gelatin-coated prussian blue nanoparticles with monoclonal antibodies. Gelatin amine groups were cross-linked with glutaraldehyde. Then, amine groups of antibodies were reacted with the surface carbonyl groups.

For covalent attachment 'artificial peroxidase' nanoparticles were coated with gelatin $\mathrm{A}$, then the gelatin layer was cross-linked with glutaraldehyde. Primary amines of protein $\mathrm{G}$ were reacted with free aldehyde groups (Figure 6). The gelatin coating was chosen for several reasons. First, gelatin provides good colloidal stability over a wide range of $\mathrm{pH}$ values including acidic ones [68], which is significant, because hydrolysis of prussian blue occurs at neutral and alkaline $\mathrm{pH}$ (see below in this section) [69]. Second, gelatin is a commonly available non-toxic polymer containing multiple functional groups.

Gelatin A has a pI of 7-9, being positively charged at neutral and acidic $\mathrm{pH}$ and, therefore, readily adsorbed to negatively charged nanoparticles. As can be seen from Figure S13, the adsorption capacity of gelatin reached about $1 \mathrm{mg}$ per $1 \mathrm{mg}$ of nanoparticles for nanoparticles $\mathbf{R}, \mathbf{R 2 C}$, and $\mathbf{R 2 O}$, but was much lower for the R4.5C (almost $0.1 \mathrm{mg}$ per $1 \mathrm{mg}$ ). Such a difference is explained by the lower specific surface area of $\mathbf{R 4 . 5 C}$, which has the largest size. The diameter of nanoparticles also increased after the coating with gelatin (Figure S13), probably because positively charged gelatin promoted aggregation of several oppositely charged nanoparticles into gelatin-coated nanoclusters. Nanoparticles R2C were used as catalytic labels, because of their high catalytic activity (Figure 5E) and high gelatin adsorption, which potentially provides better colloidal stability and more amine groups for covalent attachment. Besides, their large size (in comparison with other nanoparticles possessing high catalytic activity, such as $\mathbf{R}$ or R2O) facilitated washing by centrifugation. It is important because small nanoparticles can only be sedimented at a very high speed which can lead to the formation of very dense pellets of nanoparticles, which is impossible to re-disperse without the formation of aggregates. Technological challenges caused by using very small prussian blue nanoparticles have been described recently by Farka et al. [10]. Gelatin cross-linking 
and binding of affine molecules was carried out at $\mathrm{pH}$ 7. At this $\mathrm{pH}$ prussian blue nanoparticles are less susceptible to hydrolysis (see below). Besides, glutaraldehyde reacts with primary amines at neutral and alkaline $\mathrm{pH}$, while in acidic $\mathrm{pH}$ reaction is less efficient [70]. One should note that a sufficient amount (approximately 40\%) of prussian blue nanoparticles were lost due to hydrolysis after overnight incubation at pH 7 (measured by $\mathrm{A}_{700}$ difference).
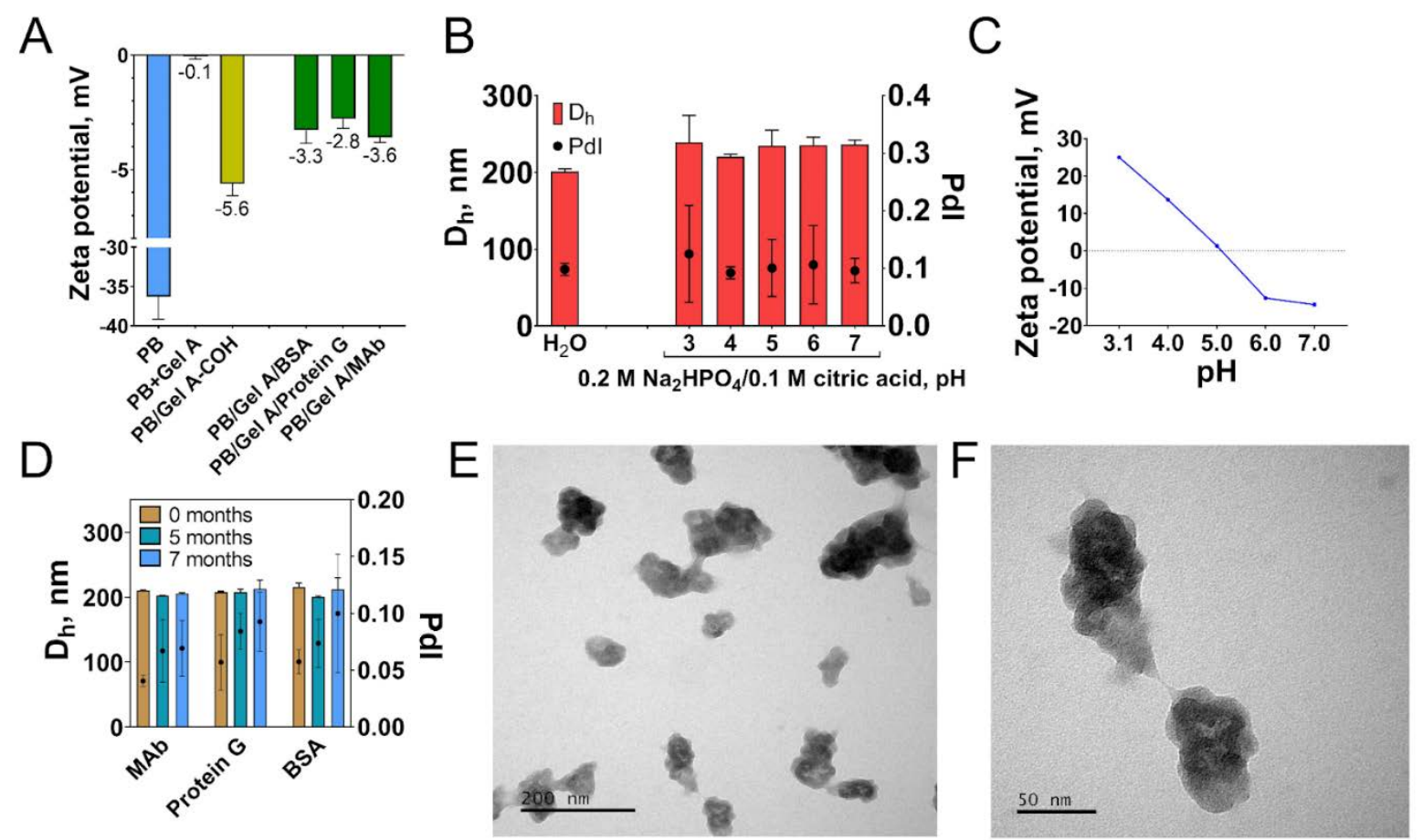

Figure 7. (A) - change of nanoparticle zeta potential in the course of conjugation. (B) - colloidal stability of $\mathrm{PB} / \mathrm{Gel} \mathrm{A} /$ Protein $\mathrm{G}$ in water and McIlvaine buffer with $\mathrm{pH}$ 3-8 (60 min incubation). (C) - Zeta potential of $\mathrm{PB} / \mathrm{Gel} \mathrm{A} /$ Protein $\mathrm{G}$ in $5 \mathrm{mM} \mathrm{Na}_{2} \mathrm{HPO}_{4} /$ citric acid buffer, $\mathrm{pH}$ 3.1-7. (D) - long-term colloidal stability of $\mathrm{PB} / \mathrm{Gel} \mathrm{A} / \mathrm{MAb}, \mathrm{PB} / \mathrm{Gel} \mathrm{A} /$ Protein $\mathrm{G}$, and $\mathrm{PB} / \mathrm{Gel} \mathrm{A} / \mathrm{BSA}$ in water. (E, F) - TEM images of PB/Gel A/MAb. Scale bars: e - $200 \mathrm{~nm}$, f - $50 \mathrm{~nm}$. $\mathrm{n}=3$, mean $\pm \mathrm{SD}$

Successful functionalization was confirmed by measuring colloidal stability, zeta potential, and functional activity of nanoparticles. Alteration of zeta potential reflects the change of nanoparticle surface structure (Figure 7A). Uncoated nanoparticles have a strong negative charge $(-36.3 \mathrm{mV})$, whereas after coating with gelatin zeta potential value becomes more positive: $-0.1 \mathrm{mV}$. Cross-linking results in the decrease of zeta potential $(-5.6 \mathrm{mV})$ which is explained by lowering the number of surface primary amines. Attachment of affine molecules and blocking with glycine changed zeta potential to more positive values. In contrast to noncoated prussian blue nanoparticles, gelatin-modified ones were stable in McIlvaine buffer with $\mathrm{pH}$ from 3 to 7 after $60 \mathrm{~min}$ of incubation (Figure 7B). The zeta potential of gelatin-coated nanoparticles was positive at a $\mathrm{pH}$ lower than 5 (Figure 7C). We measured zeta-potential in a medium with very low ionic strength $(5 \mathrm{mM}$ citratephosphate buffer), therefore in the McIlvaine buffer, it was closer to neutral values. Nevertheless, we did not observe aggregation of nanoparticles, which indicates that 
not only electrostatic repulsion provides stability of nanoparticles. The morphology of nanoparticles was studied by TEM (Figure 7E,F). Nanoparticles have irregular shapes; and their sizes were substantially different, which is not in line with DLS data which reported low polydispersity of nanoparticles. The possible reason is an underestimation of smaller nanoparticles by DLS which is a well-known feature of this method [71].

In the neutral and alkaline conditions hydrolysis of prussian blue occurs [69, $\mathbf{7 2}, \mathbf{7 3}, \mathbf{7 4}, \mathbf{7 5}$. The mechanism of hydrolysis is the attack of $\mathrm{Fe}^{\mathrm{II}}-\mathrm{CN}-\mathrm{Fe}^{\mathrm{III}}$ bonds by hydroxyl ions [73]. This limitation forces researchers to develop various methods of improving the storage stability of prussian blue nanoparticles, such as storage in highly acidic conditions [9] or protection by nickel hexacyanoferrate [76, 77]. Despite that, some authors report successful functionalization [12] or storage [31, 78] of prussian blue nanoparticles in neutral and even alkaline mediums. Keeping in mind these discrepancies, we assessed the long-term stability of $\mathrm{PB} / \mathrm{Gel} \mathrm{A} / \mathrm{MAb}$ at acidic and alkaline $\mathrm{pH}$. In this experiment, nanoparticles were kept in buffer solutions having $\mathrm{pH}$ 2-8 and relatively high ionic strength. Two types of buffers were used: 1) McIlvaine buffer which allows covering all desired range of $\mathrm{pH}$ values; 2) Range of buffers (glycine, acetate, MES, TRIS), which do not contain citric acid or phosphate ions to preclude the specific influence of these buffer components. Strikingly, even after 24 hours a decrease of $A_{700}$ was observed in all samples (Figures S14 and S15). The decline was more prominent at $\mathrm{pH}$ 6-8. In some samples, this can be explained by nanoparticle aggregation (Figures S16), but in most of them, the size of nanoparticles changed insignificantly. Moreover, decoloration was almost complete in McIlvaine buffer, in TRIS-HCl buffer absorbance halved (Figures S14). Interestingly, in water nanoparticles aggregated, which completely contradicted results of the shelf-life study: all gelatin-coated nanoparticles stored in water at a concentration of approximately $1 \mathrm{mg} / \mathrm{mL}$ kept their initial size (Figure 7D), whereas the decline of $\mathrm{A}_{700}$ did not exceed 15\% (Figure S17). Probably, the stability of gelatin-coated nanoparticles depends on their concentration. We have already observed a similar phenomenon for nanoparticles prepared from gelatin $\mathrm{A}$ in our previous work [79].

In total, it's obvious that prussian blue nanoparticles are sensitive to the $\mathrm{pH}$ and composition of the buffer. In our study, nanoparticles were stable when stored in water without any stabilizers. Undoubtedly, polymer coating and surface structure significantly affect the colloidal and structural stability of prussian blue nanoparticles $[\mathbf{8 0}]$. Probably, some polymers can effectively protect prussian blue nanoparticles in alkaline medium, e.g. polyvinylpyrrolidone-coated nanoparticles were reported to withstand alkaline and neutral $\mathrm{pH}[\mathbf{3 1}$. Nevertheless, the issue of stability of prussian blue nanoparticles at physiological $\mathrm{pH}$ (circa 7.4) and optimization of their long-term storage conditions are essential for their practical application and require more detailed study.

Apart from covalent conjugation, 'artificial peroxidase' nanoparticles were non-covalently functionalized with protein $\mathrm{G}$ and BSA (negative control). For this, nanoparticles were incubated with affine molecules, followed by blocking of unoccupied sites with an excessive amount of gelatin A. Antibody-to-nanoparticle 
ratio, buffer composition, and washing procedures were similar to that of covalent functionalization. During functionalization nanoparticles aggregated (Figure S18), besides they generated high non-specific signal in an immunoassay (Figure S19), being therefore practically inapplicable. We suggest that optimization of conjugation procedure could provide better performance of nanoconjugates, but it was outside the scope of our study.

\section{Colorimetric immunoassay with obtained conjugates}

The practical applicability of $\mathrm{PB} / \mathrm{Gel} \mathrm{A} / \mathrm{MAb}$ and $\mathrm{PB} / \mathrm{Gel} \mathrm{A} /$ Protein $\mathrm{G}$ as diagnostic reagents for colorimetric immunoassay was proven by quantitative detection of two model analytes: prostate-specific antigen (PSA) and anti-tetanus IgG. Detection of PSA was realized by sandwich assay: capture monoclonal antibodies were adsorbed on 96-well plates, then after the incubation with PSA, $\mathrm{PB} / \mathrm{Gel} \mathrm{A} / \mathrm{MAb}$ was added (Figure 8D). An indirect assay format was utilized to detect anti-tetanus antibodies. Wells were coated with tetanus toxoid (inactivated toxin, which is a component of tetanus vaccines), then anti-tetanus IgG was added (WHO standard of anti-tetanus antibodies), followed by the addition of $\mathrm{PB} / \mathrm{Gel}$ $\mathrm{A} /$ Protein $\mathrm{G}$ (Figure $8 \mathrm{E}$ ). In control experiments, $\mathrm{PB} / \mathrm{Gel} \mathrm{A} / \mathrm{BSA}$ was used to reveal possible non-specific interactions between nanoconjugates and immunosorbents.

Conjugates of 'artificial peroxidase' nanoparticles detected analytes with sensitivity sufficient for practical application (Figure 8D,E). Limit of detection (LOD) was determined as the concentration of analyte which corresponds to the mean absorbance value of zero calibrators plus three standard deviations. For PSA assay LOD was $0.068 \mathrm{ng} / \mathrm{mL}$, for tetanus toxoid $-0.035 \mathrm{mIU} / \mathrm{mL}$. As can be seen from Figure 8D, the LOD value of $0.068 \mathrm{ng} / \mathrm{mL}$ for PSA is probably overestimated because of fitting issues at a low concentration range. We suppose that the true LOD value is slightly below the calibrator with the lowest PSA concentration, i.e. between $0.200-0.244 \mathrm{ng} / \mathrm{ml}$. In experiments where nanoparticles conjugated with monoclonal antibodies and protein $\mathrm{G}$ were replaced with control nanoparticles (conjugated with BSA), only a slight increase of absorbance at the highest analyte levels was observed (see Figure 8B-2,C-2 and red curves in Figure 8D,E). This result demonstrates that the ability of nanoconjugates to interact with analytes is due to the presence of affine molecules on their surface and not due to nonspecific interactions. Anyway, even though we did not perform complete systematic optimization of immunoassay procedures, both of them allow detection of analytes at concentrations, which are relevant for clinical application. For PSA it is concentration range from 0.1-0.2 to more than $20 \mathrm{ng} / \mathrm{mL}$ [81], for tetanus IgG tests should be able to detect antibodies from the lowest protective titers $(10-100 \mathrm{mIU} / \mathrm{mL})$ to the highest titers in immunized individuals (several $\mathrm{U} / \mathrm{mL}$ ) [82]. One can see that sensitivity of developed immunoassay is enough to detect PSA in undiluted blood serum/plasma, whereas detection of anti-tetanus IgG is possible even in highly diluted specimens. Undoubtedly, the real clinical value of the 'artificial peroxidase'-based assays can be assessed only after their strict optimization and validation. Besides, despite sufficient sensitivity, presented assays do not outperform commercial ELISAs, which allow detection of the same analytes at lower concentrations (for example, 
https://www.abcam.com/human-psa-elisa-kit-ab264615.html. Accessed 10 Feb 2022).
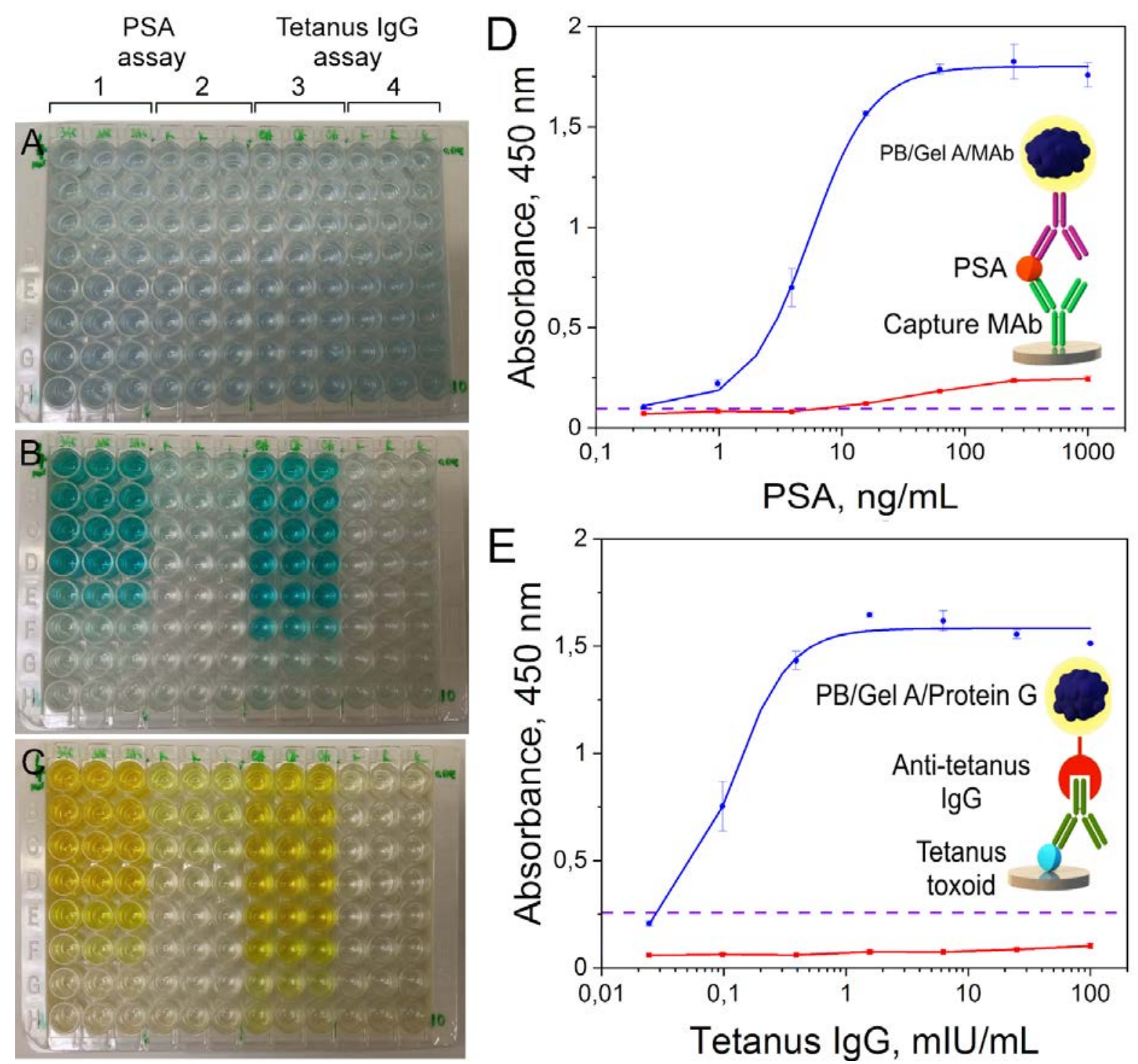

Figure 8. Colorimetric assay of PSA and anti-tetanus IgG. (A-C) polystyrene plate at different stages of the assay; (D, E) corresponding dose-response curves. (A) plate filled with conjugates of prussian blue nanoparticles, (B) plate after $30 \mathrm{~min}$ of reaction with substrate, $(\mathrm{C})$ plate after the addition of $2 \mathrm{M} \mathrm{H}_{2} \mathrm{SO}_{4}$. Concentration of PSA and anti-tetanus IgG decreased from top to bottom row. 1 - wells filled with $\mathrm{PB} / \mathrm{Gel} \mathrm{A} / \mathrm{MAb}, 3$ - wells filled with PB/Gel A/Protein G, 2 and 4 - wells filled with $\mathrm{PB} / \mathrm{Gel} \mathrm{A} / \mathrm{BSA}$ (negative control). Blue lines - sigmoidal fit of PSA and anti-tetanus IgG calibration curves. Red lines - dose-response curves obtained using $\mathrm{PB} / \mathrm{Gel}$ A/BSA. Purple dashed line at absorbance value equal to mean absorbance of the zero calibrator $+3 *$ standard deviation. $n=3$, mean \pm SD

\section{Conclusion}

Nanozymes 'artificial peroxidase' is a promising alternative to natural enzymes, due to high catalytic activity, facile synthesis procedure from cheap reagents, and satisfactory storage stability. In this work, we developed a robust and reproducible method for the preparation of 'artificial peroxidase' nanozymes with 
tunable size. The method relies on the addition of citric and oxalic acids which change the size of nanoparticles by decreasing the reaction rate. Besides, we demonstrated that tuning of various synthesis parameters such as temperature, $\mathrm{pH}$, and salt concentration can also be used to manipulate properties of 'artificial peroxidase' nanozymes. In total, our results confirm that prussian blue nanoparticles prepared by the reductive approach have higher peroxidatic activity compared to those prepared by the traditional method. Moreover, synthesis in the presence of carboxylic acids enables the preparation of 'artificial peroxidase' with enhanced peroxidatic activity in comparison with nanozymes synthesized by the original method [9].

Although we synthesized nanozymes in tens- to hundreds-of-milligram-scale, further optimization and scale-up are necessary. Nowadays, significant attention is paid to the large-scale preparation of nanoparticles with the aid of micro-and nanofluidics [49]. Indeed, flow synthesis of 'artificial peroxidase' has been recently developed [83]. Panariello and colleagues demonstrated that in some circumstances conditions of nanoparticle synthesis may be directly translated from batch to flow reactors [51], therefore we believe that our data on the synthesis process can be employed during the preparation of prussian blue nanozymes in flow systems.

Coating of prussian blue nanoparticles with a gelatin shell endows them with excellent colloidal and shelf-life stability. Our results demonstrate that optimization of prussian blue nanoparticle coating is important not only in terms of their colloidal stability, non-specific interactions in immunoassay, and attachment of affine molecules but also in terms of their stability to hydrolysis in neutral and alkaline conditions. We suggest that assessment of hydrolysis intensity needs to be performed for all prussian blue nanoparticles encountering physiological media (buffers, blood serum or plasma, cultural fluids, and so on) or alkaline solutions.

Diagnostic reagents for colorimetric immunoassay were prepared from gelatin-coated 'artificial peroxidase' nanozymes. They allowed successful detection of model analytes demonstrating suitability for real-world applications. Nevertheless, high efficiency in immunoassay and storage stability alone are not enough to consider 'artificial peroxidase' nanozymes as competitors of enzymes in the field of colorimetric assays [6]. Nanozymes should propose significant advantages compared to enzymes, because commercial enzyme-based assays possess excellent analytical characteristics, and are technologically mature and well optimized. Issues of high-throughput synthesis and hydrolysis stability of 'artificial peroxidase' nanozymes despite being partially addressed $[77,83]$, however still to be completely resolved. Further improvement of catalytic activity via defect engineering $[\mathbf{8 4}]$ or active sites microenvironment $[\mathbf{8 5}]$ is also necessary.

\section{AUTHOR INFORMATION \\ Corresponding Author}

Pavel Khramtsov - Faculty of Biology, Perm State University, 614068 Perm, Russia; Lab of Ecological Immunology, Institute of Ecology and Genetics of 
Microorganisms, 614081 Perm, Russia; orcid.org/0000-0002-1707-4423; Phone: +7 342 2807794; Email: khramtsovpavel@yandex.ru

\section{Authors}

Maria Kropaneva - Faculty of Biology, Perm State University, 614068 Perm, Russia; Lab of Ecological Immunology, Institute of Ecology and Genetics of Microorganisms, 614081 Perm, Russia; Phone: +7 342 2807794; Email: kropanevamasha@gmail.com

Artem Minin - Lab of Applied Magnetism, M.N. Mikheev Institute of Metal Physics of the UB RAS, 620108 Yekaterinburg, Russia; Faculty of Biology and Fundamental Medicine, Ural Federal University Named after The First President of Russia B.N. Yeltsin, 620002 Yekaterinburg, Russia; orcid.org/0000-0003-33053195; Phone: +7 343 3783748; Email: calamatica@gmail.com

Maria Bochkova - Faculty of Biology, Perm State University, 614068 Perm, Russia; Lab of Ecological Immunology, Institute of Ecology and Genetics of Microorganisms, 614081 Perm, Russia; Phone: +7 342 2807794; Email: krasnykhm@mail.ru

Valeria Timganova - Lab of Ecological Immunology, Institute of Ecology and Genetics of Microorganisms, 614081 Perm, Russia; orcid.org/0000-0003-45811969; Phone: +7 342 2807794; Email: timganovavp@gmail.com

Andrey Maximov - Department of Analytical Chemistry and Expertise, Faculty of Chemistry, Perm State University, 614068 Perm, Russia; Lab of Ecological Immunology, Institute of Ecology and Genetics of Microorganisms, 614081 Perm, Russia; Phone: +7 342 2396760; Email: htb03starosta@gmail.com

Alexey Puzik - Faculty of Geology, Department of Mineralogy and Petrography, Perm State University, 614068 Perm, Russia; Core Facilities and Lab of Hydrochemical Analysis, Perm State University, 614068 Perm, Russia; Lab of Technological Mineralogy, Institute of Natural Science, Perm State University, 614068 Perm, Russia; Lab of Biogeochemistry of Technogenic Landscapes; Phone: +7 342 2396332; Email: Alex.Puzik@mail.ru

Svetlana Zamorina - Faculty of Biology, Perm State University, 614068 Perm, Russia; Lab of Ecological Immunology, Institute of Ecology and Genetics of Microorganisms, 614081 Perm, Russia; orcid.org/0000-0002-6474-1487; Phone: +7 342 2807794; Email: mantissa7@mail.ru

Mikhail Rayev - Faculty of Biology, Perm State University, 614068 Perm, Russia; Lab of Ecological Immunology, Institute of Ecology and Genetics of Microorganisms, 614081 Perm, Russia; Phone: +7 342 2807794; Email: mraev@iegm.ru

\section{Funding}

This study was supported by the Russian Science Foundation, grant 20-7500029

\section{Notes}

The authors declare no competing financial interest. 


\section{Acknowledgements}

Determination of potassium and iron was carried out using atomic emission spectrometers Thermo iCAP 6500 Duo and Bruker Aurora M90 ICP-MS, which are

the part of the Center for Collective Use of Perm State University (Head of the Center for Collective Use - Dr. Boris M. Osovetskiy)

\section{References}

1. Huang, Y.; Ren, J.; Qu, X. Nanozymes: Classification, Catalytic Mechanisms, Activity Regulation, and Applications. Chem. Rev. 2019, 119, 4357-4412. DOI: $10.1021 /$ acs.chemrev.8b00672

2. Goya, G. F.; Mayoral, A.; Winkler, E.; Zysler, R. D.; Bagnato, C.; Raineri, M.; Fuentes-García, J. A.; Lima Jr.; E. Next generation of nanozymes: A perspective of the challenges to match biological performance. J. Appl. Phys. 2021, 130, 190903. doi: 10.1063/5.0061499

3. Liu, L.; Hao, Y.; Deng, D.; Xia, N. Nanomaterials-based colorimetric immunoassays. Nanomaterials 2019, 9, 316. DOI: 10.3390/nano9030316

4. Mohamad, A.; Teo, H.; Keasberry, N. A.; Ahmed, M. U. Recent developments in colorimetric immunoassays using nanozymes and plasmonic nanoparticles. Crit. Rev. Biotechnol. 2018, 39, 50-66. doi: 10.1080/07388551.2018.1496063

5. Wu, L.; Zhou, S.; Wang, G.; Yun, Y.; Liu, G.; Zhang, W. Nanozyme Applications: A Glimpse of Insight in Food Safety. Front. Bioeng. Biotechnol. 2021, 9, 727886. doi: 10.3389/fbioe.2021.727886

6. Das, B.; Franco, J. L.; Logan, N.; Balasubramanian, P.; Kim, M. I.; \& Cao, C. Nanozymes in Point-of-Care Diagnosis: An Emerging Futuristic Approach for Biosensing. Nano-Micro Lett. 2021, 13, 193. doi: 10.1007/s40820-02100717-0

7. Gooding, J. J. Can Nanozymes Have an Impact on Sensing? ACS Sens. 2019, 4, 2213-2214. doi:10.1021/acssensors.9b01760

8. Gao, Y.; Zhou, Y.; Chandrawati, R. Metal and Metal Oxide Nanoparticles to Enhance the Performance of Enzyme-Linked Immunosorbent Assay (ELISA). ACS Appl. Nano Mater. 2020, 3, 1-21. DOI: 10.1021/acsanm.9b02003

9. Komkova, M. A.; Karyakina, E. E.; Karyakin, A. A. Catalytically synthesized Prussian Blue nanoparticles defeating natural enzyme peroxidase. $J$. Am. Chem. Soc. 2018, 140, 11302-11307. doi:10.1021/jacs.8b05223

10. Farka, Z.; Čunderlová, V.; Horáčková, V.; Pastucha, M.; Mikušová, Z.; Hlaváček, A.; Skládal, P. Prussian Blue Nanoparticles as a Catalytic Label in a Sandwich Nanozyme-Linked Immunosorbent Assay. Anal. Chem. 2018, 90, 2348-2354. DOI: 10.1021/acs.analchem.7b04883

11. Tian, M.; Xie, W.; Zhang, T.; Liu, Y.; Lu, Z.; Li, C. M.; Liu, Y. A sensitive lateral flow immunochromatographic strip with prussian blue nanoparticles mediated signal generation and cascade amplification. Sens. Actuators, B 2020, 309, 127728. doi: 10.1016/j.snb.2020.127728 
12. Liu, Z.; Hua, Q.; Wang, J.; Liang, Z.; Zhou, Z.; Shen, X.; Lei, H.; Li, X. Prussian blue immunochromatography with portable smartphone-based detection device for zearalenone in cereals. Food Chem. 2022, 369, 131008. DOI: 10.1016/j.foodchem.2021.131008

13. Zhou, Q.; Yang, H.; Chen, X.; Xu, Y.; Han, D.; Zhou, S.; Liu, S.; Shen, Y. Zhang, Y. Cascaded Nanozyme System with High Reaction Selectivity by Substrate Screening and Channeling in a Microfluidic Device. Angew. Chem. Int. Ed. 2021, 61, e202112453. doi: 10.1002/anie.202112453

14. Komkova, M.A.; Eliseev, A.A.; Poyarkov, A.A.; Daboss, E.V.; Evdokimov, P.V.; Eliseev, A.A.; Karyakin, A.A. Simultaneous monitoring of sweat lactate content and sweat secretion rate by wearable remote biosensors. Biosens. Bioelectron. 2022, 202, 113970. DOI: 10.1016/j.bios.2022.113970

15. Shavokshina, V. A.; Komkova, M. A.; Aparin, I. O.; Zatsepin, T. S.; Karyakin, A. A.; Andreev, E. A. Improved Electroactivity of Redox Probes onto Electropolymerized Azidomethyl-PEDOT: Enabling Click Chemistry for Advanced (Bio)Sensors. ACS Appl. Polym. Mater. 2021, 3, 1518-1524. doi:10.1021/acsapm.0c01371

16. Zakaria, M. B.; Chikyow, T. Recent advances in Prussian blue and Prussian blue analogues: synthesis and thermal treatments. Coord. Chem. Rev. 2017, 352, 328-345. doi: 10.1016/j.ccr.2017.09.014

17. Qin, Z.; Li, Y.; Gu, N. Progress in Applications of Prussian Blue Nanoparticles in Biomedicine. Adv. Healthcare Mater. 2018, 7, 1800347. doi: 10.1002/adhm.201800347

18. Shokouhimehr, M.; Soehnlen, E. S.; Khitrin, A.; Basu, S.; Huang, S. D. Biocompatible Prussian blue nanoparticles: Preparation, stability, cytotoxicity, and potential use as an MRI contrast agent. Inorg. Chem. Commun. 2010, 13, 58-61. doi: 10.1016/j.inoche.2009.10.015

19. Zheng, X.-J.; Kuang, Q.; Xu, T.; Jiang, Z.-Y.; Zhang, S.-H.; Xie, Z.-X.; huang, R.-B. Zheng, L.-S. Growth of Prussian Blue Microcubes under a Hydrothermal Condition: Possible Nonclassical Crystallization by a Mesoscale Self-Assembly. J. Phys. Chem. C 2007, 111, 4499-4502. doi: 10.1021/jp065055n

20. Liu, S.-Q.; Xu, J.-J.; Chen, H.-Y. Electrochemical behavior of nanosized Prussian blue self-assembled on Au electrode surface. Electrochem. Commun. 2002, 4, 421-425. doi: 10.1016/s1388-2481(02)00336-3

21. Fiorito, P. A.; Gonçales, V. R.; Ponzio, E. A.; de Torresi, S. I. C. Synthesis, characterization and immobilization of Prussian blue nanoparticles. A potential tool for biosensing devices. Chem. Commun. 2005, 3, 366-368. doi: $10.1039 / \mathrm{b} 412583 \mathrm{e}$

22. Shiba, F.; Nito, M.; Kawakita, K.; Okawa, Y. Size Control of Monodisperse Prussian Blue Nanoparticles by Enforced-Nucleation and Additional-Growth Procedures in a Citrate Reduction System. Part. Sci. Technol. 2015, 33, 671676. doi: 10.1080/02726351.2015.1020181 
23. Shiba, F.; Mameuda, U.; Tatejima, S.; Okawa, Y. Synthesis of uniform Prussian blue nanoparticles by a polyol process using a polyethylene glycol aqueous solution. $R S C A d v$. 2019, 9, 34589-34594. doi: 10.1039/c9ra07080j

24. Hornok, V.; Dékány, I. Synthesis and stabilization of Prussian blue nanoparticles and application for sensors. J. Colloid Interface Sci. 2007, 309, 176-182. doi: 10.1016/j.jcis.2007.02.022

25. Uemura, T.; Kitagawa, S. Prussian Blue Nanoparticles Protected by Poly(vinylpyrrolidone). J. Am. Chem. Soc. 2003, 125, 7814-7815. doi: $10.1021 / \mathrm{ja} 0356582$

26. Jiang, B.; Duan, D.; Gao, L.; Zhou, M.; Fan, K.; Tang, Y.; Xi, J.; Bi, Y.; Tong, Z.; Gao, G. F.; Xie, N.; Tang, A.; Nie, G.; Liang, M.; Yan, X. Standardized assays for determining the catalytic activity and kinetics of peroxidase-like nanozymes. Nat. Protoc. 2018, 13, 1506-1520. doi: 10.1038/s41596-0180001-1

27. Danaei, M.; Dehghankhold, M.; Ataei, S.; Hasanzadeh Davarani, F.; Javanmard, R.; Dokhani, A.; Khorasani, S.; Mozafari, M.R. Impact of Particle Size and Polydispersity Index on the Clinical Applications of Lipidic Nanocarrier Systems. Pharmaceutics 2018, 10, 57. doi: 10.3390/pharmaceutics10020057

28. Wu, X.; Cao, M.; Hu, C.; He, X. Sonochemical Synthesis of Prussian Blue Nanocubes from a Single-Source Precursor. Cryst. Growth Des. 2006, 6, 2628. doi: 10.1021/cg050371x

29. Zhou, A.; Xu, Z.; Gao, H.; Xue, L.; Li, J.; Goodenough, J. B. Size-, Water-, and Defect-Regulated Potassium Manganese Hexacyanoferrate with Superior Cycling Stability and Rate Capability for Low-Cost Sodium-Ion Batteries. Small 2019, 15, 1902420. doi: 10.1002/smll.201902420

30. Ming, H.; Torad, N. L. K.; Chiang, Y.-D.; Wu, K. C.-W.; Yamauchi, Y. Sizeand shape-controlled synthesis of Prussian Blue nanoparticles by a polyvinylpyrrolidone-assisted crystallization process. CrystEngComm 2012, 14, 3387-3396. doi: 10.1039/c2ce25040c

31. Xu, Y.; Zhang, Y.; Cai, X.; Gao, W.; Tang, X.; Chen, Y.; Chen, J.; Chen, L.; Tian, Q.; Yang, S.; Zheng, Y.; Hu, B. Large-scale synthesis of monodisperse Prussian blue nanoparticles for cancer theranostics via an "in situ modification" strategy. Int. J. Nanomed. 2018, 14, 271-288. doi: 10.2147/IJN.S183858

32. Shokouhimehr, M.; Soehnlen, E.S.; Hao, J.; Griswold, M.; Flask, C.; Fan, X.; Basilion, J.P.; Basu, S.; Huang, S.D. Dual purpose Prussian blue nanoparticles for cellular imaging and drug delivery: A new generation of T1-weighted MRI contrast and small molecule delivery agents. J. Mater. Chem. 2010, 20, 52515259. DOI: 10.1039/b923184f

33. Chiang, Y.-D.; Hu, M.; Kamachi, Y.; Ishihara, S.; Takai, K.; Tsujimoto, Y.; Ariga K.; Wu, K. C.W.; Yamauchi, Y. Rational Design and Synthesis of Cyano-Bridged Coordination Polymers with Precise Control of Particle Size from 20 to $500 \mathrm{~nm}$. Eur. J. Inorg. Chem. 2013, 18, 3141-3145. doi: 10.1002/ejic.201300112 
34. Feng, K.; Zhang, J.; Dong, H.; Li, Z.; Gu, N.; Ma, M.; Zhang, Y. Prussian Blue Nanoparticles Having Various Sizes and Crystallinities for Multienzyme Catalysis and Magnetic Resonance Imaging. ACS Appl. Nano Mater. 2021, 4, 5176-5186. doi: 10.1021/acsanm.1c00617

35. Wang, H.; Zhu, Q.; Li, H.; Xie, C.; Zeng, D. Tuning Particle Size of Prussian Blue by a Dual Anion Source Method. Cryst. Growth Des. 2018, 18, 57805789. doi: 10.1021/acs.cgd.8b00239

36. Vo, V.; Van, M. N.; Lee, H. I.; Kim, J. M.; Kim, Y.; \& Kim, S. J. A new route for obtaining Prussian blue nanoparticles. Mater. Chem. Phys. 2008, 107, 68. doi:10.1016/j.matchemphys.2007.07

37. Qin, Z.; Chen, B.; Mao, Y.; Shi, C.; Li, Y.; Huang, X.; Yang, F.; Gu, N. Achieving Ultrasmall Prussian Blue Nanoparticles as High-Performance Biomedical Agents with Multifunctions. ACS Appl. Mater. Interf. 2020, 51, 57382-57390. doi: 10.1021/acsami.0c18357

38. Goh, E. G.; Xu, X.; McCormick, P. G. Effect of particle size on the UV absorbance of zinc oxide nanoparticles. Scr. Mater. 2014, 78-79, 49-52. doi: 10.1016/j.scriptamat.2014.01.

39. Liu, H.; Zhang, H.; Wang, J.; Wei, J. Effect of temperature on the size of biosynthesized silver nanoparticle: Deep insight into microscopic kinetics analysis. Arabian J. Chem. 2020, 13, 1011-1019. doi: 10.1016/j.arabjc.2017.09.004

40. Qin, M.; Ren, W.; Jiang, R.; Li, Q.; Yao, X.; Wang, S.; You, Y.; Mai, L. Highly Crystallized Prussian Blue with Enhanced Kinetics for Highly Efficient Sodium Storage. ACS Appl. Mater. Interf. 2021, 13, 3999-4007. doi: 10.1021/acsami.0c20067

41. Shokouhimehr, M. Prussian Blue Nanoparticles and its Analogues as NewGeneration T1-Weighted MRI Contrast Agents for Cellular Imaging. Master's thesis, Kent State University, Kent, OH, 2010. http://rave.ohiolink.edu/etdc/view?acc num $=$ kent1275612500 $\quad$ (accessed 2022-02-09)

42. Kim, T.; Lemaster, J.E.; Chen, F.; Li, J.; Jokerst, J.V. Photoacoustic Imaging of Human Mesenchymal Stem Cells Labeled with Prussian Blue-Poly(1 lysine) Nanocomplexes. ACS Nano 2017, 11, 9022-9032. DOI: 10.1021/acsnano.7b03519

43. Jia, Z. Synthesis of Prussian Blue nanocrystals with metal complexes as precursors: Quantitative calculations of species distribution and its effects on particles size. Colloids Surf., A 2011, 389, 144-148. doi:10.1016/j.colsurfa.2011.08.03

44. Martell A.E.; Smith R.M. Carboxylic Acids. In: Other Organic Ligands. Critical Stability Constants, vol 3.; Springer, Boston, MA, 1977; pp 1-171. doi: 10.1007/978-1-4757-1568-2 1

45. Cornell, R.M.; Schwertmann, U. Dissolution. In The Iron Oxides (eds R.M. Cornell and U. Schwertmann), $2^{\text {nd }}$ ed., WILEY-VCH, Weinheim, 2003, pp. 297-344. doi: 10.1002/3527602097.ch12 
46. Ruiz-Agudo, E.; Kowacz, M.; Putnis, C.V.; Putnis, A. The role of background electrolytes on the kinetics and mechanism of calcite dissolution. Geochim. Cosmochim. Acta 2010, 74, 1256-1267. DOI: 10.1016/j.gca.2009.11.004

47. Ruiz-Agudo, E.; Putnis, C.V.; Wang, L.; Putnis, A. Specific effects of background electrolytes on the kinetics of step propagation during calcite growth. Geochim. Cosmochim. Acta 2011, 75, 3803-3814. DOI: 10.1016/j.gca.2011.04.012

48. Colby, A.H.; Liu, R.; Doyle, R.P.; Merting, A.; Zhang, H.; Savage, N.; Chu, N.-Q.; Hollister, B.A.; McCulloch, W.; Burdette, J.E.; Pearce, C.J.; Liu, K.; Oberlies, N.H.; Colson, Y.L.; Grinstaff, M.W. Pilot-scale production of expansile nanoparticles: Practical methods for clinical scale-up. J. Controlled Release 2021, 337, 144-154. DOI: 10.1016/j.jconrel.2021.07.012

49. Liu, X.; Meng, H. Consideration for the scale-up manufacture of nanotherapeutics-A critical step for technology transfer. VIEW 2021, 2, 20200190. doi: 10.1002/viw.20200190

50. Langevin, D.; Raspaud, E.; Mariot, S.; Knyazev, A.; Stocco, A.; Salon en, A.; Luch, A.; Haase, A.; Trouiller, B.; Relier, C.; Lozano, O.; Thomas, S.; Salvati, A.; Dawson, K. Towards reproducible measurement of nanoparticle size using dynamic light scattering: Important controls and considerations. NanoImpact 2018, 10, 161-167. DOI: 10.1016/j.impact.2018.04.002

51. Panariello, L.; Damilos, S.; du Toit, H.; Wu, G.; Radhakrishnan, A. N. P.; Parkin, I. P.; Gavriilidis, A. Highly reproducible, high-yield flow synthesis of gold nanoparticles based on a rational reactor design exploiting the reduction of passivated $\mathrm{Au}(\mathrm{III})$. React. Chem. Eng. 2020, 5, 663-676 doi:10.1039/c9re00469f

52. Hauser, A.K.; Mathias, R.; Anderson, K.W.; Zach Hilt, J. The effects of synthesis method on the physical and chemical properties of dextran coated iron oxide nanoparticles. Mater. Chem. Phys. 2015, 160, 177-186. DOI: 10.1016/j.matchemphys.2015.04.022

53. Haque, S.; Boyd, B.J.; McIntosh, M.P.; Pouton, C.W.; Kaminskas, L.M.; Whittaker, M. Suggested procedures for the reproducible synthesis of poly(D,l-lactide-co-glycolide) nanoparticles using the emulsification solvent diffusion platform. Curr. Nanosci. 2018, 14, 448-453. DOI: $10.2174 / 1573413714666180313130235$

54. Kraft, A. Some considerations on the structure, composition, and properties of Prussian blue: a contribution to the current discussion. Ionics 2021, 27, 2289-2305. doi: 10.1007/s11581-021-04013-0

55. Doumic, L. I.; Salierno, G.; Ramos, C.; Haure, P. M.; Cassanello, M. C.; Ayude, M. A. "Soluble" vs. "insoluble" Prussian blue based catalysts: influence on Fenton-type treatment. $R S C A d v$. 2016, 6, 46625-46633. doi: 10.1039/c6ra06618f

56. Zandieh M.; Liu J. Nanozyme Catalytic Turnover and Self-Limited Reactions. ACS Nano, 2021, 15, 15645. DOI: 10.1021/acsnano.1c07520 
57. Komkova, M. A.; Ibragimova, O. A.; Karyakina, E. E.; Karyakin, A. A. Catalytic Pathway of Nanozyme "Artificial Peroxidase" with 100- Fold Greater Bimolecular Rate Constants Compared to Those of the Enzyme. $J$. Phys. Chem. Lett. 2021, 12, 171-176.

58. Panferov, V.G.; Safenkova, I.V.; Zherdev, A.V.; Dzantiev, B.B. Urchin peroxidase-mimicking $\mathrm{Au} @$ Pt nanoparticles as a label in lateral flow immunoassay: impact of nanoparticle composition on detection limit of Clavibacter michiganensis. Microchim. Acta 2020, 187, 268. DOI: 10.1007/s00604-020-04253-3

59. Sun, J.; Li, C.; Qi, Y.; Guo, S.; Liang, X. Optimizing Colorimetric Assay Based on $\mathrm{V}_{2} \mathrm{O}_{5}$ Nanozymes for Sensitive Detection of $\mathrm{H}_{2} \mathrm{O}_{2}$ and Glucose. Sensors 2016, 16, 584. doi: 10.3390/s16040584

60. Gao, L.; Zhuang, J.; Nie, L.; Zhang, J.; Zhang, Y.; Gu, N.; Wang, T.; Feng, J.; Yang, D.; Perrett, S.; Yan, X. Intrinsic peroxidase-like activity of ferromagnetic nanoparticles. Nat. Nanotechnol. 2007, 2, 577-583. DOI: 10.1038/nnano.2007.260

61. Yan, H.; Chen, Y.; Jiao, L.; Gu, W.; Zhu, C. Amorphous RuTe $\mathrm{T}_{2}$ nanorods as efficient peroxidase mimics for colorimetric immunoassay. Sens. Actuators, B 2021, 341, 130007. doi:10.1016/j.snb.2021.130007

62. Volkert, A. A.; Subramaniam, V.; Haes, A. J. Implications of citrate concentration during the seeded growth synthesis of gold nanoparticles. Chem. Commun. 2011, 47, 478-480. doi: 10.1039/c0cc02075c

63. Wu, X.; Wu, C.; Wei, C.; Hu, L.; Qian, J.; Cao, Y.; Ai, X.; Wang, J.; Yang, H. Highly Crystallized $\mathrm{Na}_{2} \mathrm{CoFe}(\mathrm{CN})_{6}$ with Suppressed Lattice Defects as Superior Cathode Material for Sodium-Ion Batteries. ACS Appl. Mater. Interf. 2016, 8, 5393-5399. doi: 10.1021/acsami.5b12620

64. Samain, L.; Grandjean, F.; Long, G. J.; Martinetto, P.; Bordet, P.; Strivay, D. Relationship between the Synthesis of Prussian Blue Pigments, Their Color, Physical Properties, and Their Behavior in Paint Layers. J. Phys. Chem. C 2013, 117, 9693-9712. doi:10.1021/jp3111327

65. Kjeldgaard, S.; Dugulan, I.; Mamakhel, A.; Wagemaker, M.; Iversen, B. B.; Bentien, A. Strategies for synthesis of Prussian blue analogues. R. Soc. Open Sci. 2021, 8, 201779. doi: 10.1098/rsos.201779

66. Yu, F.; Huang, Y.; Cole, A. J.; Yang, V. C. The artificial peroxidase activity of magnetic iron oxide nanoparticles and its application to glucose detection. Biomaterials 2009, 30, 4716-4722. doi: 10.1016/j.biomaterials.2009.05.005

67. Ciaurriz, P.; Fernández, F.; Tellechea, E.; Moran, J. F.; Asensio, A. C. (2017). Comparison of four functionalization methods of gold nanoparticles for enhancing the enzyme-linked immunosorbent assay (ELISA). Beilstein J. Nanotechnol. 2017, 8, 244-253. doi: 10.3762/bjnano.8.27

68. Gaihre, B.; Aryal, S.; Khil, M. S.; Kim, H. Y. Encapsulation of $\mathrm{Fe}_{3} \mathrm{O}_{4}$ in gelatin nanoparticles: Effect of different parameters on size and stability of the colloidal dispersion. J. Microencapsulation 2008, 25, 21-30. doi:10.1080/02652040701737697 
69. Karyakin, A. A. Advances of Prussian blue and its analogues in (bio)sensors. Curr. Opin. Electrochem. 2017, 5, 92-98. doi: 10.1016/j.coelec.2017.07.006

70. Migneault, I.; Dartiguenave, C.; Bertrand, M. J.; \& Waldron, K. C. Glutaraldehyde: behavior in aqueous solution, reaction with proteins, and application to enzyme crosslinking. BioTechniques 2004, 37, 790-802. doi: 10.2144/04375rv01

71. Bhattacharjee, S. DLS and zeta potential - What they are and what they are not? J. Controlled Release 2016, 235, 337-351. doi:10.1016/j.jconrel.2016.06.017

72. Scholz, F.; Schwudke, D.; Stösser, R.; Boháček, J. The Interaction of Prussian Blue and Dissolved Hexacyanoferrate Ions with Goethite $(\alpha-\mathrm{FeOOH})$ Studied to Assess the Chemical Stability and Physical Mobility of Prussian Blue in Soils. Ecotoxicol. Environ. Saf. 2001, 49, 245-254. doi:10.1006/eesa.2001.2060

73. Cano-Mejia, J.; Burga, R. A.; Sweeney, E. E.; Fisher, J. P.; Bollard, C. M.; Sandler, A. D.; Cruz, C.; Fernandes, R. Prussian blue nanoparticle-based photothermal therapy combined with checkpoint inhibition for photothermal immunotherapy of neuroblastoma. Nanomed.: Nanotechnol. Biol. Med. 2017, 13, 771-781. doi: 10.1016/j.nano.2016.10.015

74. Cheng, M.; Peng, W.; Hua, P.; Chen, Z.; Sheng, J.; Yang, J.; Wu, Y. In situ formation of $\mathrm{pH}-$-responsive Prussian blue for photoacoustic imaging and photothermal therapy of cancer. RSC $A d v$. 2017, 7, 18270-18276. doi:10.1039/c7ra01879g

75. Lee, I.; Kim, S.-H.; Rethinasabapathy, M.; Haldorai, Y.; Lee, G.-W.; Choe, S.R.; Jang, S.-C.; Kang, S.-M.; Han, Y.-K.; Roh, C.; Cho, W.-S.; Huh, Y.S. Porous 3D Prussian blue/cellulose aerogel as a decorporation agent for removal of ingested cesium from the gastrointestinal tract. Sci. Rep. 2018, 8 , 4540. DOI: $10.1038 / \mathrm{s} 41598-018-22715-\mathrm{w}$

76. Ishizaki, M.; Ohshida, E.; Tanno, H.; Kawamoto, T.; Tanaka, H.; Hara, K.; Kominami, H.; Kurihara, M. $\mathrm{H}_{2} \mathrm{O}_{2}$-sensing abilities of mixed-metal (Fe-Ni) Prussian blue analogs in a wide $\mathrm{pH}$ range. Inorg. Chim. Acta 2020, 502, 119314. DOI: $10.1016 /$ j.ica.2019.119314

77. Karpova, E. V.; Shcherbacheva, E. V.; Komkova, M. A.; Eliseev, A. A.; Karyakin, A. A. Core-Shell Nanozymes "Artificial Peroxidase": Stability with Superior Catalytic Properties. J. Phys. Chem. Lett. 2021, 12, 5547-5551. doi: 10.1021/acs.jpclett.1c01200

78. Ren, J.; Su, L.; Hu, H.; Yin, X.; Xu, J.; Liu, S.; Wang, J.; Wang, Z.; Zhang, D. Expanded detection range of lateral flow immunoassay endowed with a third-stage amplifier indirect probe. Food Chem. 2021, 377, 131920. Doi: 10.1016/j.foodchem.2021.131920

79. Khramtsov, P.; Burdina, O.; Lazarev, S.; Novokshonova, A.; Bochkova, M.; Timganova, V.; Kiselkov, D.; Minin, A.; Zamorina, S.; Rayev, M. Modified Desolvation Method Enables Simple One-Step Synthesis of Gelatin Nanoparticles from Different Gelatin Types with Any Bloom Values. Pharmaceutics 2021, 13, 1537. doi: 10.3390/pharmaceutics 13101537 
80. Wang, Z.; Long, Y.; Fan, J.; Xiao, C.; Tong, C.; Guo, C.; Chen, X.; Liu, B.; Yang, X. Biosafety and biocompatibility assessment of Prussian blue nanoparticles in vitro and in vivo. Nanomedicine (London, U.K.) 2020, 15, 2655-2670. doi: 10.2217/nnm-2020-0191

81. Duffy, M.J. Biomarkers for prostate cancer: Prostate-specific antigen and beyond. Clin. Chem. Lab. Med. 2020, 58, 326-339. DOI: 10.1515/cclm-20190693

82. Yen, L. M.; Thwaites, C. L. Tetanus. Lancet 2019, 393, 1657-1668. doi: 10.1016/S0140-6736(18)33131-3

83. Komkova, M.A.; Vetoshev, K.R.; Andreev, E.A.; Karyakin, A.A. Flowelectrochemical synthesis of Prussian Blue based nanozyme 'artificial peroxidase'. Dalton Trans. 2021, 50, 11385-11389. DOI: 10.1039/d1dt02107a

84. Wu, Y., Xu, W., Jiao, L., Tang, Y., Chen, Y., Gu, W., Zhu, C. Defect engineering in nanozymes. Mater. Today 2021. DOI: 10.1016/j.mattod.2021.10.032

85. Wang, Z.; Zhang, R.; Yan, X.; Fan, K. Structure and activity of nanozymes: Inspirations for de novo design of nanozymes. Mater. Today 2021, 41, 81119. DOI: $10.1016 /$ j.mattod.2020.08.020

\section{Supporting information}

Reagents and instrumentation

Iron (III) chloride hexahydrate and 3,3',5,5'-tetramethylbenzidine dihydrochloride (TMB) were from AppliChem (USA); potassium hexacyanoferrate (II) trihydrate, potassium hexacyanoferrate (III), casein, gelatin A 180 bloom, Proclin-950 were from Sigma-Aldrich (USA). Tween-20, glutaraldehyde, citric acid, oxalic acid, glycine, sodium phosphate, sodium bicarbonate, and glycerol were from ITW (USA). Potassium hydroxide, sodium hydroxide, sulphuric acid, and hydrochloric acid were from Reakhim (Russia). Recombinant protein G from Streptococcus $s p$. was kindly provided by Dr. Tatyana Gupalova, Institute of Experimental Medicine (St.-Petersburg, Russia). Tetanus toxoid was from Mikrogen (Russia). WHO standard of human anti-tetanus IgG (TE-3) was from NIBSC (UK). PSA and anti-PSA monoclonal antibodies (clones $3 \mathrm{~A} 6$ and 1A6) were obtained from Bialexa (Russia). 96-well polystyrene plates (high binding) were from SPL Life Sciences (South Korea) Dialysis tubing (cellulose membrane; 10,000 MWCO) was from Thermo Scientific (USA). Horseradish peroxidase (RZ 3.0; $307 \mathrm{U} / \mathrm{mg}$ ) was from VWR (USA).

Buffers for immunoassay. 0.2 $\mathrm{M}$ carbonate buffer, $\mathrm{pH}$ 9.6; phosphate buffer (PB, $10 \mathrm{mM} \mathrm{Na}_{2} \mathrm{HPO}_{4}, 10 \mathrm{mM} \mathrm{NaH}_{2} \mathrm{PO}_{4}$, and $0.05 \%$ Proclin-950, $\mathrm{pH} 7$ ) and PBT ( $\mathrm{PB}+0.1 \%$ Tween-20). Substrate buffer: $5 \mathrm{mM}$ citrate-phosphate buffer, $\mathrm{pH} 4$ and $0.1 \mathrm{M}$ citrate-phosphate buffer, $\mathrm{pH} 5$.

Instrumentation. Stat Fax 2600 microplate washer was from Awareness Technology (USA). Multiskan Sky UV-Vis Reader and iCAP 6500 Duo ICP-MS were from Thermo Scientific (USA). ZetaSizer NanoZS particle analyzer was from Malvern (UK). Aurora M90 ICP-MS was from Bruker Corp. (USA). Peristaltic 
pump P-1 was from Pharmacia (Sweden). VCX-130 ultrasonic processor was from Sonics \& Materials (USA).

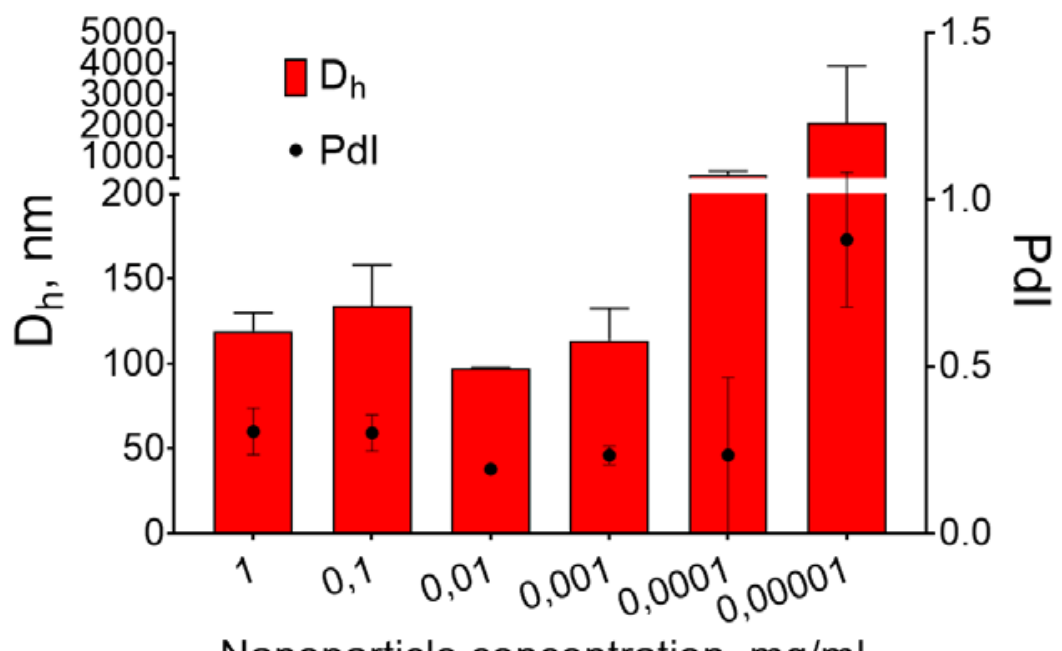

Nanoparticle concentration, $\mathrm{mg} / \mathrm{mL}$

Figure S1. Relationship between nanoparticle concentration and DLS results. $\mathrm{Dh}$ - hydrodynamic diameter, $\mathrm{PdI}$ - polydispersity index. $\mathrm{n}=3$, mean $\pm \mathrm{SD}$

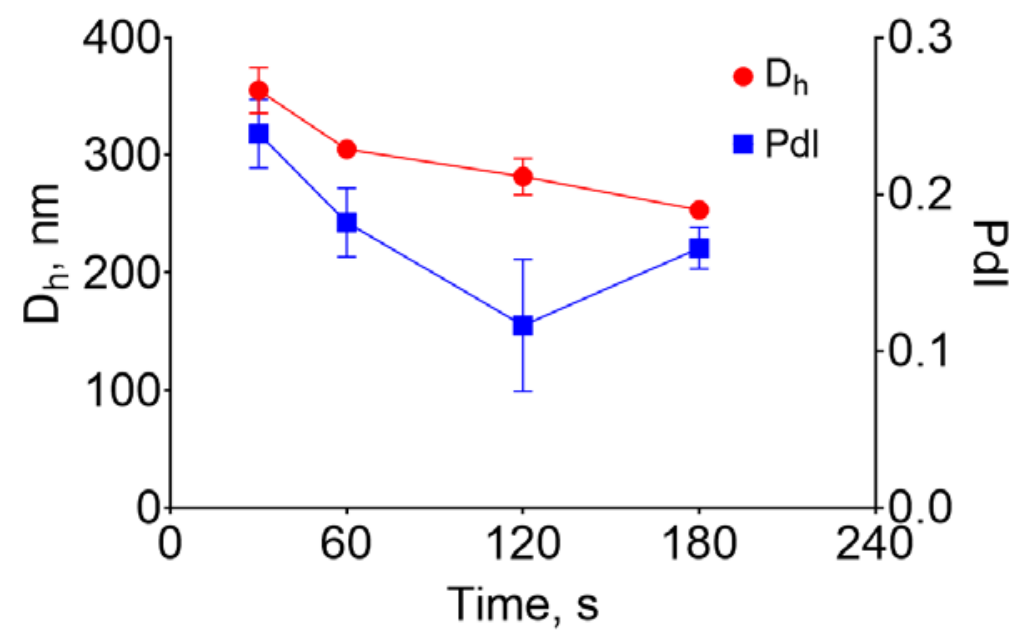

Figure S2. Effect of sonication time on the size and polydispersity of nanoparticles. Dh - hydrodynamic diameter, PdI - polydispersity index. $\mathrm{n}=3$, mean \pm SD 

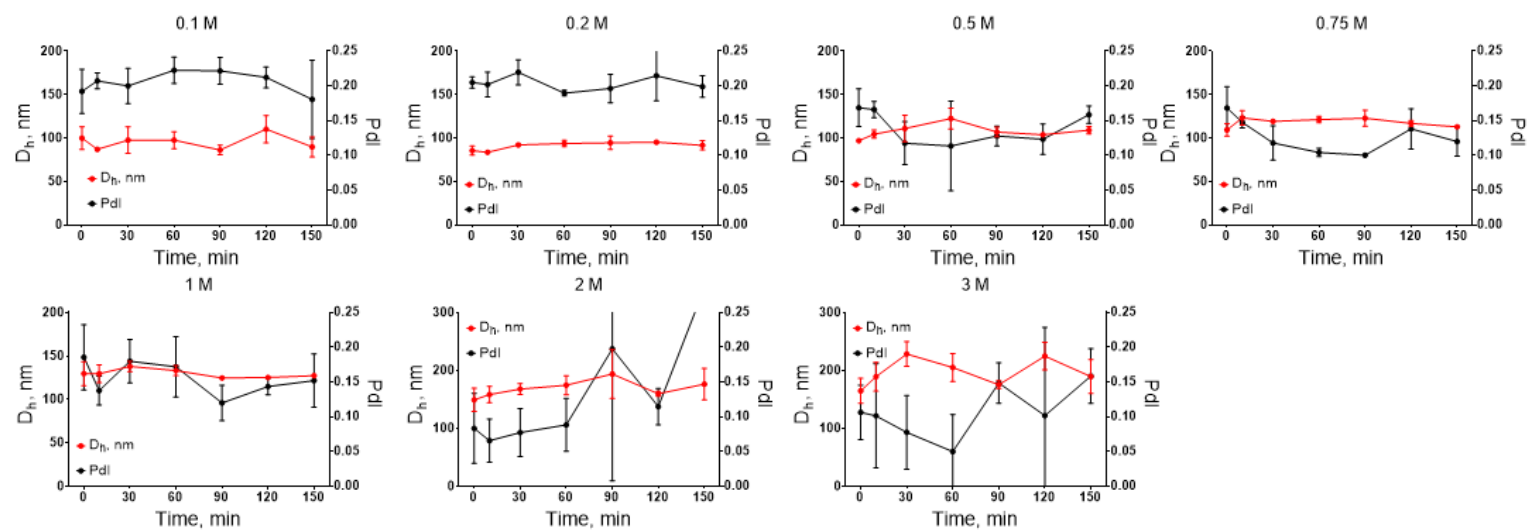

Figure S3. Change of size and polydispersity of nanoparticles in the course of synthesis. Centrifuged samples. Ionic strength experiment. Concentration of added $\mathrm{KCl}$ is above the graphs. Dh - hydrodynamic diameter, PdI - polydispersity index. $\mathrm{n}=3$, mean $\pm \mathrm{SD}$

$\mathrm{pH} 1$

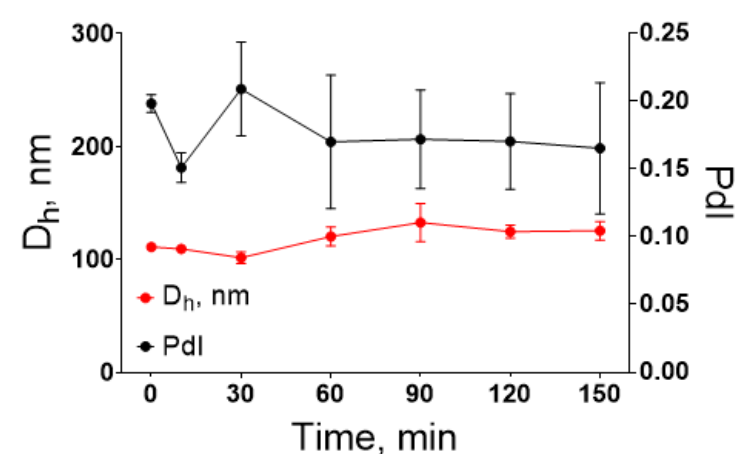

$\mathrm{pH} 2$

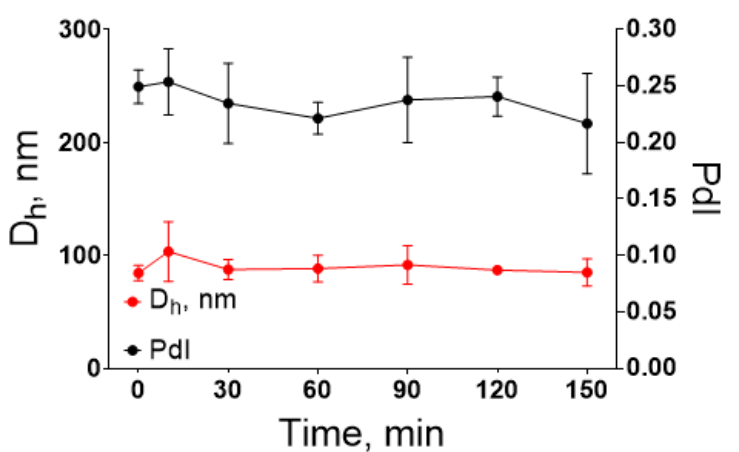

Figure S4. Change of size and polydispersity of nanoparticles in the course of synthesis. Centrifuged samples. $\mathrm{pH}$ experiment. $\mathrm{pH}$ value is above the graphs. $\mathrm{Dh}$ - hydrodynamic diameter, $\mathrm{PdI}$ - polydispersity index. $\mathrm{n}=3$, mean $\pm \mathrm{SD}$ 

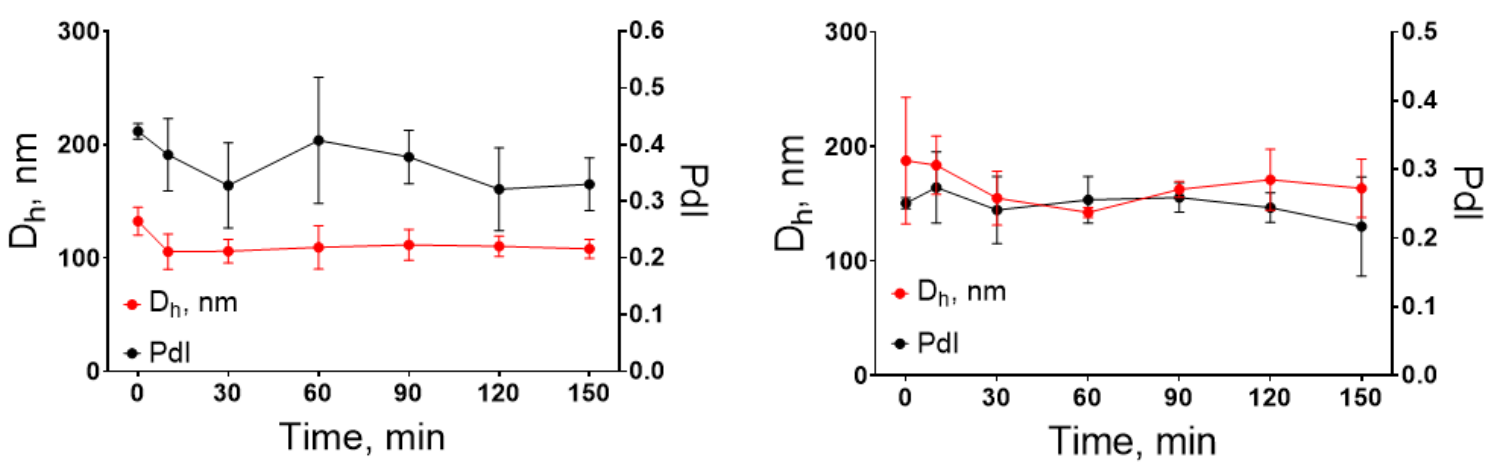

$\mathrm{FeCl}_{3}: \mathrm{K}_{3}\left[\mathrm{Fe}(\mathrm{CN})_{6}\right]=3.125: 6.25$

$\mathrm{FeCl}_{3}: \mathrm{K}_{3}\left[\mathrm{Fe}(\mathrm{CN})_{6}\right]=3.125: 15.625$
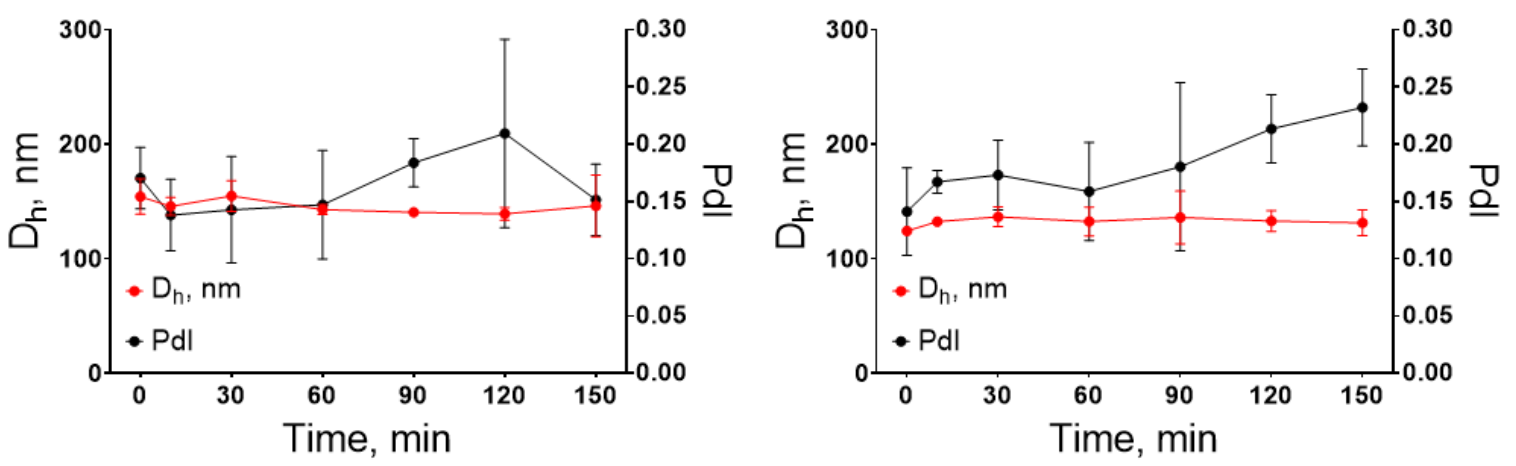

Figure S5. Change of size and polydispersity of nanoparticles in the course of synthesis. Centrifuged samples. Salt ratio experiment. $\mathrm{FeCl}_{3}: \mathrm{K}_{3}\left[\mathrm{Fe}(\mathrm{CN})_{6}\right]$ ratio is above the graphs. Dh - hydrodynamic diameter, PdI - polydispersity index. $n=3$, mean \pm SD
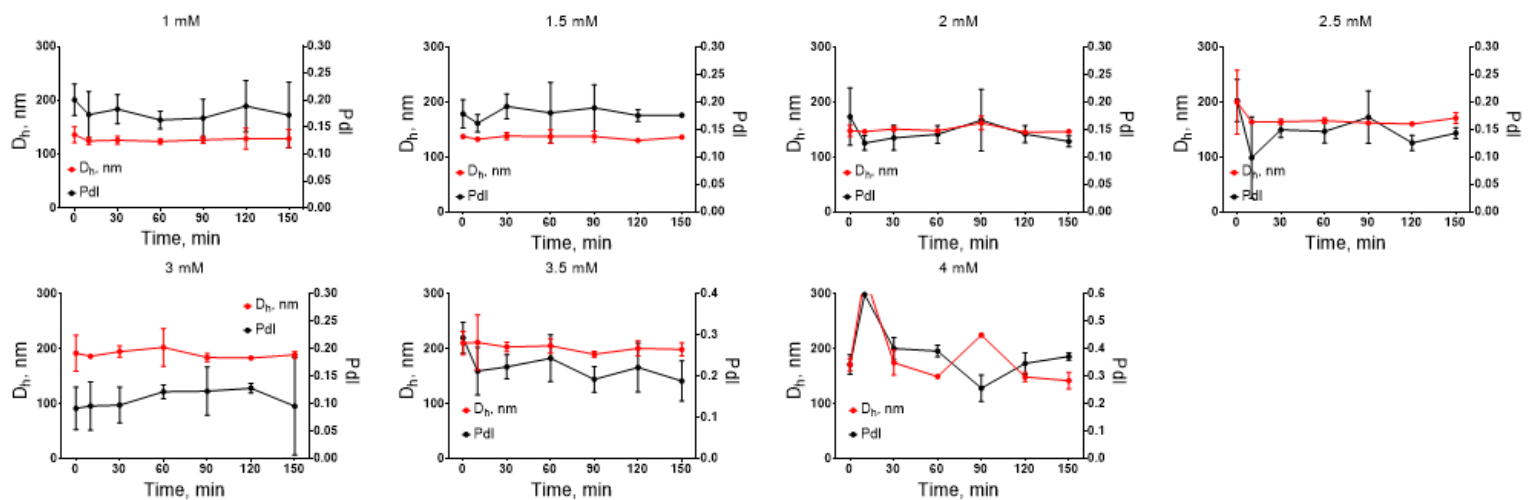

Figure S6. Change of size and polydispersity of nanoparticles in the course of synthesis. Centrifuged samples. Oxalic acid concentration experiment. Concentration of added oxalic acid is above the graphs. Dh - hydrodynamic diameter, PdI - polydispersity index. $n=3$, mean \pm SD 

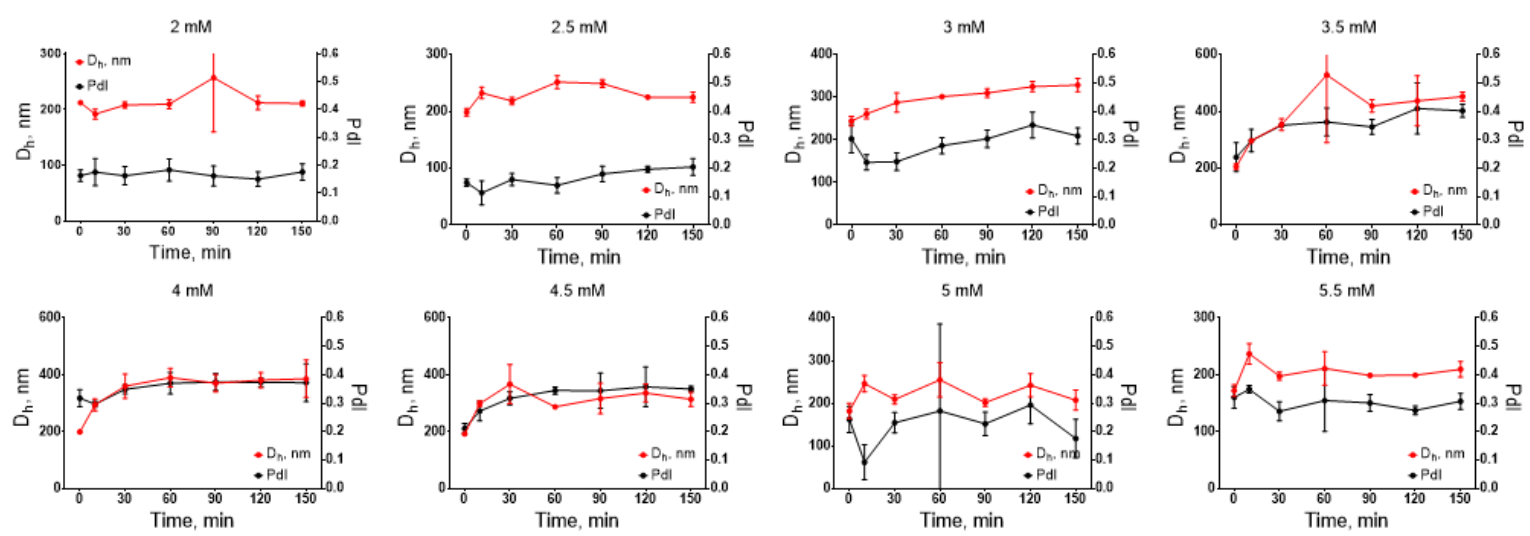

Figure S7. Change of size and polydispersity of nanoparticles in the course of synthesis. Centrifuged samples. citric acid concentration experiment. Concentration of added citric acid is above the graphs. Dh - hydrodynamic diameter, $\mathrm{PdI}$ - polydispersity index. $\mathrm{n}=3$, mean $\pm \mathrm{SD}$

$+30^{\circ} \mathrm{C}$, experiment 1



$+60^{\circ} \mathrm{C}$, experiment 1

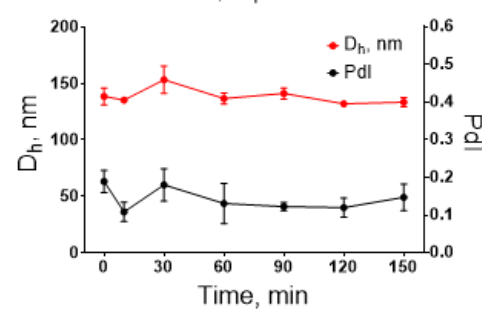

$+30^{\circ} \mathrm{C}$, experiment 2

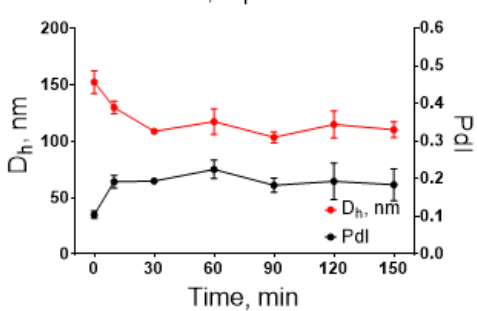

$+60{ }^{\circ} \mathrm{C}$, experiment 2



$+30{ }^{\circ} \mathrm{C}$, experiment 3



$+60^{\circ} \mathrm{C}$, experiment 3

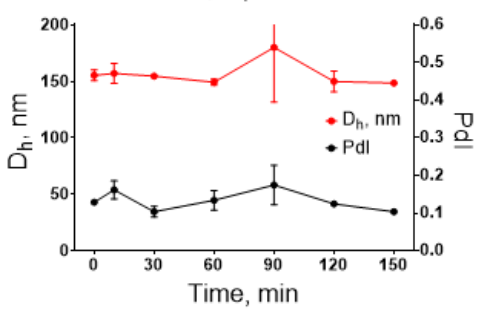

Figure S8. Change of size and polydispersity of nanoparticles in the course of synthesis. Centrifuged samples. Temperature experiment (three identical experiments were performed for each temperature). Temperature and number of experiment are above the graphs. Dh - hydrodynamic diameter, PdI - polydispersity index. $\mathrm{n}=3$, mean $\pm \mathrm{SD}$ 

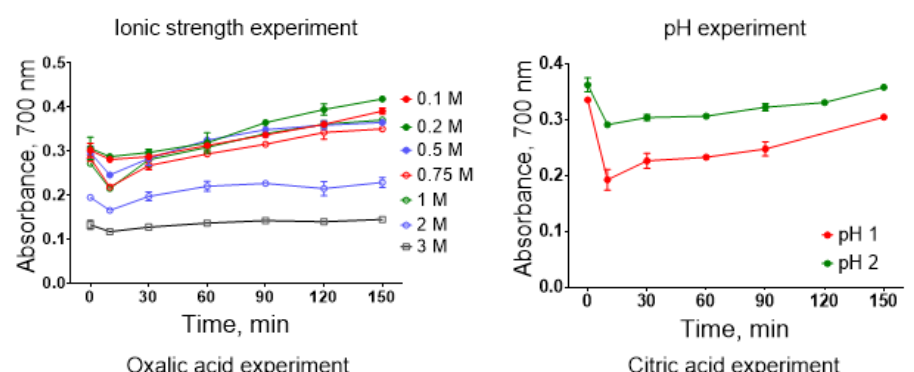

Citric acid experiment
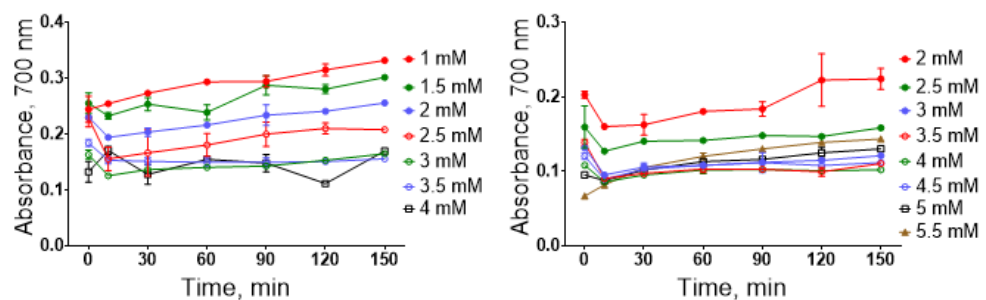

$\mathrm{FeCl}_{3}: \mathrm{K}_{3}\left[\mathrm{Fe}(\mathrm{CN})_{6}\right]$ experiment

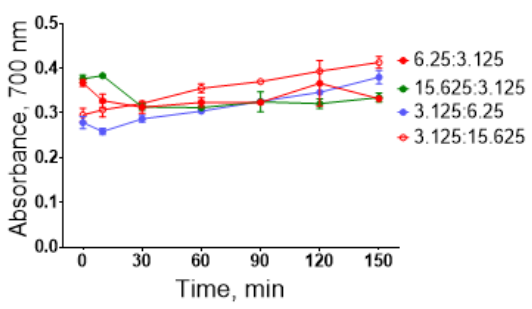

Temperature experiment



Figure S9. Change of absorbance at $700 \mathrm{~nm}$ in the course of synthesis. In situ samples. Type of experiment is above the graphs. $\mathrm{n}=3$, mean $\pm \mathrm{SD}$

Citric acid, $A_{700}$ dynamics

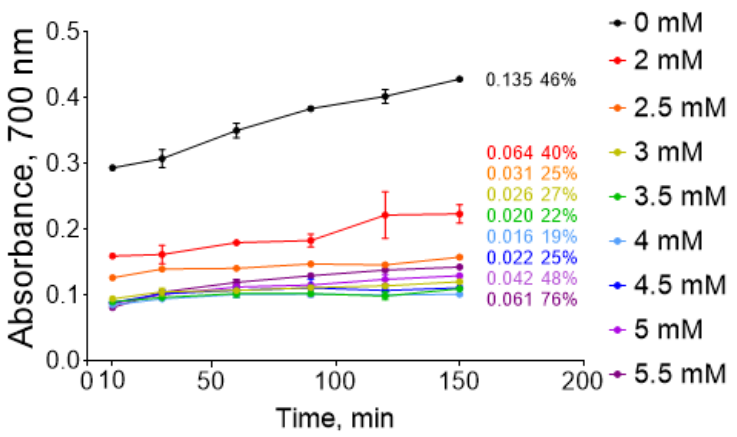

Oxalic acid, $A_{700}$ dynamics

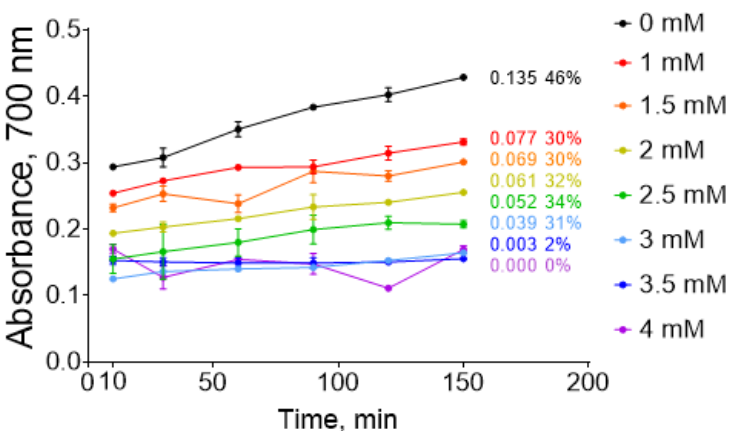

Figure S10. Change of $\mathrm{A}_{700}$ in the course of "artificial peroxidase" synthesis in the presence of various concentrations of citric and oxalic acids. The numbers to the right of the graphs show the difference in $\mathrm{A}_{700}$ between the time points of 10 and 150 minutes in absolute values and percentages. $n=3$, mean $\pm S D$ 


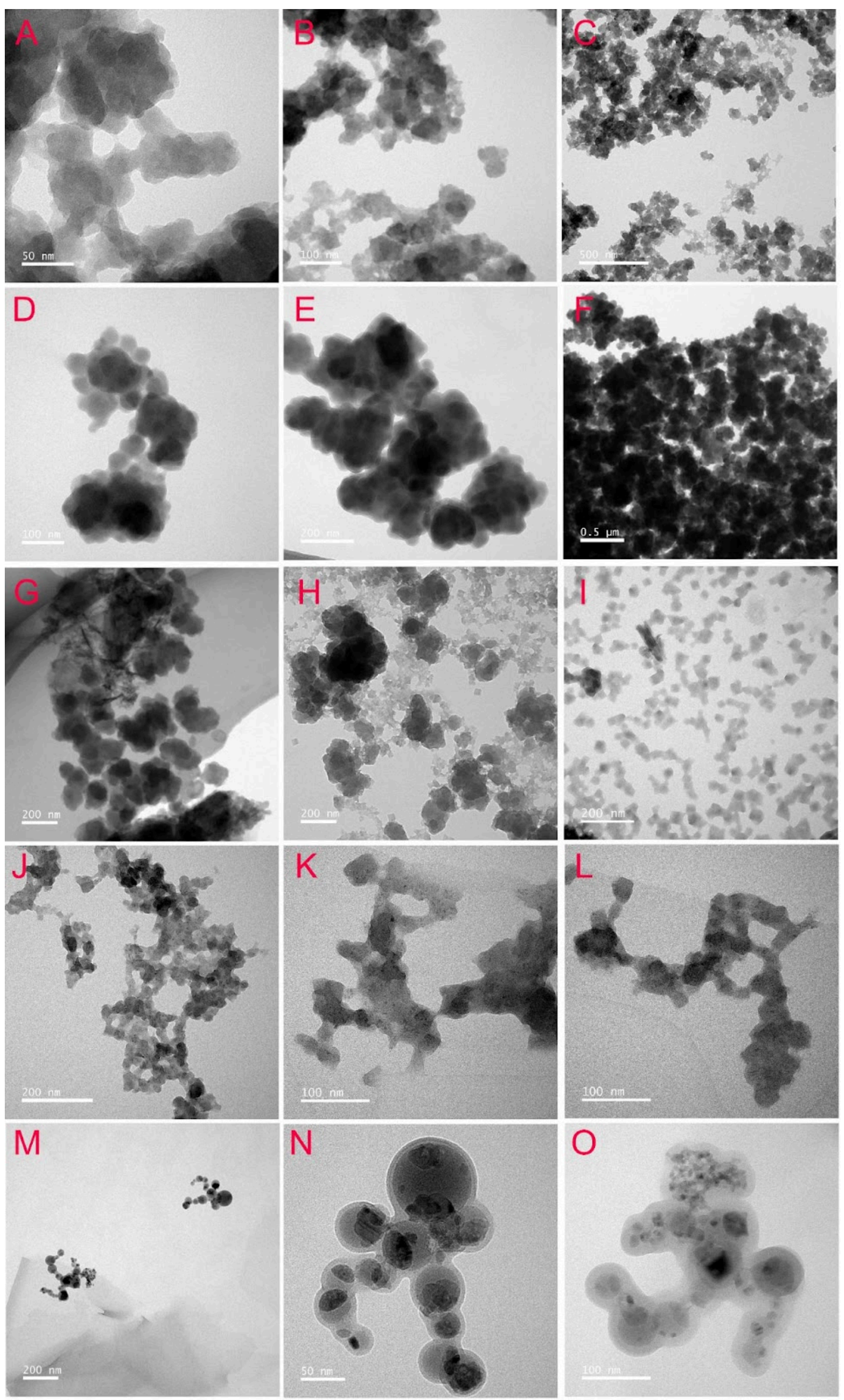


Figure S11. TEM images of prussian blue nanoparticles. (A-C) - R2C. (D-F) - R4.5C. (G-I) - RKH. (J-L) - T. (M-O) - T25C.
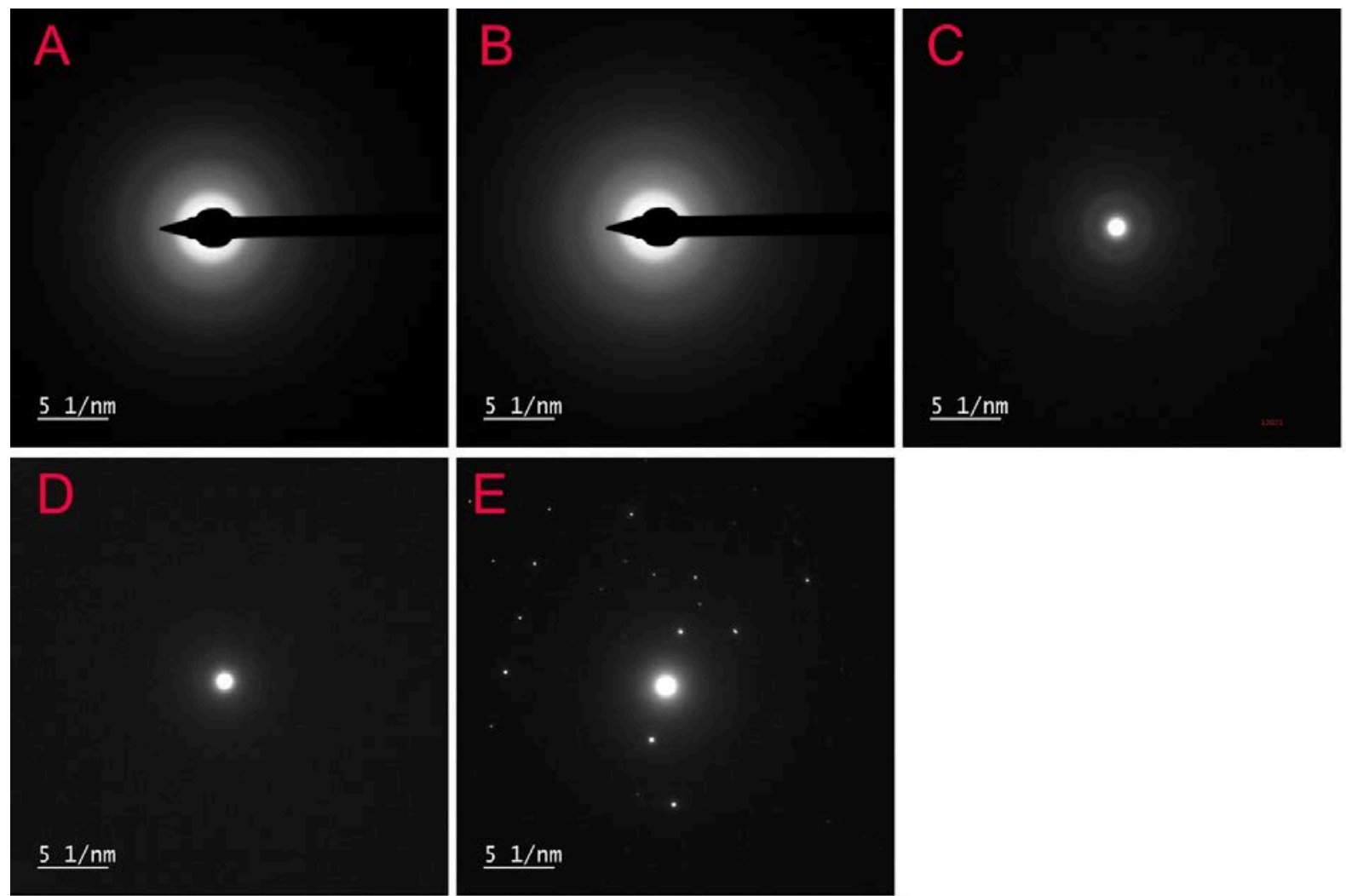

Figure S12. Selected area electron diffraction results for R4.5C (A), R2C (B), RKH (C), T25C (D), and T (E).


Figure S13. (A) Adsorption of gelatin A (180 bloom) on prussian blue nanoparticles prepared by reductive approach. (B) Change of hydrodynamic diameter $(\mathrm{Dh})$ of nanoparticles after adsorption of gelatin and activation with glutaraldehyde. $\mathrm{n}=3$, mean $\pm \mathrm{SD}$ 

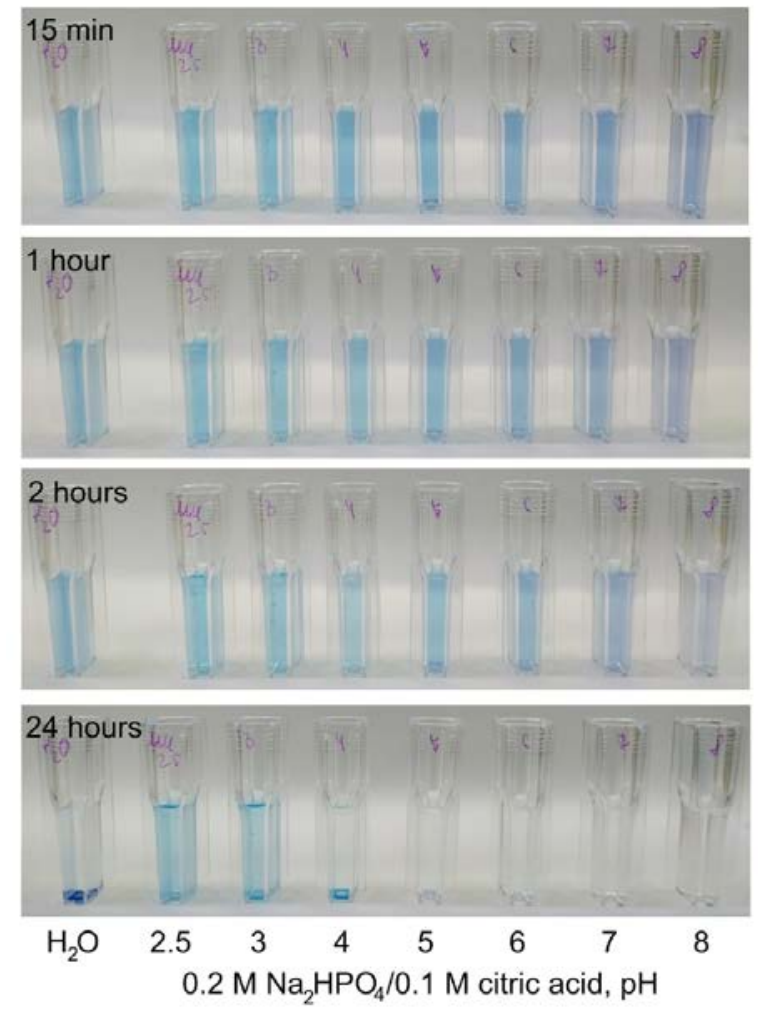
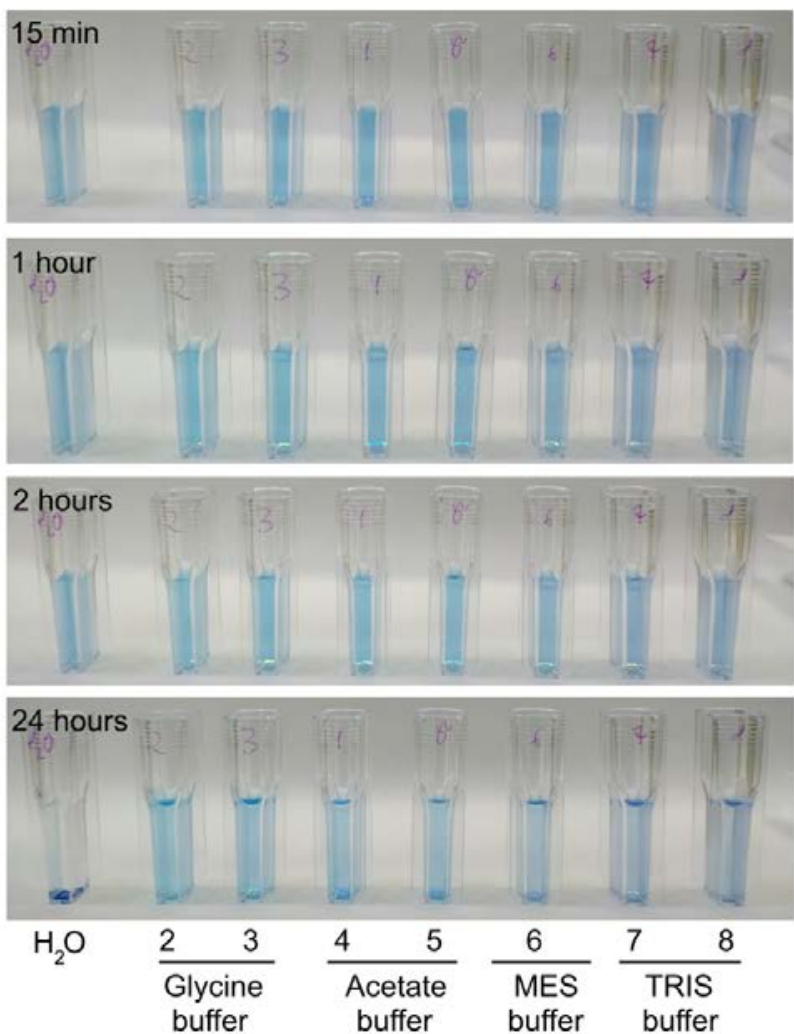

Figure S14. Color change of $\mathrm{PB} / \mathrm{Gel} \mathrm{A} / \mathrm{BSA}$ diluted to $25 \mu \mathrm{g} / \mathrm{mL}$ in water and buffers with various $\mathrm{pH}$ ( $24 \mathrm{~h}$ of incubation). Left - McIlvaine buffer, right $0.1 \mathrm{M}$ Glycine-HCl, $\mathrm{pH} 2$ and 3; $0.1 \mathrm{M}$ acetic acid-NaOH, $\mathrm{pH} 4$ and 5; $0.1 \mathrm{M}$ MES$\mathrm{NaOH}, \mathrm{pH}$ 6; $0.1 \mathrm{M}$ TRIS-HCl, $\mathrm{pH} 7$ and 8. Size of nanoparticles is given in Figure S16. Change of absorbance at $700 \mathrm{~nm}$ is given in Figure S15.
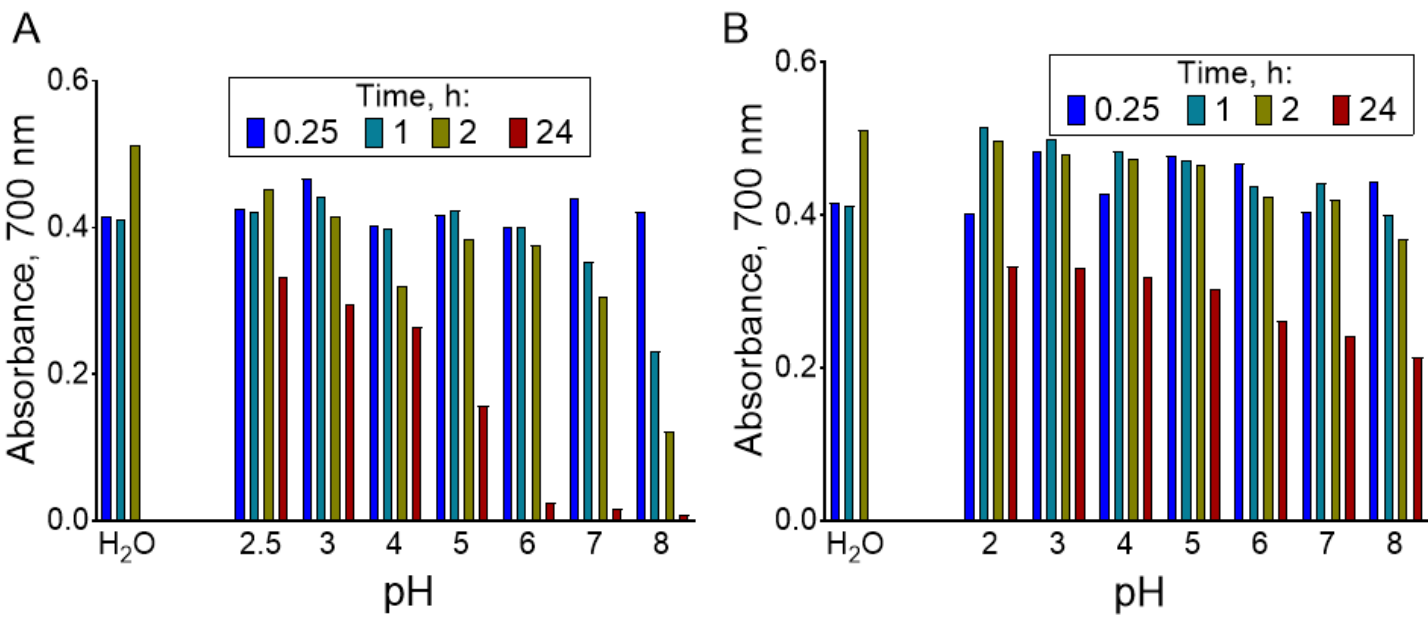

Figure S15. Absorbance at $700 \mathrm{~nm}$ of $\mathrm{PB} / \mathrm{Gel} \mathrm{A} / \mathrm{BSA}$ diluted to $25 \mu \mathrm{g} / \mathrm{mL}$ in water and buffers with various $\mathrm{pH}$ (24 h of incubation). (A) - McIlvaine buffer, (B) - 0.1 M Glycine-HCl, $\mathrm{pH} 2$ and 3; $0.1 \mathrm{M}$ acetic acid-NaOH, $\mathrm{pH} 4$ and 5; $0.1 \mathrm{M}$ MES$\mathrm{NaOH}, \mathrm{pH}$ 6; 0.1 M TRIS-HCl, $\mathrm{pH} 7$ and 8. $\mathrm{n}=1$ 
A

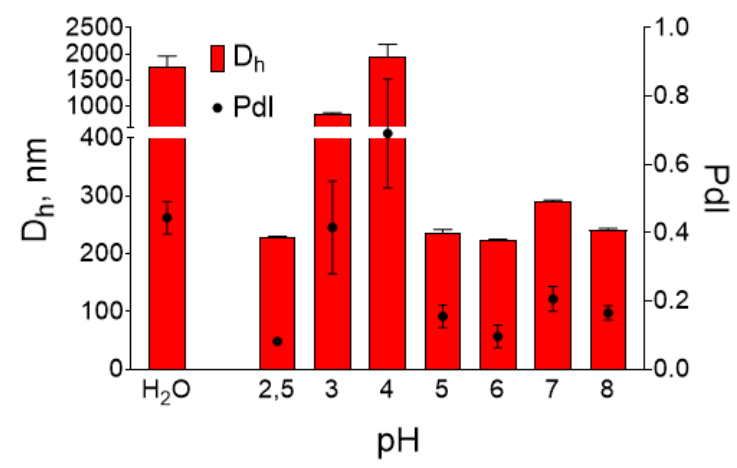

B

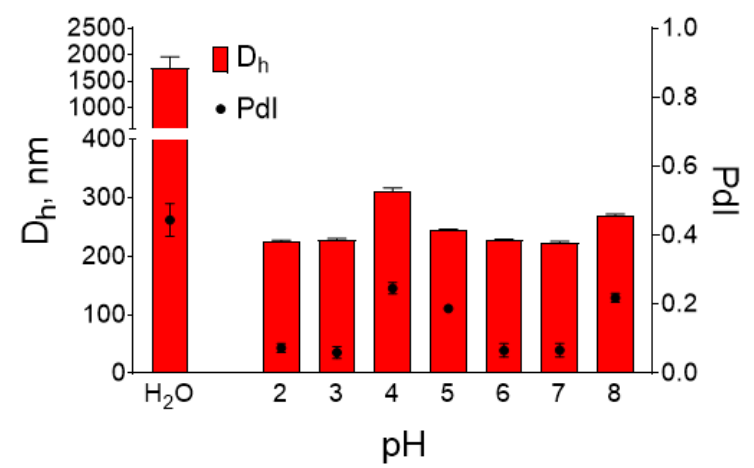

Figure S16. Size of PB/Gel A/BSA diluted to $25 \mu \mathrm{g} / \mathrm{mL}$ in water and buffers with various $\mathrm{pH}$ (24 h of incubation). (A) - McIlvaine buffer, (B) - $0.1 \mathrm{M}$ Glycine$\mathrm{HCl}, \mathrm{pH} 2$ and 3; $0.1 \mathrm{M}$ acetic acid-NaOH, pH 4 and 5; $0.1 \mathrm{M} \mathrm{MES-NaOH,} \mathrm{pH} \mathrm{6;}$ $0.1 \mathrm{M}$ TRIS-HCl, pH 7 and 8. Dh - hydrodynamic diameter, PdI - polydispersity index. $\mathrm{n}=3$, mean $\pm \mathrm{SD}$



Figure S17. Change of absorbance at $700 \mathrm{~nm}$ of gelatin-coated prussian blue nanoparticles conjugated with affine molecules while storage at $+4{ }^{\circ} \mathrm{C}, \mathrm{n}=3$, mean \pm SD. Mean values are given above the bars.




Figure S18. Size of prussian blue nanoparticles conjugated with protein $G$ (PB@Protein G) or BSA (PB@BSA) via adsorption. Dh - hydrodynamic diameter, $\mathrm{PdI}$ - polydispersity index. $\mathrm{n}=3$, mean $\pm \mathrm{SD}$



Figure S19. Calibration curves of anti-tetanus IgG (TE-3), which were obtained using nanozymes, synthesized by different methods: PBNP/GelA/protein $\mathrm{G}$ - protein $\mathrm{G}$ attached to gelatin-coated nanoparticles via glutaraldehyde; PBNP@protein G - protein G was directly adsorbed on prussian blue nanoparticles; PBNP@BSA - BSA was directly adsorbed on prussian blue nanoparticles (negative control). $n=3$, mean \pm SD. Substrate buffer: $0.1 \mathrm{M}$ citrate-phosphate buffer, $\mathrm{pH} 5$.

Table S1. Details of additional manipulation with aggregated batches of prussian blue nanoparticles after three months of storage at $+4{ }^{\circ} \mathrm{C}$.

\begin{tabular}{|l|c|c|c|c|}
\hline $\begin{array}{l}\text { Type of } \\
\text { nanoparticles }\end{array}$ & $\begin{array}{l}\text { Time of additional } \\
\text { ultrasonication }(60 \% \\
\text { amplification), } \mathrm{min}\end{array}$ & $\begin{array}{l}\text { Time of additional } \\
\text { centrifugation }(500 \\
\mathrm{g}), \mathrm{min}\end{array}$ & $\begin{array}{l}\text { Time of additional } \\
\text { centrifugation }(1600 \\
\mathrm{g}), \text { min }\end{array}$ & $\begin{array}{l}\text { Time of additional } \\
\text { centrifugation (4500 } \\
\mathrm{g}), \text { min }\end{array}$ \\
\hline R & 20 & - & 10 & 45 \\
\hline R2C & - & - & 75 & 45 \\
\hline R2O & 20 & 35 & 60 & 60 \\
\hline
\end{tabular}

Table S2. Specific activity (U/mgFe) of prussian blue nanoparticles synthesized by different methods. Mean of 3 technical replicates is reported for each batch.

\begin{tabular}{|l|c|c|c|c|c|c|c|l|}
\hline & $\mathbf{R}$ & $\mathbf{R 4 . 5 C}$ & $\mathbf{R 2 C}$ & $\mathbf{R 2 O}$ & $\mathbf{R K H}$ & $\mathbf{T 2 5 C}$ & $\mathbf{T}$ & $\mathbf{T} / \mathbf{d w} / \mathbf{r t}$ \\
\hline Batch 1 & 2.463 & 1.470 & 2.813 & 3.203 & 2.171 & 2.616 & 2.273 & 1.896 \\
\hline Batch 2 & 2.376 & 1.660 & 2.566 & 3.130 & 2.052 & 2.316 & 2.013 & 1.810 \\
\hline
\end{tabular}




\begin{tabular}{|l|l|l|l|l|l|l|l|l|}
\hline Batch 3 & 2.543 & 1.583 & 2.836 & 3.066 & 2.093 & 2.79 & 1.900 & - \\
\hline Mean & 2.461 & 1.571 & 2.739 & 3.133 & 2.105 & 2.574 & 2.062 & 1.853 \\
\hline Standard deviation & 0.083 & 0.095 & 0.149 & 0.068 & 0.060 & 0.239 & 0.191 & 0.061 \\
\hline
\end{tabular}

Table S3. Comparison of specific activity (U/mgFe) of prussian blue nanoparticles synthesized by different methods. One-way ANOVA with Sidak's post-hoc test. $\mathrm{n}=3$ (for $\mathrm{T} / \mathrm{dw} / \mathrm{rt} \mathrm{n}=2$ ).

\begin{tabular}{|c|c|c|c|}
\hline Compared samples & Mean specific activity of group 1 & Mean specific activity of group 2 & $\mathrm{p}$ value \\
\hline R vs. R4.5C & 2.461 & 1.571 & $<0.0001$ \\
\hline $\mathrm{R}$ vs. $\mathrm{R} 2 \mathrm{C}$ & 2.461 & 2.739 & 0.5244 \\
\hline $\mathrm{R}$ vs. $\mathrm{R} 2 \mathrm{O}$ & 2.461 & 3.133 & 0.0007 \\
\hline R vs. RKH & 2.461 & 2.105 & 0.1669 \\
\hline R vs. T25C & 2.461 & 2.574 & $>0.9999$ \\
\hline R vs. T & 2.461 & 2.062 & 0.0797 \\
\hline R vs. T/dw/rt & 2.461 & 1.853 & 0.0062 \\
\hline $\mathrm{R} 4.5 \mathrm{C}$ vs. $\mathrm{R} 2 \mathrm{C}$ & 1.571 & 2.739 & $<0.0001$ \\
\hline $\mathrm{R} 4.5 \mathrm{C}$ vs. $\mathrm{R} 2 \mathrm{O}$ & 1.571 & 3.133 & $<0.0001$ \\
\hline R4.5C vs. RKH & 1.571 & 2.105 & 0.0073 \\
\hline $\mathrm{R} 4.5 \mathrm{C}$ vs. $\mathrm{T} 25 \mathrm{C}$ & 1.571 & 2.574 & $<0.0001$ \\
\hline R4.5C vs. $\mathrm{T}$ & 1.571 & 2.062 & 0.0156 \\
\hline $\mathrm{R} 4.5 \mathrm{C}$ vs. $\mathrm{T} / \mathrm{dw} / \mathrm{rt}$ & 1.571 & 1.853 & 0.6877 \\
\hline $\mathrm{R} 2 \mathrm{C}$ vs. $\mathrm{R} 2 \mathrm{O}$ & 2.739 & 3.133 & 0.0861 \\
\hline R2C vs. RKH & 2.739 & 2.105 & 0.0014 \\
\hline $\mathrm{R} 2 \mathrm{C}$ vs. T25C & 2.739 & 2.574 & 0.9936 \\
\hline R2C vs. T & 2.739 & 2.062 & 0.0007 \\
\hline $\mathrm{R} 2 \mathrm{C}$ vs. $\mathrm{T} / \mathrm{dw} / \mathrm{rt}$ & 2.739 & 1.853 & 0.0001 \\
\hline R2O vs. RKH & 3.133 & 2.105 & $<0.0001$ \\
\hline $\mathrm{R} 2 \mathrm{O}$ vs. T25C & 3.133 & 2.574 & 0.0048 \\
\hline $\mathrm{R} 2 \mathrm{O}$ vs. $\mathrm{T}$ & 3.133 & 2.062 & $<0.0001$ \\
\hline $\mathrm{R} 2 \mathrm{O}$ vs. $\mathrm{T} / \mathrm{dw} / \mathrm{rt}$ & 3.133 & 1.853 & $<0.0001$ \\
\hline RKH vs. T25C & 2.105 & 2.574 & 0.023 \\
\hline RKH vs. T & 2.105 & 2.062 & $>0.9999$ \\
\hline RKH vs. T/dw/rt & 2.105 & 1.853 & 0.8417 \\
\hline
\end{tabular}




\begin{tabular}{|c|c|c|c|}
\hline T25C vs. T & 2.574 & 2.062 & 0.0107 \\
\hline T25C vs. T/dw/rt & 2.574 & 1.853 & 0.0011 \\
\hline T vs. T/dw/rt & 2.062 & 1.853 & 0.9702 \\
\hline
\end{tabular}


Table S. Hydrodynamic diameters of prussian blue nanoparticles after 1, 3, and 5 months of storage at $+4{ }^{\circ} \mathrm{C}$. Dh hydrodynamic diameter, PdI - polydispersity index. Bold type indicate values, which were excluded from calculation of nanoparticle mean size and polydispersity index.

\begin{tabular}{|c|c|c|c|c|c|c|c|c|c|c|c|c|c|c|c|c|}
\hline & \multicolumn{3}{|c|}{ R4.5C } & $\mathrm{R} 2 \mathrm{C}$ & \multicolumn{3}{|c|}{ R2O } & $\mathbf{R}$ & \multicolumn{2}{|r|}{ RKH } & \multicolumn{2}{|r|}{$\mathbf{T}$} & \multicolumn{2}{|r|}{$\underset{t}{T / d w / r}$} & \multicolumn{2}{|r|}{ T25C } \\
\hline & $\begin{array}{l}\text { Dh, } \\
\text { nm }\end{array}$ & PDI & $\begin{array}{l}\text { Dh, } \\
\text { nm }\end{array}$ & PDI & $\begin{array}{l}\text { Dh, } \\
\text { nm }\end{array}$ & PDI & $\begin{array}{l}\text { Dh, } \\
\text { nm }\end{array}$ & PDI & $\begin{array}{l}\text { Dh, } \\
\text { nm }\end{array}$ & PDI & $\begin{array}{l}\text { Dh, } \\
\text { nm }\end{array}$ & PDI & $\begin{array}{l}\text { Dh, } \\
\text { nm }\end{array}$ & PDI & $\begin{array}{l}\text { Dh, } \\
\text { nm }\end{array}$ & PDI \\
\hline & 348.9 & 0.187 & 202 & 0.073 & 179.8 & 0.281 & 90.68 & 0.15 & 196 & 0.137 & 88.84 & 0.143 & 126.6 & 0.133 & 66.67 & 0.128 \\
\hline 1 & 360.6 & 0.095 & 202.4 & 0.118 & 135.2 & 0.11 & 89.52 & 0.166 & 195 & 0.132 & 90.32 & 0.121 & 127.2 & 0.123 & 67.29 & 0.175 \\
\hline & 357.2 & 0.172 & 314.7 & 0.235 & 136.7 & 0.116 & 108.8 & 0.26 & 191.4 & 0.114 & 90.39 & 0.126 & 126.4 & 0.126 & 67.59 & 0.179 \\
\hline & 330.5 & 0.268 & 202 & 0.206 & 134.3 & 0.162 & 92.91 & 0.158 & 203.9 & 0.125 & 90.42 & 0.189 & 124.5 & 0.107 & 77.46 & 0.168 \\
\hline 2 & 328.7 & 0.279 & 295.6 & 0.263 & 133.6 & 0.118 & 139.6 & 0.283 & 202.3 & 0.122 & 89.84 & 0.134 & 123 & 0.125 & 73.67 & 0.131 \\
\hline & 333.4 & 0.245 & 203.8 & 0.102 & 132.5 & 0.137 & 92.92 & 0.16 & 203.6 & 0.08 & 93.02 & 0.107 & 123.2 & 0.1 & 73.94 & 0.151 \\
\hline & 322.4 & 0.217 & 202.9 & 0.078 & 193.8 & 0.264 & 98.52 & 0.13 & 200.4 & 0.107 & 91.41 & 0.135 & & & 67.42 & 0.126 \\
\hline 3 & 321.6 & 0.182 & 200.5 & 0.098 & 136 & 0.113 & 97.26 & 0.13 & 201.4 & 0.154 & 91.45 & 0.087 & & & 66.95 & 0.121 \\
\hline & 326.6 & 0.181 & 206.9 & 0.13 & 133.3 & 0.13 & 97.28 & 0.116 & 205.9 & 0.113 & 90.77 & 0.126 & & & 70.54 & 0.174 \\
\hline
\end{tabular}




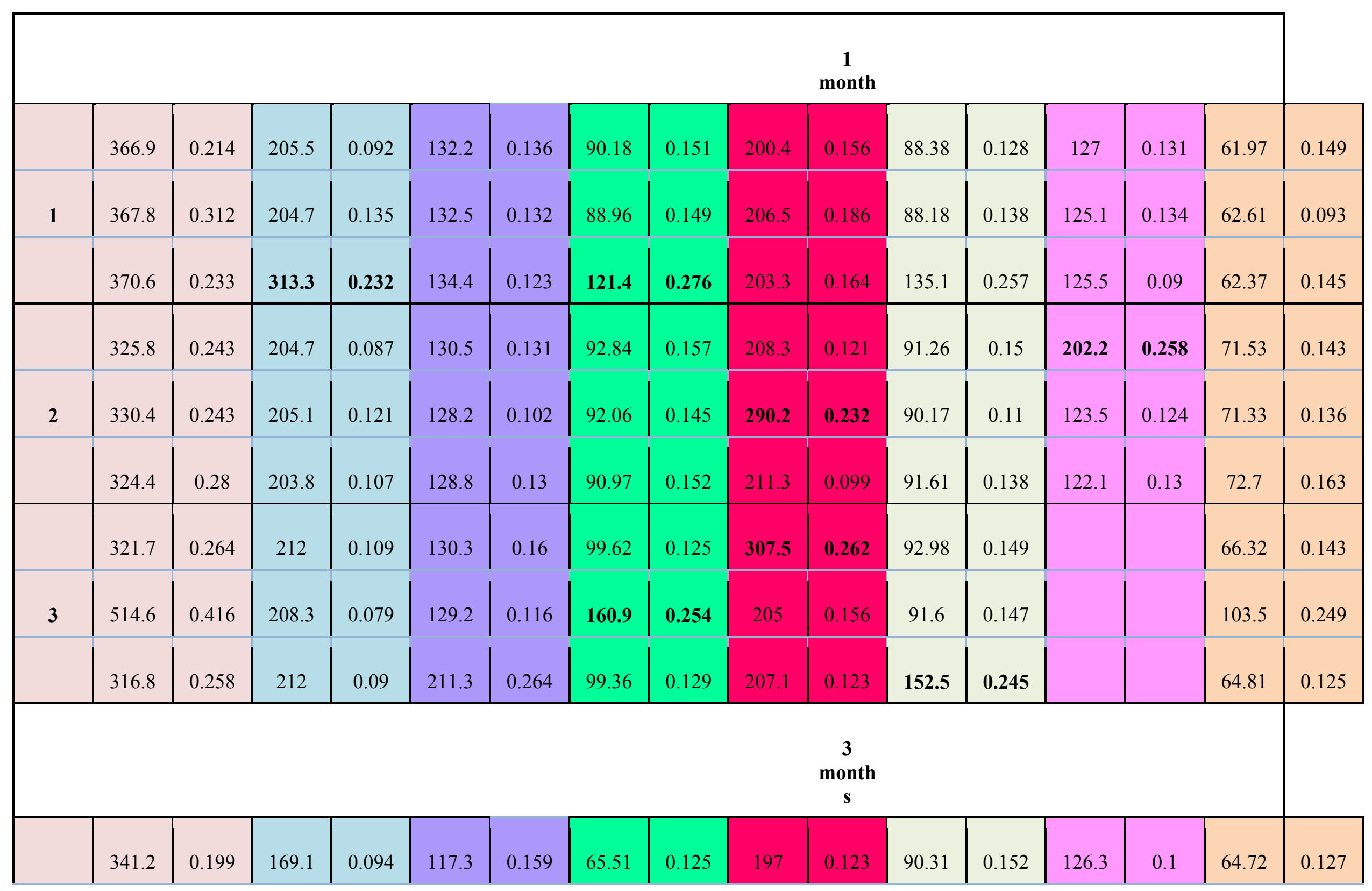









\begin{tabular}{|c|c|c|c|c|c|c|c|c|c|c|c|c|c|c|c|c|}
\hline & 305.6 & 0.231 & 174.7 & 0.117 & 113.4 & 0.095 & 82.05 & 0.117 & 192.2 & 0.097 & 90.88 & 0.132 & 121.2 & 0.141 & 71 & 0.142 \\
\hline \multirow[t]{3}{*}{2} & 309.3 & 0.281 & 173.6 & 0.09 & 115 & 0.13 & 81.22 & 0.129 & 194 & 0.067 & 93.69 & 0.128 & 122 & 0.123 & 72.95 & 0.133 \\
\hline & 309.5 & 0.221 & 178.5 & 0.072 & 116.5 & 0.131 & 120.4 & 0.254 & 193.3 & 0.092 & 89.6 & 0.145 & 151.6 & 0.244 & 71.63 & 0.151 \\
\hline & 308.1 & 0.212 & 172.9 & 0.064 & 114 & 0.116 & 119 & 0.174 & 194.5 & 0.123 & 90.56 & 0.114 & & & 62.69 & 0.117 \\
\hline \multirow[t]{2}{*}{3} & 307.3 & 0.217 & 169.3 & 0.1 & 113.2 & 0.097 & 88.24 & 0.116 & & 0.212 & 88.89 & 0.138 & & & 63.45 & 0.122 \\
\hline & 312.3 & 0.251 & 169.5 & 0.089 & 113.9 & 0.095 & 86.55 & 0.12 & 195.1 & 0.092 & 88.92 & 0.116 & & & 57.32 & 0.38 \\
\hline
\end{tabular}

